Supporting Information

\title{
Synthesis and Optical Properties of Axially Chiral Bibenzo[b]carbazole (BBCz) Derivatives
}

\author{
Ryo Takishima, ${ }^{\dagger}$ Yuji Nishii, ${ }^{* \dagger}$ and Masahiro Miura*,† \\ ${ }^{\dagger}$ Department of Applied Chemistry, Graduate School of Engineering, Osaka University, Suita, Osaka 565-0871, Japan \\ y-nishii@chem.eng.osaka-u.ac.jp \\ miura@chem.eng.osaka-u.ac.jp
}

\section{Contents}

1. General Information $\quad$ S2

2. Experimental Procedures and Identification Data S3

3. Summary of Optical Properties $\quad \mathrm{S} 12$

4. X-ray Crystallographic Analysis $\quad \mathrm{S} 13$

5. Copy of HPLC Charts $\quad$ S16

6. Copy of NMR Spectra $\quad$ S29

7. References $\quad$ S42 


\section{General Information}

Dimethylsulfoxide (DMSO), $N$-methylpyrrolidone (NMP), $N, N$-dimethylacetamide (DMAc), and $o$-xylene were distilled from $\mathrm{CaH}_{2}$ and stored with molecular sieves 4A. DCM was dried over molecular sieves $4 \mathrm{~A}$ and stored under $\mathrm{N}_{2}$. Silica gel column chromatography was performed using Wakosil ${ }^{\circledR}$ C-200 $(64-210 \mu \mathrm{m})$. Other chemicals were purchased from commercial resource and used without further purification.

Nuclear magnetic resonance spectra were measured at $400 \mathrm{MHz}\left({ }^{1} \mathrm{H} \mathrm{NMR}\right)$ and $100 \mathrm{MHz}\left({ }^{13} \mathrm{C}\right.$ NMR) in $5 \mathrm{~mm}$ NMR tubes. ${ }^{1} \mathrm{H}$ NMR chemical shifts were reported in ppm relative to the resonance of TMS $(\delta 0.00)$ or the residual solvent signals at $\delta 7.26$ for $\mathrm{CDCl}_{3} \cdot{ }^{13} \mathrm{C}$ NMR chemical shifts were reported in ppm relative to the residual solvent signals at $\delta 77.2$ for $\mathrm{CDCl}_{3}$. Melting points were measured with Mettler Toledo MP90. High resolution mass spectra (HRMS) were recorded by APCI-TOF. Preparative gel permeation chromatography (GPC) was conducted with YMC GPC-T2000 column eluting with $\mathrm{CHCl}_{3}$. Absorption spectra were recorded with JASCO V750 spectrometer. Photoluminescence spectra were recorded with JASCO FP-8500 spectrometer. Quantum yield was determined using an integration sphere system. CD and CPL spectra were recorded with JASCO J-820AC and JASCO CPL-300 spectrometers. HPLC analysis was carried out with JASCO EXTREMA system (PU4180/MD4015/CO4065) equipped with YMC CHIRAL ART Amylose-SA column. 


\section{Experimental Procedures and Identification Data}

\section{1,1'-binaphthyl-2,2'-diamine (BINAM) ${ }^{1}$}

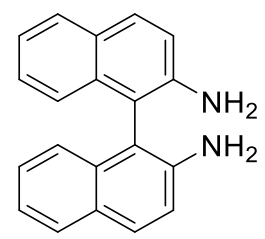

To a $10 \mathrm{~mL}$ Schlenk flask were added $(S)$ - or $(R)$-1,1'-binaphthyl-2,2'-diol (143 mg, $0.5 \mathrm{mmol})$, 2bromopropanamide (273 mg, $1.5 \mathrm{mmol}), \mathrm{K}_{2} \mathrm{CO}_{3}$ (207 mg, $1.5 \mathrm{mmol}$ ), and $\mathrm{KI}$ (8.3 mg, $\left.0.05 \mathrm{mmol}\right)$. DMSO $(5.0 \mathrm{~mL})$ was added via the syringe. The mixture was stirred at $50{ }^{\circ} \mathrm{C}$ for $20 \mathrm{~h}$ with an oil bath under air. To the mixture was added $\mathrm{KOH}(360 \mathrm{mg}, 6.25 \mathrm{mmol})$, and this was heated at $150^{\circ} \mathrm{C}$ for $4 \mathrm{~h}$ with an oil bath under air. The resulting mixture was extracted with EtOAc, and the combined organic layer was washed with water, dried over $\mathrm{Na}_{2} \mathrm{SO}_{4}$, and concentrated in vacuo. The residue was purified by silica gel column chromatography (eluent: $n$-hexane/EtOAc $=4 / 1)$ and GPC to give the title compound as white solid; (S)-BINAM (104 mg, 73\% yield), $(R)$-BINAM (99.4 mg, 70\% yield).

We attempted the synthesis of BINAM in larger scale (up to $2.0 \mathrm{mmol}$ ), but the yield was significantly low (less than 10\%). For the better reproducibility, it is recommended to conduct in separate batches. With this method $(0.5 \mathrm{mmol} \times 8$ batches $)$, combined before the extraction and column chromatography, $(S)$-BINAM could be prepared in sub-gram scale ( $818.1 \mathrm{mg}, 72 \%$ yield). m.p. $243-245{ }^{\circ} \mathrm{C} ;{ }^{1} \mathrm{H}$ NMR $\left(400 \mathrm{MHz}, \mathrm{CDCl}_{3}\right) \delta$ 7.78-7.82 (m, 4H), 7.18-7.24 (m, 4H), $7.16(\mathrm{~d}, J$ $=8.6 \mathrm{~Hz}, 2 \mathrm{H}), 7.07(\mathrm{~d}, J=8.2 \mathrm{~Hz}, 2 \mathrm{H}), 3.07$ (br s, 4H); ${ }^{13} \mathrm{C}$ NMR $\left(100 \mathrm{MHz}, \mathrm{CDCl}_{3}\right) \delta 142.7$, 133.7, 129.5, 128.5, 128.2, 126.9, 124.0, 122. 5, 118.3, 112.6; HRMS (APCI) m/z: [M] Calcd for $\mathrm{C}_{20} \mathrm{H}_{16} \mathrm{~N}_{2}$ 284.1313; Found 284.1311. The enantiomeric ratio was determined by HPLC analysis (CHIRAL ART Amylose-SA column, $n$-hexane/chloroform = 80/20, $1.0 \mathrm{~mL} / \mathrm{min},(S)$-BINAM: $\mathrm{t}_{\mathrm{R}}$ $=24.89 \mathrm{~min},(R)$-BINAM: $\mathrm{t}_{\mathrm{R}}=21.37 \mathrm{~min}, \mathrm{UV}$ detection at $250.0 \mathrm{~nm}, 40^{\circ} \mathrm{C}$ ).

$N, N^{\prime}$-([1,1'-binaphthalene]-2,2'-diyl)diacetamide $\left(\mathrm{Ac}_{2} \text {-BINAM }\right)^{2}$

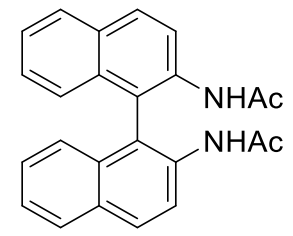

To a $20 \mathrm{~mL}$ two-necked round-bottom flask were added $(S)$ - or $(R)-\mathbf{1}(142 \mathrm{mg}, 0.5 \mathrm{mmol})$, acetic 
anhydride (178 $\mathrm{mg}, 1.75 \mathrm{mmol})$, and DCM (10 mL). The mixture was stirred at room temperature for $12 \mathrm{~h}$ under $\mathrm{N}_{2}$. The resulting mixture was extracted with DCM, and the combined layer was washed with water, dried over $\mathrm{Na}_{2} \mathrm{SO}_{4}$, and concentrated in vacuo. The residue was purified by silica gel column chromatography (eluent: DCM) to give the title compound as white solid; $(S)$ $\mathrm{Ac}_{2}$-BINAM (182 mg, 99\% yield), $(R)$-Ac 2 -BINAM (183 mg, quant.).

m.p. $165-167{ }^{\circ} \mathrm{C} ;{ }^{1} \mathrm{H}$ NMR $\left(400 \mathrm{MHz}, \mathrm{CDCl}_{3}\right) \delta 8.35(\mathrm{~d}, J=9.2 \mathrm{~Hz}, 2 \mathrm{H}), 8.05(\mathrm{~d}, J=9.2 \mathrm{~Hz}, 2 \mathrm{H})$, $7.95(\mathrm{~d}, J=8.4 \mathrm{~Hz}, 2 \mathrm{H}), 7.46(\mathrm{td}, J=1.2,6.8 \mathrm{~Hz}, 2 \mathrm{H}), 7.28(\mathrm{td}, J=1.2,6.8 \mathrm{~Hz}, 2 \mathrm{H}), 7.03(\mathrm{~d}, J=$ $8.4 \mathrm{~Hz}, 2 \mathrm{H}), 6.91$ (brs, 2H), 1.84 (s, 6H); $\left.{ }^{13} \mathrm{C} \mathrm{NMR} \mathrm{(100} \mathrm{MHz,} \mathrm{CDCl}_{3}\right) \delta 169.4,134.8,132.4$, 131.4, 129.9, 128.3, 127.2, 125.7, 125.3, 122.5, 121.6, 24.2; HRMS (APCI) $m / z:[\mathrm{M}]^{+}$Calcd for $\mathrm{C}_{24} \mathrm{H}_{20} \mathrm{~N}_{2} \mathrm{O}_{2} 368.1525$; Found 368.1528. The enantiomeric ratio was determined by HPLC analysis (CHIRAL ART Amylose-SA column, $n$-hexane/isopropyl alcohol =95/5, $1.0 \mathrm{~mL} / \mathrm{min},(S)-\mathrm{Ac}_{2}-$ BINAM: $t_{\mathrm{R}}=38.58 \mathrm{~min},(R)-\mathrm{Ac}_{2}$-BINAM: $\mathrm{t}_{\mathrm{R}}=29.00 \mathrm{~min}, \mathrm{UV}$ detection at $\left.250.0 \mathrm{~nm}, 20^{\circ} \mathrm{C}\right)$.

$N, N^{\prime}$-(3,3'-diphenyl-[1,1'-binaphthalene]-2,2'-diyl)diacetamide (1a) ${ }^{3}$

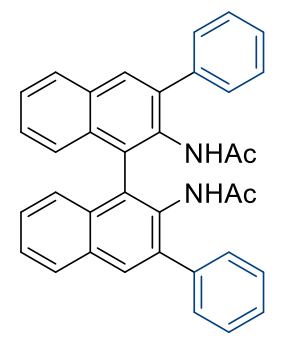

To a $10 \mathrm{~mL}$ pressure-resistant grass tube were added $(S)$ - or $(R)$-Ac $\mathrm{Ac}_{2}$-BINAM (184 mg, $\left.0.5 \mathrm{mmol}\right)$, $\mathrm{Pd}(\mathrm{OAc})_{2}(16.8 \mathrm{mg}, 0.075 \mathrm{mmol}), \mathrm{AgOAc}(167 \mathrm{mg}, 1.0 \mathrm{mmol})$, iodobenzene (510 mg, $\left.2.5 \mathrm{mmol}\right)$, and TFA $(1.5 \mathrm{~mL})$. The mixture was heated at $100{ }^{\circ} \mathrm{C}$ for $6 \mathrm{~h}$ with an oil bath under $\mathrm{N}_{2}$. After cooling to room temperature, the resulting mixture was filtered through a pad of Celite eluting with toluene. The filtrate was concentrated in vacuo, and the residue was purified by silica gel column chromatography (eluent: toluene/ $\mathrm{Et}_{2} \mathrm{O}=1 / 1$ ) and $\mathrm{GPC}$ to give the title compound as white solid; $(S)-\mathbf{1 a}(83.2 \mathrm{mg}, 32 \%$ yield $),(R)-\mathbf{1 a}(117 \mathrm{mg}, 45 \%$ yield $)$.

m.p. 258-260 ${ }^{\circ} \mathrm{C} ;{ }^{1} \mathrm{H}$ NMR (400 MHz, $\left.\mathrm{CDCl}_{3}\right) \delta 7.98(\mathrm{~s}, 2 \mathrm{H}), 7.93(\mathrm{~d}, J=8.0 \mathrm{~Hz}, 2 \mathrm{H}), 7.56(\mathrm{~d}, J$ $=8.0 \mathrm{~Hz}, 4 \mathrm{H}), 7.41-7.49(\mathrm{~m}, 10 \mathrm{H}), 7.37(\mathrm{~d}, J=7.2 \mathrm{~Hz}, 2 \mathrm{H}), 7.27(\mathrm{~d}, J=7.2 \mathrm{~Hz}, 2 \mathrm{H}), 1.45(\mathrm{~s}, 6 \mathrm{H})$; ${ }^{13} \mathrm{C} \mathrm{NMR}\left(100 \mathrm{MHz}, \mathrm{CDCl}_{3}\right) \delta 169.0,139.8,138.9,132.7,132.0,129.8,129.1,128.86,128.85$, 128.2, 128.0, 127.3, 126.8, 126.7, 125.8, 22.6; HRMS (APCI) $m / z$ : $[\mathrm{M}+\mathrm{H}]^{+}$Calcd for $\mathrm{C}_{36} \mathrm{H}_{29} \mathrm{~N}_{2} \mathrm{O}_{2}$ 521.2223; Found 521.2206. The enantiomeric ratio was determined by HPLC analysis (CHIRAL 
ART Amylose-SA column, $n$-hexane/ isopropyl alcohol $=95 / 5,1.0 \mathrm{~mL} / \mathrm{min},(S)-1 \mathbf{a}: \mathrm{t}_{\mathrm{R}}=14.21$ $\min ,(R)-\mathbf{1 a}: \mathrm{t}_{\mathrm{R}}=18.09 \mathrm{~min}, \mathrm{UV}$ detection at $\left.250.0 \mathrm{~nm}, 20^{\circ} \mathrm{C}\right)$.

$N, N^{\prime}$-(3,3'-bis(4-(tert-butyl)phenyl)-[1,1'-binaphthalene]-2,2'-diyl)diacetamide (1b)

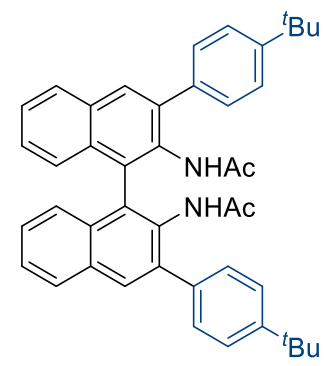

Synthesized similarly to 1a using 1-tert-butyl-4-iodobenzene (heated at $120^{\circ} \mathrm{C}$ for $4 \mathrm{~h}$ with an oil bath). Purified by silica gel column chromatography (eluent: toluene/ $\mathrm{Et}_{2} \mathrm{O}=1 / 1$ ) and GPC to give the title compound as white solid; $(S)-\mathbf{1 b}$ (79.3 $\mathrm{mg}, 25 \%$ yield), $(R)-\mathbf{1 b}$ (72.9 $\mathrm{mg}, 23 \%$ yield).

m.p. 194-196 ${ }^{\circ} \mathrm{C} ;{ }^{1} \mathrm{H}$ NMR $\left(400 \mathrm{MHz}, \mathrm{CDCl}_{3}\right) \delta 7.98(\mathrm{~s}, 2 \mathrm{H}), 7.91(\mathrm{~d}, J=8.2 \mathrm{~Hz}, 2 \mathrm{H})$, 7.44-7.52 (m, 12H), 7.22 (br, 4H), 1.46 (s, 6H), 1.36 (s, 18H); $\left.{ }^{13} \mathrm{C} \mathrm{NMR} \mathrm{(100} \mathrm{MHz,} \mathrm{CDCl}_{3}\right) \delta 150.1,138.9$, $136.9,132.7,132.0,129.7,129.1,129.0,128.6,127.9,126.9,126.5,125.7,125.1,124.4,34.5$, 31.4, 22.5; HRMS (APCI) $m / z$ : [M+H] ${ }^{+}$Calcd for $\mathrm{C}_{44} \mathrm{H}_{45} \mathrm{~N}_{2} \mathrm{O}_{2}$ 633.3475; Found 633.3459. The enantiomeric ratio was determined by HPLC analysis (CHIRAL ART Amylose-SA column, $n$ hexane/ isopropyl alcohol $=95 / 5,1.0 \mathrm{~mL} / \mathrm{min},(S)-\mathbf{1 b}: \mathrm{t}_{\mathrm{R}}=20.77 \mathrm{~min},(R)-\mathbf{1 b}: \mathrm{t}_{\mathrm{R}}=10.53 \mathrm{~min}, \mathrm{UV}$ detection at $250.0 \mathrm{~nm}, 20{ }^{\circ} \mathrm{C}$ ).

$N, N^{\prime}$-(3,3'-bis(4-methoxyphenyl)-[1,1'-binaphthalene]-2,2'-diyl)diacetamide (1c)

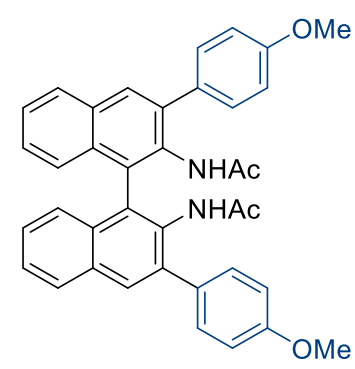

Synthesized similarly to $1 \mathrm{a}$ using 1-iodo-4-methoxybenzene (heated at $120{ }^{\circ} \mathrm{C}$ for $4 \mathrm{~h}$ with an oil bath). Purified by silica gel column chromatography (eluent: toluene $/ \mathrm{Et}_{2} \mathrm{O}=1 / 1$ ) and GPC to give the title compound as white solid; $(S)-1 \mathrm{c}(61.0 \mathrm{mg}, 21 \%$ yield $),(R)-\mathbf{1 c}(63.7 \mathrm{mg}, 22 \%$ yield $)$. m.p. 202-204 ${ }^{\circ} \mathrm{C} ;{ }^{1} \mathrm{H}$ NMR $\left(400 \mathrm{MHz}, \mathrm{CDCl}_{3}\right) \delta 7.95(\mathrm{~s}, 2 \mathrm{H}), 7.91$ (d, $\left.J=8.2 \mathrm{~Hz}, 2 \mathrm{H}\right), 7.49(\mathrm{~d}, J$ 
$=8.2 \mathrm{~Hz}, 4 \mathrm{H}), 7.44(\mathrm{~d}, J=7.8 \mathrm{~Hz}, 2 \mathrm{H}), 7.21-7.23(\mathrm{~m}, 6 \mathrm{H}), 6.96(\mathrm{~d}, J=8.8 \mathrm{~Hz}, 4 \mathrm{H}), 3.84(\mathrm{~s}, 6 \mathrm{H})$, $1.48(\mathrm{~s}, 6 \mathrm{H}) ;{ }^{13} \mathrm{C} \mathrm{NMR}\left(100 \mathrm{MHz}, \mathrm{CDCl}_{3}\right) \delta 158.9,138.6,133.2,132.7,132.3,131.9,130.7,130.4$, 130.0, 129.5, 128.4, 127.9, 126.5, 114.3, 113.6, 55.2, 22.6; HRMS (APCI) $m / z:[\mathrm{M}+\mathrm{H}]^{+}$Calcd for $\mathrm{C}_{38} \mathrm{H}_{33} \mathrm{~N}_{2} \mathrm{O}_{4}$ 581.2434; Found 581.2452. The enantiomeric ratio was determined by HPLC analysis (CHIRAL ART Amylose-SA column, $n$-hexane/isopropyl alcohol =95/5, $0.5 \mathrm{~mL} / \mathrm{min},(S)-1 \mathrm{c}: \mathrm{t}_{\mathrm{R}}=$ $16.75 \mathrm{~min},(R)-\mathbf{1 c}: \mathrm{t}_{\mathrm{R}}=23.02 \mathrm{~min}, \mathrm{UV}$ detection at $\left.250.0 \mathrm{~nm}, 20^{\circ} \mathrm{C}\right)$.

3,3'-diphenyl-[1,1'-binaphthalene]-2,2'-diamine (2a) ${ }^{4}$

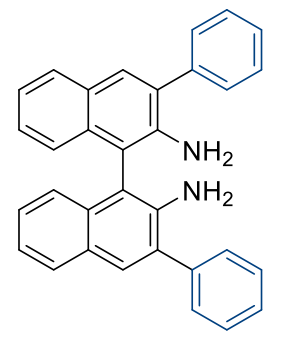

$(S)$ - or $(R)-1 \mathbf{a}(77.9 \mathrm{mg}, 0.15 \mathrm{mmol})$ was dissolved in a 1:1 (v/v) mixture of EtOH and 50\% $\mathrm{KOHaq}$ $(5.0 \mathrm{~mL})$ in a screw-top tube. The mixture was heated at $150{ }^{\circ} \mathrm{C}$ for $20 \mathrm{~h}$ with an oil bath. After cooling to room temperature, $5.0 \mathrm{~mL}$ saturated $\mathrm{NH}_{4}$ Claq was added to the suspension. The resulting mixture was extracted with DCM, and the combined organic layer was washed with water, dried over $\mathrm{Na}_{2} \mathrm{SO}_{4}$, and concentrated in vacuo. The residue was purified by silica gel column chromatography (eluent: DCM) and GPC to give the title compound as white solid; $(S)-2 \mathbf{a}(65.7$ mg, quant.), (R)-2a (65.1 mg, quant.).

m.p. 252-254 ${ }^{\circ} \mathrm{C}$; ${ }^{1} \mathrm{H}$ NMR (400 MHz, $\left.\mathrm{CDCl}_{3}\right) \delta$ 7.79-7.81 (m, 2H), 7.77 (s, 2H), $7.63(\mathrm{~d}, J=1.4$ $\mathrm{Hz}, 2 \mathrm{H}), 7.61$ (d, $J=1.2 \mathrm{~Hz}, 2 \mathrm{H}), 8.65(\mathrm{~m}, 4 \mathrm{H}), 7.41$ (tt, $J=1.2,7.4 \mathrm{~Hz}, 2 \mathrm{H}), 7.21-7.27$ (m, 4H), 7.13-7.15 (m, 2H), 3.88 (s, 4H); ${ }^{13} \mathrm{C}$ NMR (100 MHz, $\left.\mathrm{CDCl}_{3}\right) \delta 140.8,139.3,133.1,130.8,129.8$, 129.4, 128.9, 128.3, 128.2, 127.7, 126.8, 123.9, 122.7, 113.0; HRMS (APCI) $m / z:[\mathrm{M}+\mathrm{H}]^{+} \mathrm{Calcd}$ for $\mathrm{C}_{32} \mathrm{H}_{25} \mathrm{~N}_{2}$ 437.2012; Found 437.2009. The enantiomeric ratio was determined by HPLC analysis (CHIRAL ART Amylose-SA column, $n$-hexane/chloroform =95/5, $1.0 \mathrm{~mL} / \mathrm{min},(S)-2 \mathbf{a}$ : $\mathrm{t}_{\mathrm{R}}=11.08 \mathrm{~min},(R)-\mathbf{2 a}: \mathrm{t}_{\mathrm{R}}=13.20 \mathrm{~min}, \mathrm{UV}$ detection at $\left.250.0 \mathrm{~nm}, 20^{\circ} \mathrm{C}\right)$. 
3-(3,3'-bis(4-(tert-butyl)phenyl)-[1,1'-binaphthalene]-2,2'-diamine (2b) ${ }^{5}$

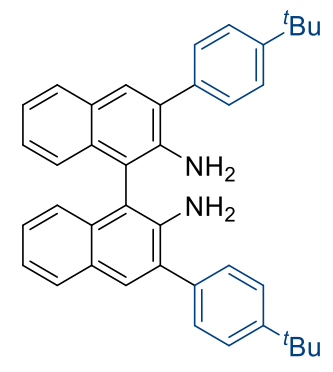

Synthesized similarly to 2a. Purified by silica gel column chromatography (eluent: $\mathrm{CHCl}_{3}$ ) and GPC to give the title compound as pale yellow solid; $(S)-\mathbf{2 b}(79.7 \mathrm{mg}, 97 \%$ yield $),(R)-\mathbf{2 b}(74.8$ mg, 91\% yield).

m.p. 239-241 ${ }^{\circ} \mathrm{C} ;{ }^{1} \mathrm{H} \mathrm{NMR}\left(400 \mathrm{MHz}, \mathrm{CDCl}_{3}\right) \delta 7.78(\mathrm{dd}, J=2.0,7.2 \mathrm{~Hz}, 2 \mathrm{H}), 7.76(\mathrm{~s}, 2 \mathrm{H}), 7.53$ (m, 8H), 7.18-7.23 (m, 4H), $7.12(\mathrm{~d}, J=7.2 \mathrm{~Hz}, 2 \mathrm{H}), 3.89(\mathrm{~s}, 4 \mathrm{H}), 1.37$ (s, 18H); ${ }^{13} \mathrm{C}$ NMR $(100$ $\left.\mathrm{MHz}, \mathrm{CDCl}_{3}\right) \delta 150.6,141.0,136.3,133.0,130.7,129.7,129.0,128.3,128.1,126.7,125.8,123.9$, 122.5, 113.0, 34.7, 31.4; HRMS (APCI) $m / z$ : $[\mathrm{M}+\mathrm{H}]^{+}$Calcd for $\mathrm{C}_{40} \mathrm{H}_{41} \mathrm{~N}_{2}$ 549.3264; Found 549.3265. The enantiomeric ratio was determined by HPLC analysis (CHIRAL ART Amylose-SA column, $n$-hexane/chloroform $=80 / 20,0.2 \mathrm{~mL} / \mathrm{min},(S)-\mathbf{2 b}: \mathrm{t}_{\mathrm{R}}=19.19 \mathrm{~min},(R)-\mathbf{2 b}: \mathrm{t}_{\mathrm{R}}=18.95 \mathrm{~min}$, UV detection at $250.0 \mathrm{~nm}, 20^{\circ} \mathrm{C}$ ).

3,3'-bis(4-methoxyphenyl)-[1,1'-binaphthalene]-2,2'-diamine (2c) ${ }^{6}$

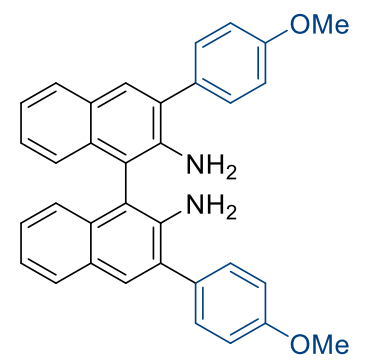

Synthesized similarly to 2 a. Purified by silica gel column chromatography (eluent: $\mathrm{CHCl}_{3}$ ) and GPC to give the title compound as pale yellow solid; $(S)-2 c$ (72.3 mg, 97\% yield), $(R)-2 c$ (68.4 mg, 92\% yield).

m.p. 243-245 ${ }^{\circ} \mathrm{C} ;{ }^{1} \mathrm{H}$ NMR (400 MHz, $\left.\mathrm{CDCl}_{3}\right) \delta 7.73$ (s, 2H), $7.54(\mathrm{dd}, J=2.1,6.7 \mathrm{~Hz}, 4 \mathrm{H}), 7.15-$ $7.24(\mathrm{~m}, 6 \mathrm{H}), 7.12(\mathrm{~d}, J=7.8 \mathrm{~Hz}, 2 \mathrm{H}), 7.02(\mathrm{dd}, J=2.1,6.7 \mathrm{~Hz}, 4 \mathrm{H}), 3.87(\mathrm{~s}, 4 \mathrm{H}), 3.87$ (s, 6H); ${ }^{13} \mathrm{C}$ NMR $\left(100 \mathrm{MHz}, \mathrm{CDCl}_{3}\right) \delta$ 159.2, 141.1, 133.0, 131.5, 130.5, 129.7, 129.1, 128.3, 128.2, 128.1, 123.9, 122.6, 114.3, 113.6, 55.4; HRMS (APCI) $m / z$ : $[\mathrm{M}+\mathrm{H}]^{+}$Calcd for $\mathrm{C}_{34} \mathrm{H}_{29} \mathrm{~N}_{2} \mathrm{O}_{2}$ 497.2223; 
Found 497.2246. The enantiomeric ratio was determined by HPLC analysis (CHIRAL ART Amylose-SA column, $n$-hexane/chloroform $=80 / 20,0.2 \mathrm{~mL} / \mathrm{min},(S)-\mathbf{2} \mathbf{c}: \mathrm{t}_{\mathrm{R}}=39.39 \mathrm{~min},(R)-\mathbf{2}$ : $\mathrm{t}_{\mathrm{R}}=48.697 \mathrm{~min}, \mathrm{UV}$ detection at $250.0 \mathrm{~nm}, 20^{\circ} \mathrm{C}$ ).

6,6'-bibenzo[b]carbazole (3a)

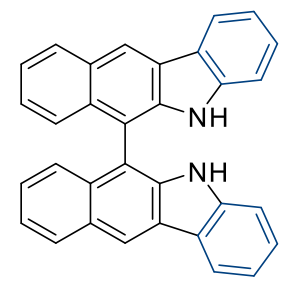

To a $10 \mathrm{~mL}$ Schlenk flask were added $(S)$ - or $(R)-\mathbf{2 a}(64.8 \mathrm{mg}, 0.15 \mathrm{mmol}),\left[\mathrm{Cp}^{*} \mathrm{Ir} \mathrm{Cl}_{2}\right]_{2}(3.7 \mathrm{mg}$, $0.006 \mathrm{mmol}), \mathrm{Cu}(\mathrm{OAc})_{2}(11.1 \mathrm{mg}, 0.06 \mathrm{mmol})$, pivalic acid $(61.2 \mathrm{mg}, 0.6 \mathrm{mmol})$, and NMP (1.8 $\mathrm{mL}$ ). The mixture was heated at $120{ }^{\circ} \mathrm{C}$ for $4 \mathrm{~h}$ with an oil bath under air. After cooling to room temperature, the resulting mixture was extracted with EtOAc. The combined organic layer was washed with water, dried over $\mathrm{Na}_{2} \mathrm{SO}_{4}$, and concentrated in vacuo. The residue was purified by silica gel column chromatography (eluent: $\mathrm{CHCl}_{3}$ ) and GPC to give the title compound as white solid; (S)-3a (16.8 mg, 26\% yield), (R)-3a (12.9 mg, 20\% yield).

Single crystals suitable for the X-ray diffraction analysis were obtained by slow evaporation from the $n$-hexane $/ \mathrm{CHCl}_{3}$ solution.

m.p. $>300{ }^{\circ} \mathrm{C} ;{ }^{1} \mathrm{H}$ NMR $\left(400 \mathrm{MHz}, \mathrm{CDCl}_{3}\right) \delta 8.79(\mathrm{~s}, 2 \mathrm{H}), 8.30(\mathrm{~d}, J=8.2 \mathrm{~Hz}, 2 \mathrm{H}), 8.23(\mathrm{~d}, J=$ $8.2 \mathrm{~Hz}, 2 \mathrm{H}), 7.40-7.48(\mathrm{~m}, 8 \mathrm{H}), 7.26-7.31(\mathrm{~m}, 4 \mathrm{H}), 7.17$ (d, $J=8.0 \mathrm{~Hz}, 2 \mathrm{H}) ;{ }^{13} \mathrm{C} \mathrm{NMR}(100 \mathrm{MHz}$, $\left.\mathrm{CDCl}_{3}\right) \delta 141.8,138.9,131.3,129.1,129.0,127.6,125.8,125.4,124.8,123.3,123.0,121.2,119.7$, 119.4, 111.0, 110.5; HRMS (APCI) $m / z$ : $[\mathrm{M}+\mathrm{H}]^{+}$Calcd for $\mathrm{C}_{32} \mathrm{H}_{21} \mathrm{~N}_{2} 433.1699$; Found 433.1700 . The enantiomeric ratio was determined by HPLC analysis (CHIRAL ART Amylose-SA column, $n$-hexane/chloroform $=80 / 20,1.0 \mathrm{~mL} / \mathrm{min},(S)-\mathbf{3 a}: \mathrm{t}_{\mathrm{R}}=12.16 \mathrm{~min},(R)-\mathbf{3 a}: \mathrm{t}_{\mathrm{R}}=9.52 \mathrm{~min}, \mathrm{UV}$ detection at $250.0 \mathrm{~nm}, 20^{\circ} \mathrm{C}$ ) 
3,3'-di-tert-butyl-6,6'-bibenzo[b]carbazole (3b)

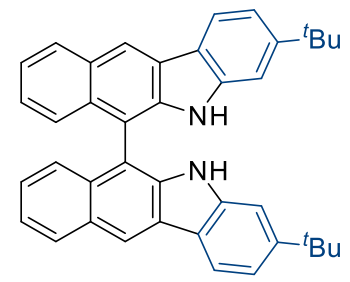

Synthesized similarly to 3a. Purified by silica gel column chromatography (eluent: $\mathrm{CHCl}_{3}$ ) and GPC to give the title compound as yellow solid; $(S)-3 \mathbf{b}(59.6 \mathrm{mg}, 73 \%$ yield), $(R)-3 \mathbf{b}(57.1 \mathrm{mg}$, $70 \%$ yield).

Single crystals suitable for the X-ray diffraction analysis were obtained by slow evaporation from the $n$-hexane/ $\mathrm{CHCl}_{3}$ solution.

m.p. $>300{ }^{\circ} \mathrm{C} ;{ }^{1} \mathrm{H}$ NMR $\left(400 \mathrm{MHz}, \mathrm{CDCl}_{3}\right) \delta 8.72(\mathrm{~s}, 2 \mathrm{H}), 8.20(\mathrm{~d}, J=8.2 \mathrm{~Hz}, 2 \mathrm{H}), 8.19(\mathrm{~d}, J=$ $8.2 \mathrm{~Hz}, 2 \mathrm{H}), 7.41-7.45(\mathrm{~m}, 6 \mathrm{H}), 7.33(\mathrm{dd}, J=1.6,8.2 \mathrm{~Hz}, 2 \mathrm{H}), 7.27$ (dd, $J=1.2,8.4 \mathrm{~Hz}, 2 \mathrm{H}), 7.18$ $(\mathrm{d}, J=1.2 \mathrm{~Hz}, 2 \mathrm{H}), 1.34(\mathrm{~s}, 18 \mathrm{H}) ;{ }^{13} \mathrm{C} \mathrm{NMR}\left(100 \mathrm{MHz}, \mathrm{CDCl}_{3}\right) \delta 151.6,142.2,139.2,131.0,129.0$ (2C), 125.5, 125.4, 124.8, 122.9, 120.9, 120.7, 119.0, 117.5, 111.0, 107.3, 35.2, 31.6; HRMS (APCI) $m / z:[\mathrm{M}+\mathrm{H}]^{+}$Calcd for $\mathrm{C}_{40} \mathrm{H}_{37} \mathrm{~N}_{2}$ 545.2951; Found 545.2981. The enantiomeric ratio was determined by HPLC analysis (CHIRAL ART Amylose-SA column, $n$-hexane/chloroform = 80/20, $0.5 \mathrm{~mL} / \mathrm{min},(S)-\mathbf{3 b}: \mathrm{t}_{\mathrm{R}}=22.31 \mathrm{~min},(R)-\mathbf{3 b}: \mathrm{t}_{\mathrm{R}}=9.19 \mathrm{~min}, \mathrm{UV}$ detection at $\left.250.0 \mathrm{~nm}, 20{ }^{\circ} \mathrm{C}\right)$.

3,3'-dimethoxy-6,6'-bibenzo[b]carbazole (3c)

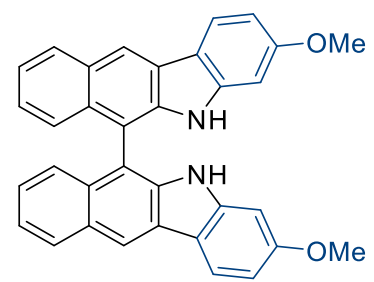

Synthesized similarly to 3a. Purified by silica gel column chromatography (eluent: $\mathrm{CHCl}_{3}$ ) and GPC to give the title compound as yellow solid; $(S)-3 \mathrm{c}(43.5 \mathrm{mg}, 59 \%$ yield), $(R)-3 \mathrm{c}(47.2 \mathrm{mg}$, $64 \%$ yield).

Single crystals suitable for the X-ray diffraction analysis were obtained by $n$-hexane vapor diffusion into the DCE solution.

m.p. $>300{ }^{\circ} \mathrm{C} ;{ }^{1} \mathrm{H}$ NMR $\left(400 \mathrm{MHz}, \mathrm{CDCl}_{3}\right) \delta 8.63$ (s, 2H), $8.18(\mathrm{~d}, J=8.9 \mathrm{~Hz}, 2 \mathrm{H}), 8.14(\mathrm{~d}, J=$ $8.6 \mathrm{~Hz}, 2 \mathrm{H}), 7.42-7.45(\mathrm{~m}, 6 \mathrm{H}), 7.27(\mathrm{dd}, J=1.2,6.6 \mathrm{~Hz}, 2 \mathrm{H}), 6.86(\mathrm{dd}, J=2.2,8.4 \mathrm{~Hz}, 2 \mathrm{H}), 6.60$ 
$(\mathrm{d}, J=2.2 \mathrm{~Hz}, 2 \mathrm{H}), 3.81(\mathrm{~s}, 6 \mathrm{H}) ;{ }^{13} \mathrm{C} \mathrm{NMR}\left(100 \mathrm{MHz}, \mathrm{CDCl}_{3}\right) \delta 160.3,143.4,139.1,130.6,129.2$, $128.8,125.5,125.3,124.8,123.7,123.0,121.9,118.1,110.9,107.9$, 94.9, 55.6; HRMS (APCI) $m / z:[\mathrm{M}+\mathrm{H}]^{+}$Calcd for $\mathrm{C}_{34} \mathrm{H}_{25} \mathrm{~N}_{2} \mathrm{O}_{2}$ 493.1910; Found 493.1907. The enantiomeric ratio was determined by HPLC analysis (CHIRAL ART Amylose-SA column, $n$-hexane/chloroform = 80/20, $0.5 \mathrm{~mL} / \mathrm{min},(S)-3 \mathbf{c}: \mathrm{t}_{\mathrm{R}}=24.24 \mathrm{~min},(R)-3 \mathbf{c}: \mathrm{t}_{\mathrm{R}}=13.32 \mathrm{~min}, \mathrm{UV}$ detection at $\left.250.0 \mathrm{~nm}, 2{ }^{\circ} \mathrm{C}\right)$.

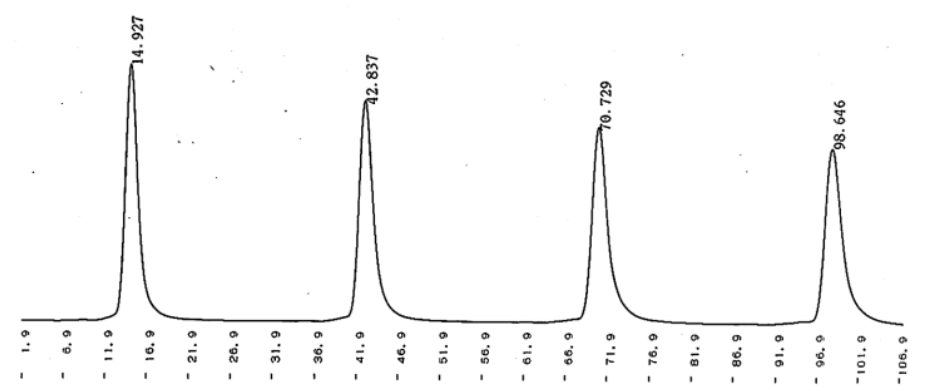

Preparative recycle GPC (5 10 cycles) chart for $\mathbf{3 c}$

bis(3-bromopyridin-2-yl)-[1,1'-binaphthalene]-2,2'-diamine (4)

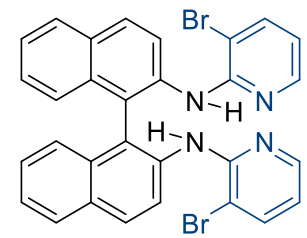

To a $10 \mathrm{~mL}$ Schlenk flask were added $(S)$ - or $(R)$-BINAM (156 mg, $0.55 \mathrm{mmol})$, 2,3dibromopyridine (237 mg, $1.0 \mathrm{mmol}), \mathrm{Pd}(\mathrm{OAc})_{2}(12.3 \mathrm{mg}, 0.055 \mathrm{mmol}), \mathrm{PPh}_{3}(28.8 \mathrm{mg}, 0.11$ $\mathrm{mmol})$, tert-BuONa (126 mg, $1.32 \mathrm{mmol})$, and $o$-xylene $(2.5 \mathrm{~mL})$. The mixture was degassed by $\mathrm{N}_{2}$ flow, and stirred at $120^{\circ} \mathrm{C}$ for $4 \mathrm{~h}$ with an oil bath under $\mathrm{N}_{2}$. After cooling to room temperature, the resulting mixture was extracted with EtOAc. The combined organic layer was washed with water and brine, dried over $\mathrm{Na}_{2} \mathrm{SO}_{4}$, and concentrated in vacuo. The residue was purified by silica gel column chromatography (eluent: hexane/ EtOAc $=4 / 1$ ) and GPC to give the title compound as white solid; (S)-4 (298 mg, 99\% yield), $(R)-4$ (315 mg, quant.).

m.p. 74-75 ${ }^{\circ} \mathrm{C} ;{ }^{1} \mathrm{H}$ NMR $\left(400 \mathrm{MHz}, \mathrm{CDCl}_{3}\right) \delta 8.94(\mathrm{~d}, J=9.1 \mathrm{~Hz}, 2 \mathrm{H}), 8.12(\mathrm{dd}, J=1.6,4.8 \mathrm{~Hz}$, 2H), $8.06(\mathrm{~d}, J=9.1 \mathrm{~Hz}, 2 \mathrm{H}), 7.92(\mathrm{~d}, J=8.2 \mathrm{~Hz}, 2 \mathrm{H}), 7.48$ (dd, $J=1.6,7.7 \mathrm{~Hz}, 2 \mathrm{H}), 7.35-7.39$ $(\mathrm{m}, 2 \mathrm{H}), 7.23-7.25(\mathrm{~m}, 4 \mathrm{H}), 7.05(\mathrm{~s}, 2 \mathrm{H}), 6.53(\mathrm{dd}, J=4.8,7.7 \mathrm{~Hz}, 2 \mathrm{H}) ;{ }^{13} \mathrm{C} \mathrm{NMR}(100 \mathrm{MHz}$, $\left.\mathrm{CDCl}_{3}\right) \delta 151.6,146.1,140.0,137.5,133.0,130.3,129.5,128.2,127.0,124.9,124.3,119.9,118.1$, 
115.9, 107.2; HRMS (APCI) $m / z$ : [M+H] ${ }^{+}$Calcd for $\mathrm{C}_{30} \mathrm{H}_{21} \mathrm{Br}_{2} \mathrm{~N}_{4}$ 597.0127; Found 597.0128. The enantiomeric ratio was determined by HPLC analysis (CHIRAL ART Amylose-SA column, $n$ hexane/chloroform $=95 / 5,0.2 \mathrm{~mL} / \mathrm{min},(S)-4: \mathrm{t}_{\mathrm{R}}=62.76 \mathrm{~min},(R)-4: \mathrm{t}_{\mathrm{R}}=55.54 \mathrm{~min}$, $\mathrm{UV}$ detection at $\left.250.0 \mathrm{~nm}, 25^{\circ} \mathrm{C}\right)$.

bibenzo[f]pyrido[2,3-b]indole (5)

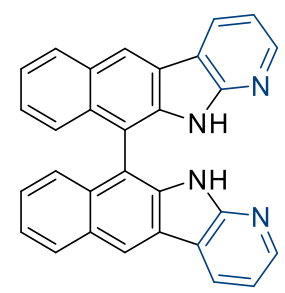

To a $10 \mathrm{~mL}$ Schlenk flask were added $(S)$ - or $(R)-4$ (298 mg, $0.5 \mathrm{mmol}), \mathrm{Pd}(\mathrm{OAc})_{2}(11.2 \mathrm{mg}, 0.05$ $\mathrm{mmol}), \mathrm{PCy}_{3} \cdot \mathrm{HBF}_{4}(28.0 \mathrm{mg}, 0.1 \mathrm{mmol}), \mathrm{DBU}(304 \mathrm{mg}, 2.0 \mathrm{mmol})$, and DMAc $(2.5 \mathrm{~mL})$. The reaction mixture was degassed by $\mathrm{N}_{2}$ flow, and stirred at $150{ }^{\circ} \mathrm{C}$ for $20 \mathrm{~h}$ with an oil bath under $\mathrm{N}_{2}$. After cooling to room temperature, the resulting mixture was filtered through a pad of Celite eluting with EtOAc. The filtrate was concentrated, and again extracted with EtOAc. The combined organic layer was washed with water and brine, dried over $\mathrm{Na}_{2} \mathrm{SO}_{4}$, and concentrated in vacuo. The residue was purified by silica gel column chromatography (eluent: hexane/EtOAc=1/1) and GPC to give the title compound as yellow solid; $(S)-5$ (78.3 mg, 36\% yield), $(R)-5(89.4 \mathrm{mg}, 41 \%$ yield).

m.p. $271-273{ }^{\circ} \mathrm{C} ;{ }^{1} \mathrm{H}$ NMR $\left(400 \mathrm{MHz}, \mathrm{CDCl}_{3}\right) \delta 11.25$ (s, 2H), 8.43 (s, 2H), 8.19 (d, J=8.6 Hz, 2H), $8.09(\mathrm{~d}, J=7.2 \mathrm{~Hz}, 2 \mathrm{H}), 7.56(\mathrm{~d}, J=8.6 \mathrm{~Hz}, 2 \mathrm{H}), 7.46-7.50(\mathrm{~m}, 2 \mathrm{H}), 7.30-7.34(\mathrm{~m}, 2 \mathrm{H}), 6.80$ (s, 2H), 6.67 (s, 2H); ${ }^{13} \mathrm{C}$ NMR $\left(100 \mathrm{MHz}, \mathrm{CDCl}_{3}\right) \delta 154.2,145.9,137.2,131.2,128.82,128.77$, 128.5, 125.9, 125.7, 123.1, 122.8, 120.7, 115.4, 114.3, 112.1; HRMS (APCI) $m / z:[\mathrm{M}+\mathrm{H}]^{+}$Calcd for $\mathrm{C}_{30} \mathrm{H}_{19} \mathrm{~N}_{4}$ 435.1604; Found 435.1609. The enantiomeric ratio was determined by HPLC analysis (CHIRAL ART Amylose-SA column, $n$-hexane/chloroform =95/5, $0.2 \mathrm{~mL} / \mathrm{min},(S)-5: t_{R}$ $=21.14 \mathrm{~min},(R)-5: \mathrm{t}_{\mathrm{R}}=20.06 \mathrm{~min}, \mathrm{UV}$ detection at $\left.350.0 \mathrm{~nm}, 25^{\circ} \mathrm{C}\right)$. 


\section{Summary of Optical Properties}

Table S1. Summary of Absorption and Emission Spectra

\begin{tabular}{|c|c|c|c|c|c|c|c|}
\hline & state $^{a}$ & $\lambda_{\max (\text { abs. })}$ & $\lambda_{\max (\text { lum) }}$ & $\lambda_{\max (\text { (excitation) }}$ & $\Phi$ & $g_{\mathrm{abs}}$ & $g_{\text {lum }}$ \\
\hline \multirow[t]{2}{*}{$3 \mathbf{a}$} & in $\mathrm{CHCl}_{3}$ & $365 \mathrm{~nm}$ & $426 \mathrm{~nm}$ & $294 \mathrm{~nm}$ & 0.38 & $1.18 \times 10^{-4}(297 \mathrm{~nm})$ & noisy \\
\hline & solid & $376 \mathrm{~nm}$ & $494 \mathrm{~nm}$ & $367 \mathrm{~nm}$ & 0.17 & -- & $2.81 \times 10^{-2}(494 \mathrm{~nm})$ \\
\hline \multirow[t]{2}{*}{$3 \mathbf{b}$} & in $\mathrm{CHCl}_{3}$ & $336 \mathrm{~nm}$ & $428 \mathrm{~nm}$ & $275 \mathrm{~nm}$ & 0.68 & $4.42 \times 10^{-4}(298 \mathrm{~nm})$ & noisy \\
\hline & solid & $375 \mathrm{~nm}$ & $479 \mathrm{~nm}$ & $368 \mathrm{~nm}$ & 0.14 & -- & $6.30 \times 10^{-3}(479 \mathrm{~nm})$ \\
\hline \multirow[t]{2}{*}{$3 \mathbf{c}$} & in $\mathrm{CHCl}_{3}$ & $340 \mathrm{~nm}$ & $421 \mathrm{~nm}$ & $274 \mathrm{~nm}$ & 0.37 & $1.14 \times 10^{-4}(303 \mathrm{~nm})$ & noisy \\
\hline & solid & $300 \mathrm{~nm}$ & $473 \mathrm{~nm}$ & $371 \mathrm{~nm}$ & 0.04 & -- & $1.73 \times 10^{-3}(473 \mathrm{~nm})$ \\
\hline \multirow[t]{2}{*}{5} & in $\mathrm{CHCl}_{3}$ & 302 & 424 & 300 & 0.41 & $3.35 \times 10^{-3}(298 \mathrm{~nm})$ & $3.90 \times 10^{-4}(424 \mathrm{~nm})$ \\
\hline & solid & 298 & 471 & 260 & 0.05 & -- & noisy \\
\hline
\end{tabular}

${ }^{a}$ Measured at room temperature as $\mathrm{CHCl}_{3}$ solution $\left(1.0 \times 10^{-5} \mathrm{M}\right)$ or in solid state.

Sample preparation for the solid state CPL

The compound was triturated with an agate mortar, and the resulting powder was dried under highvacuum. The solid material was dispersed in Fomblin ${ }^{\circledR}$ PFPE (perfluoropolyether) fluid, and placed on a quartz glass plate.

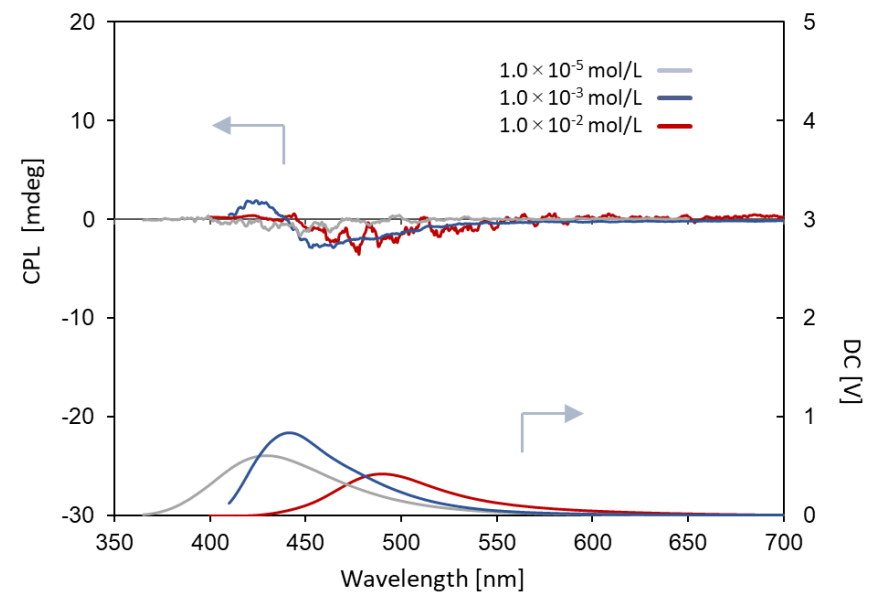

Figure S1. Absorption (bottom) and CPL (top) spectra of (R)-3a as $\mathrm{CHCl3}$ solutions (gray: $1.0 \times$ $10^{-5} \mathrm{M}$, blue: $1.0 \times 10^{-3} \mathrm{M}$, red: $1.0 \times 10^{-2} \mathrm{M}$ ). 


\section{X-ray Crystallography}

The structures were refined on $F^{2}$ by full-matrix least-squares method, using SHELXL-2016/6. ${ }^{7}$ Hydrogen atoms were included in the refinement on calculated positions riding on their carrier atoms. ORTEP- $3^{8}$ programs were used to draw the molecules.

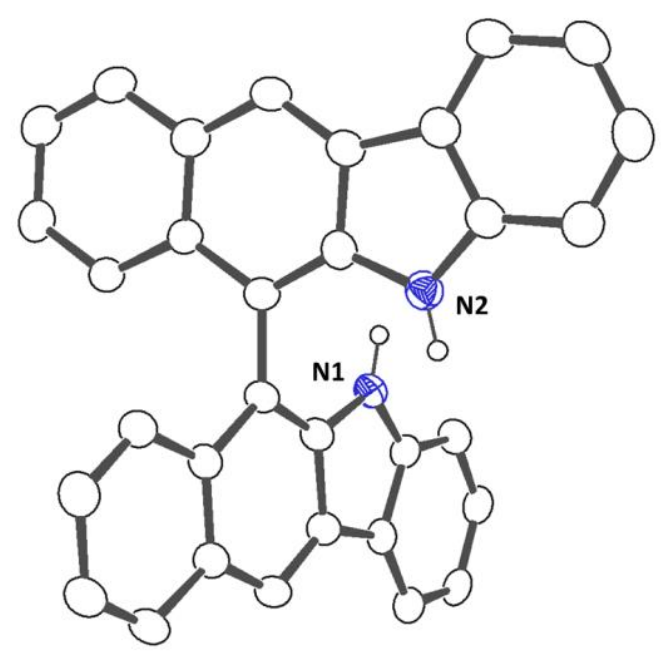

Figure S1. ORTEP drawing for $(R)-3 a$ with $40 \%$ thermal ellipsoid. Hydrogen atoms on carbon atoms are omitted for clarity.

Table S2. Crystal data for $(R)-\mathbf{3 a}$

CCDC No.

Crystal system

Space group

Unit cell parameter $[\AA, \mathrm{deg}]$

Z

$\mathrm{R}$ factor $(I>2.0 \sigma(I))$

$\mathrm{R}$ factor (all data)

Goodness of fit

Rint
2052730

monoclinic

$P 21_{1}$ (No. 4)

$\mathrm{a}=9.3388(3)$

$\mathrm{b}=8.0482(3), \beta=95.655(3)$

$\mathrm{c}=17.3640(5)$

2

$R 1=0.0557, w R 2=0.1577$

$R 1=0.0581, w R 2=0.1606$

1.063

0.0520 


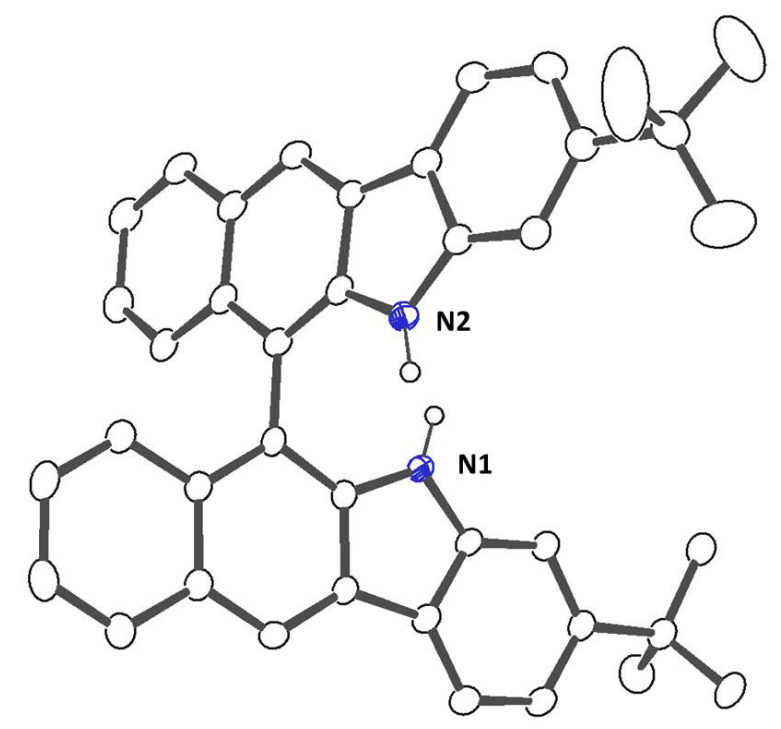

Figure S2. ORTEP drawing for $(R)-3 \mathbf{b}$ with $40 \%$ thermal ellipsoid. Hydrogen atoms on carbon atoms and solvent molecules are omitted for clarity.

Table S3. Crystal data for $(R)-\mathbf{3 b}$

CCDC No.

Crystal system

Space group

Unit cell parameter $[\AA, \operatorname{deg}]$

Z

$\mathrm{R}$ factor $(I>2.0 \sigma(I))$

$\mathrm{R}$ factor (all data)

Goodness of fit

Rint
2052729

monoclinic

C 2 (No. 5)

$\mathrm{a}=26.4061(6)$

$\mathrm{b}=8.0693(2), \beta=97.443(2)$

$\mathrm{c}=18.1534(4)$

4

$R 1=0.0464, w R 2=0.1259$

$R 1=0.0498, w R 2=0.1293$

1.089

0.0604 


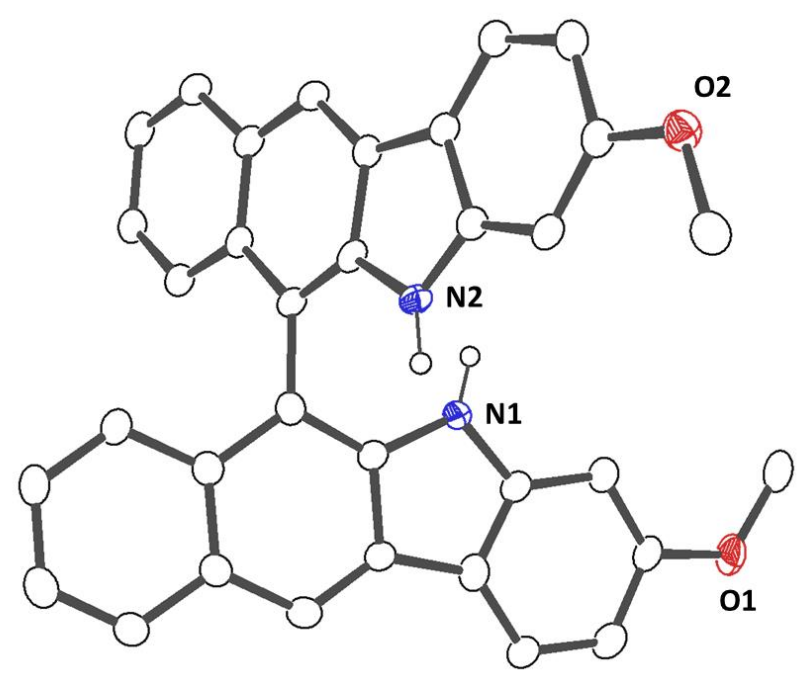

Figure S3. ORTEP drawing for $(R)$-3c with $40 \%$ thermal ellipsoid. Hydrogen atoms on carbon atoms and solvent molecules are omitted for clarity.

Table S4. Crystal data for $(R)-3$ c

CCDC No.

2052728

Crystal system

triclinic

Space group

$P 1$ (No. 1)

Unit cell parameter $[\AA, \operatorname{deg}]$

$\mathrm{a}=7.5862(3), \alpha=90.243(2)$

$\mathrm{b}=10.0771(3), \beta=92.555(3)$

$\mathrm{c}=17.1880(6), \gamma=90.668(3)$

Z

$\mathrm{R}$ factor $(I>2.0 \sigma(I))$

$R 1=0.0486, w R 2=0.1266$

$\mathrm{R}$ factor (all data)

$R 1=0.0519, w R 2=0.1288$

Goodness of fit

1.035

Rint

0.0498 


\section{Copy of HPLC Charts}

\section{(S)-BINAM}

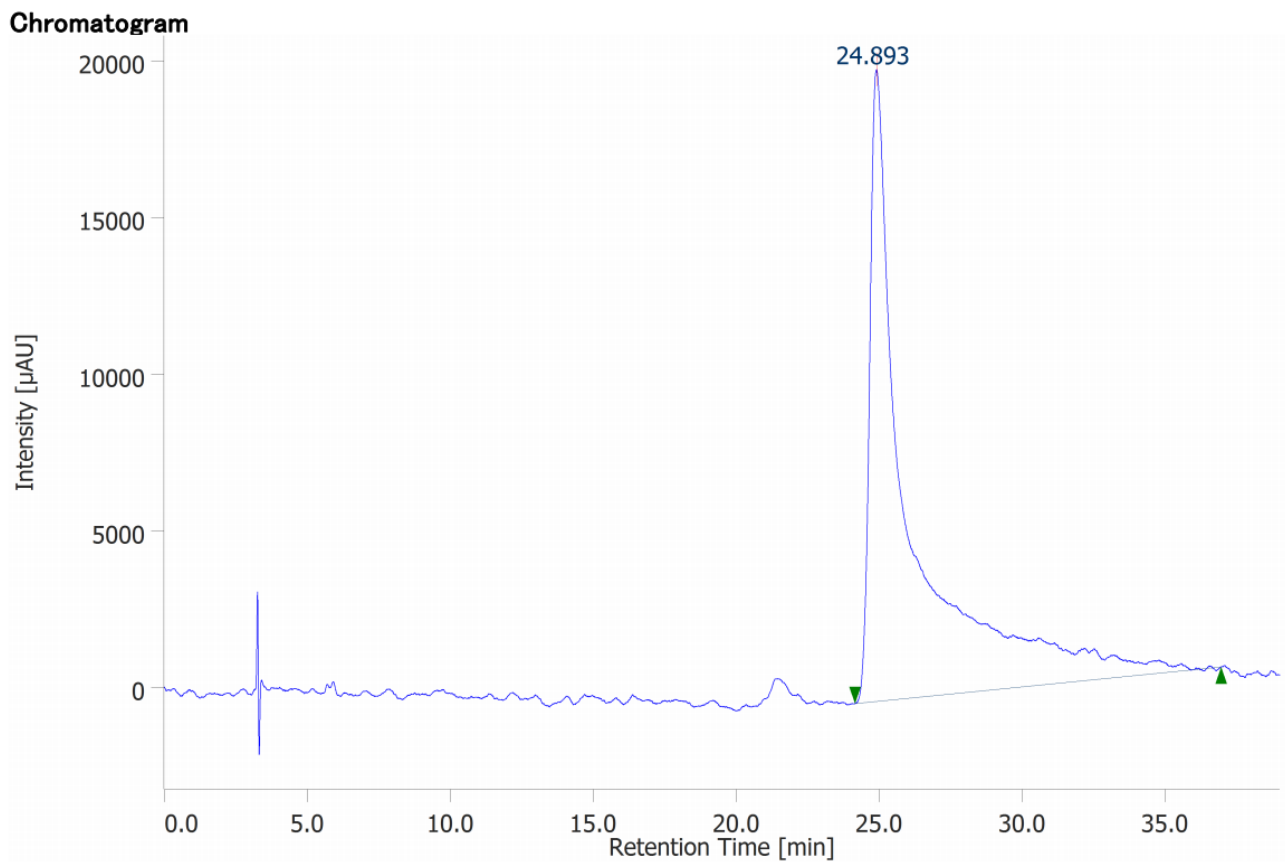

\section{(R)-BINAM}

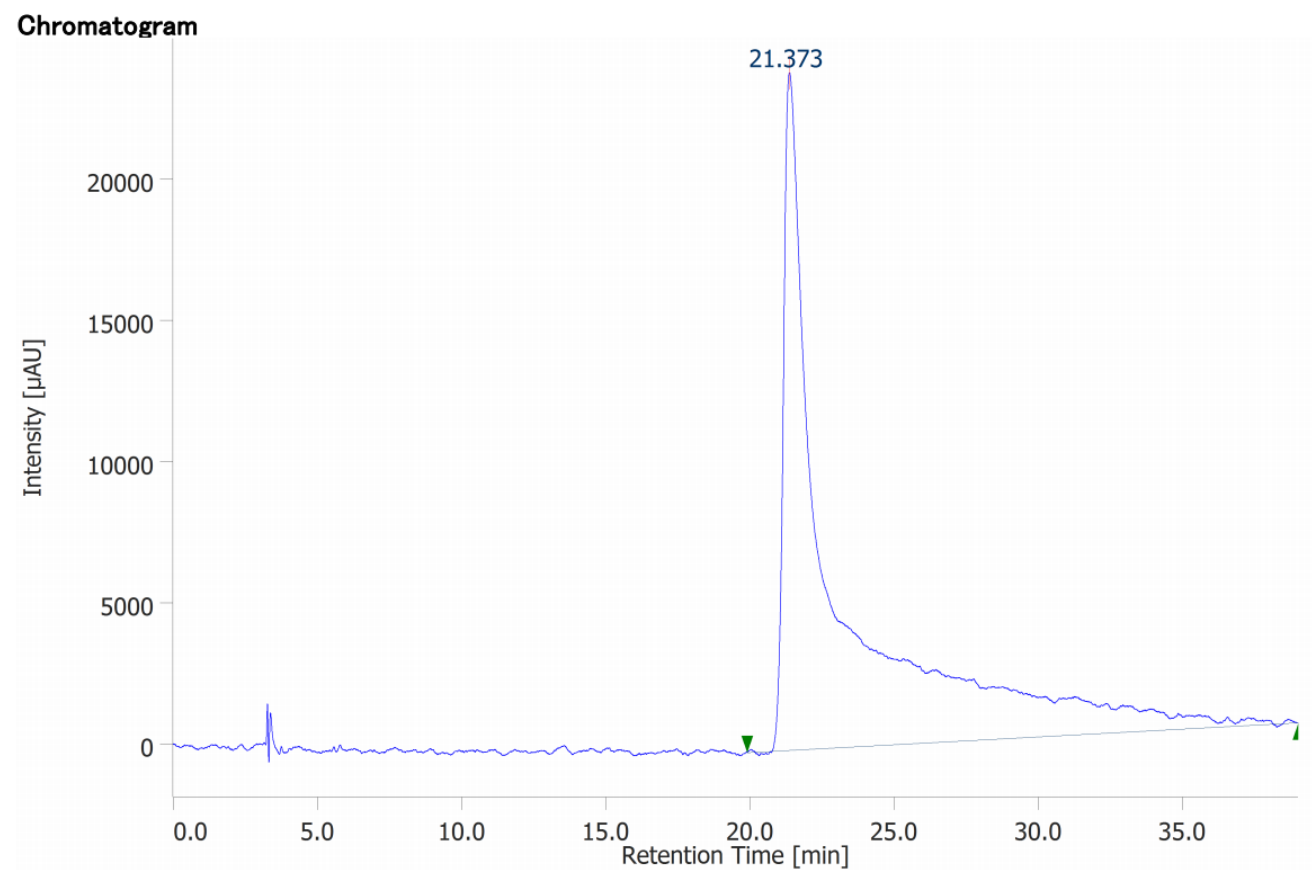




\section{(S)-Ac 2 -BINAM}

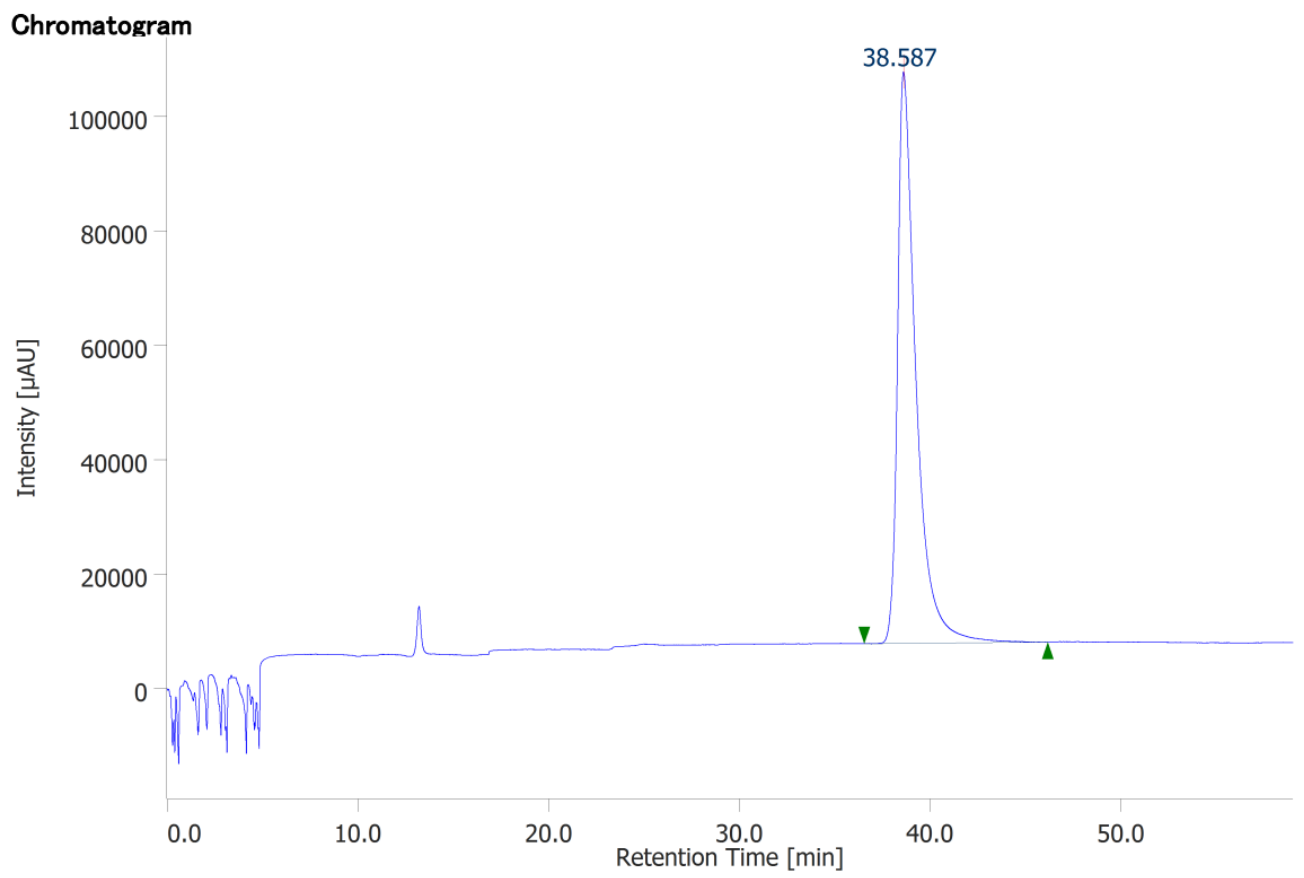

\section{(R)-Ac 2 -BINAM}

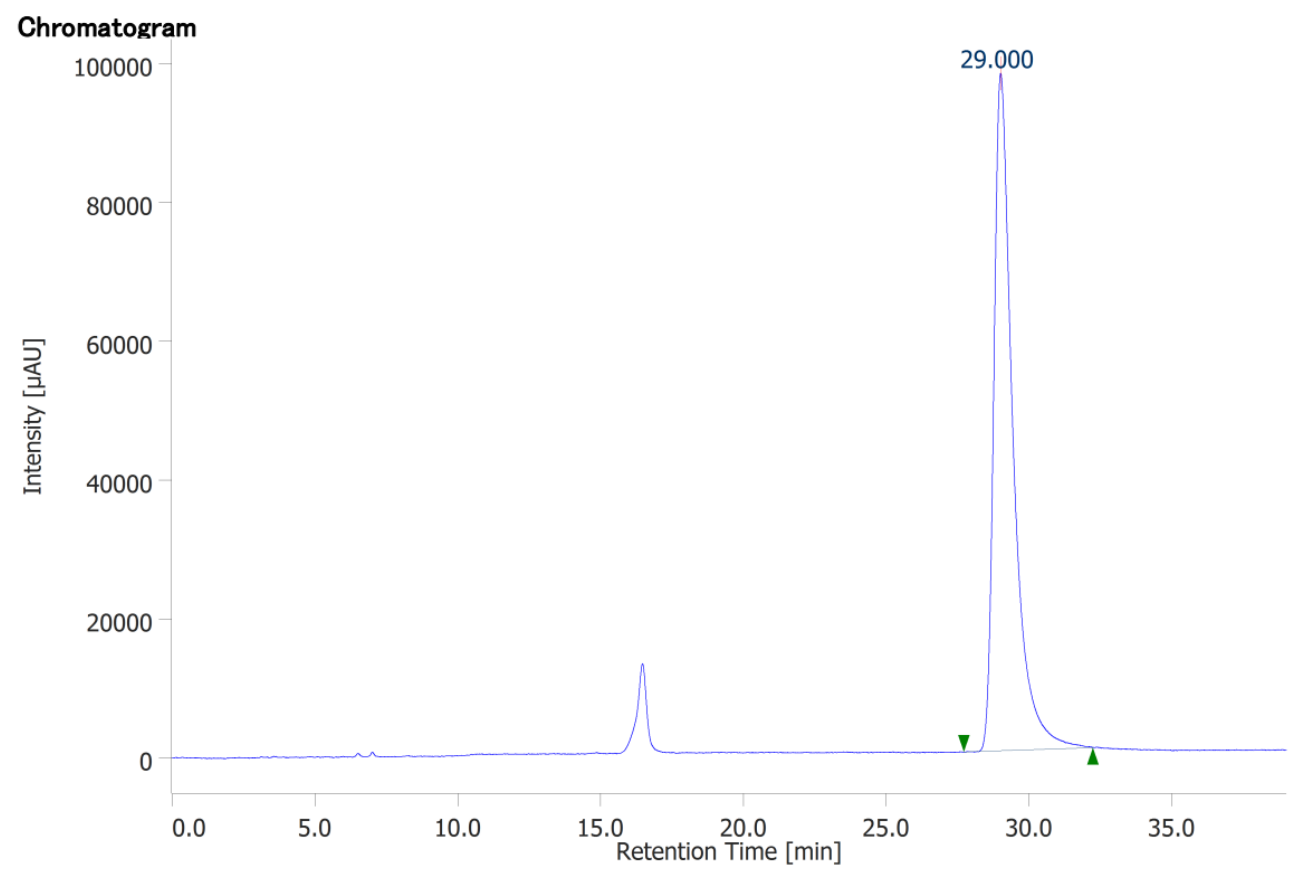


(S)-1a

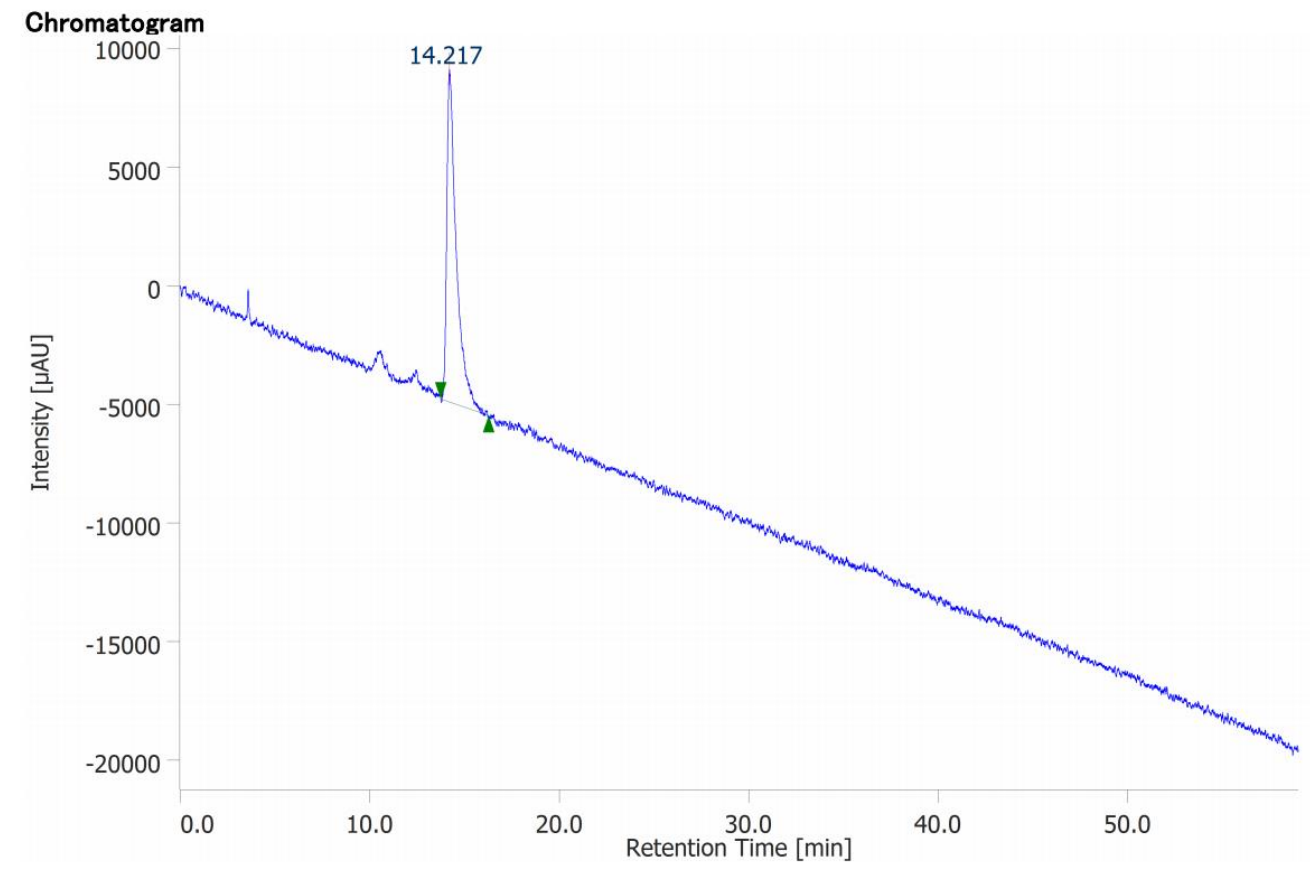

(R)-1a

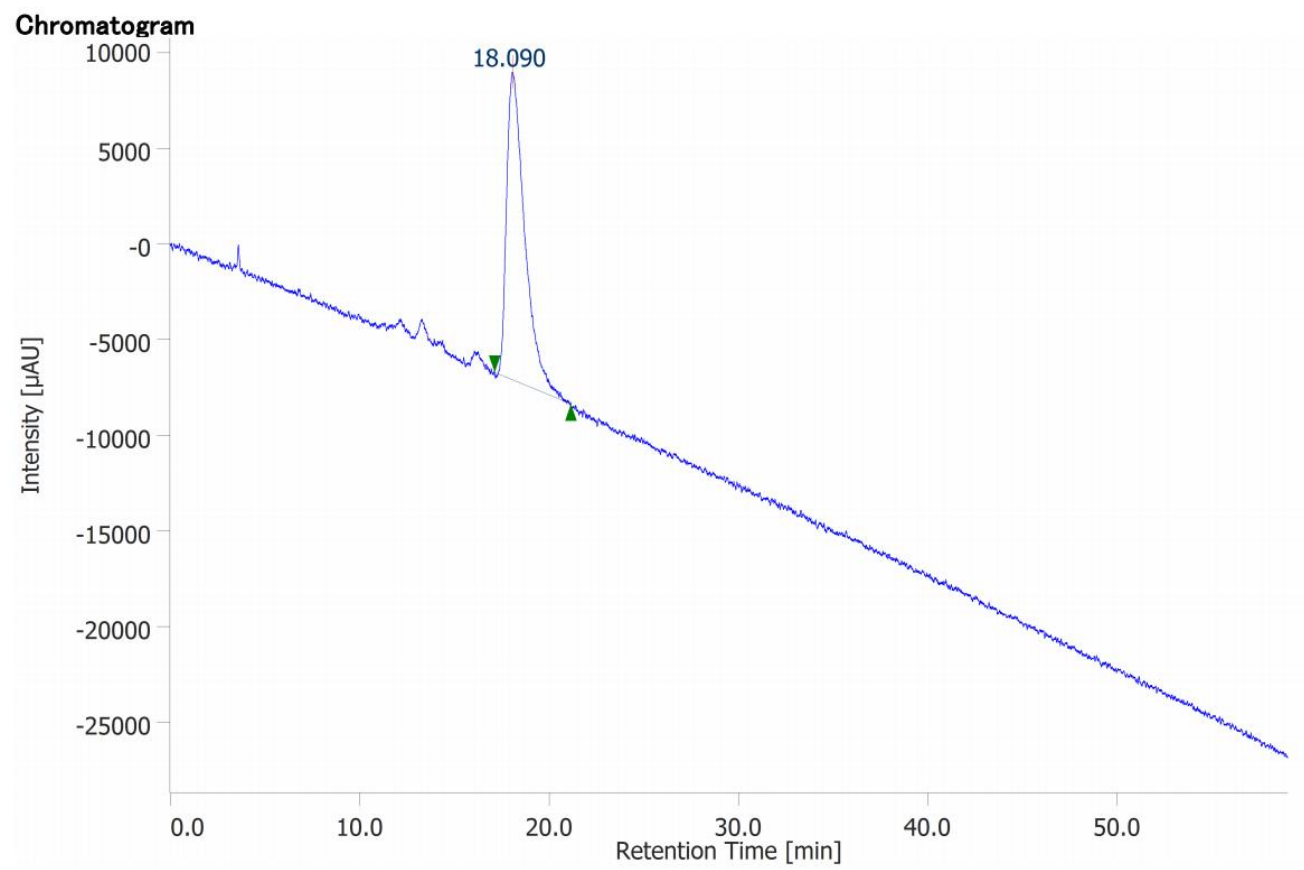


(S)-1b

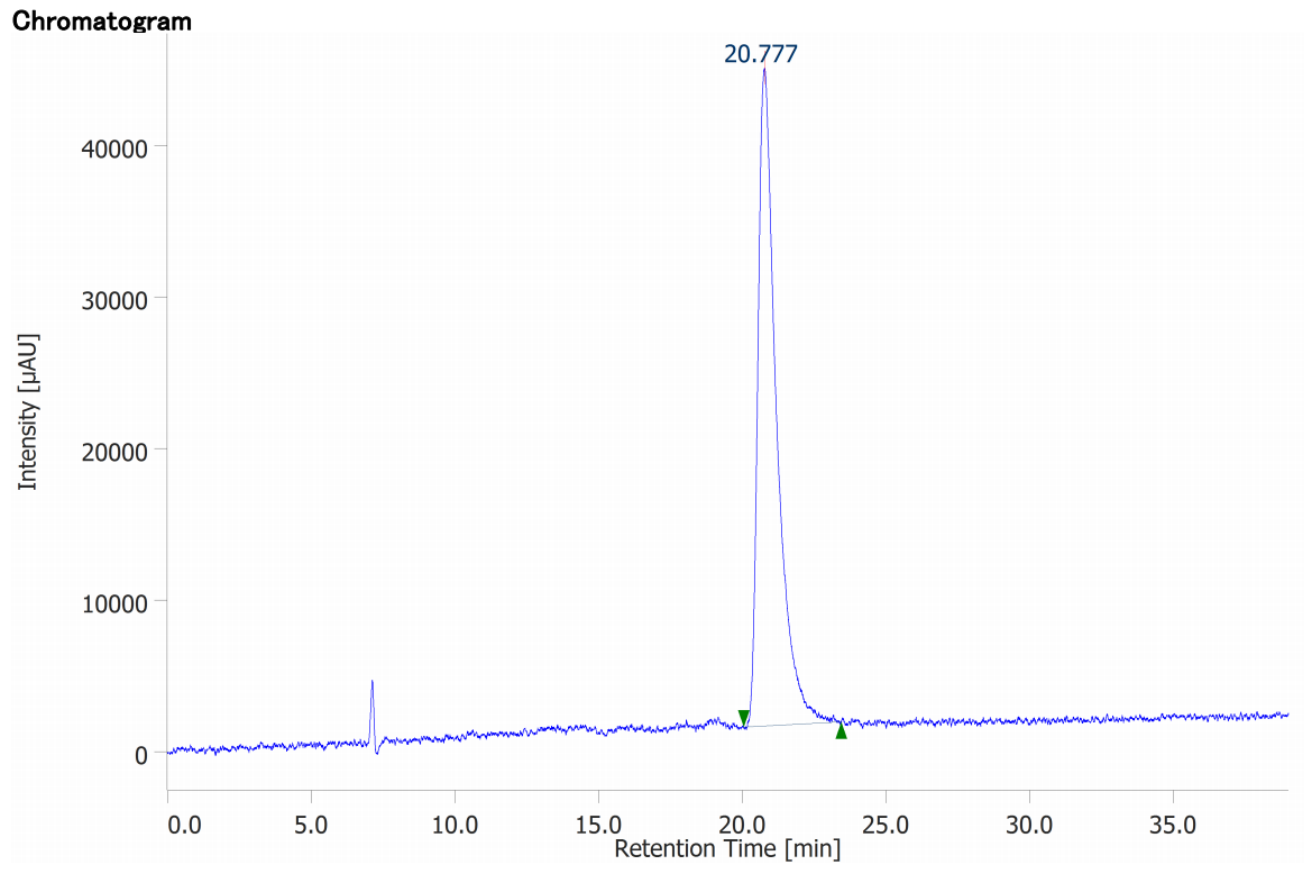

\section{(R)-1b}

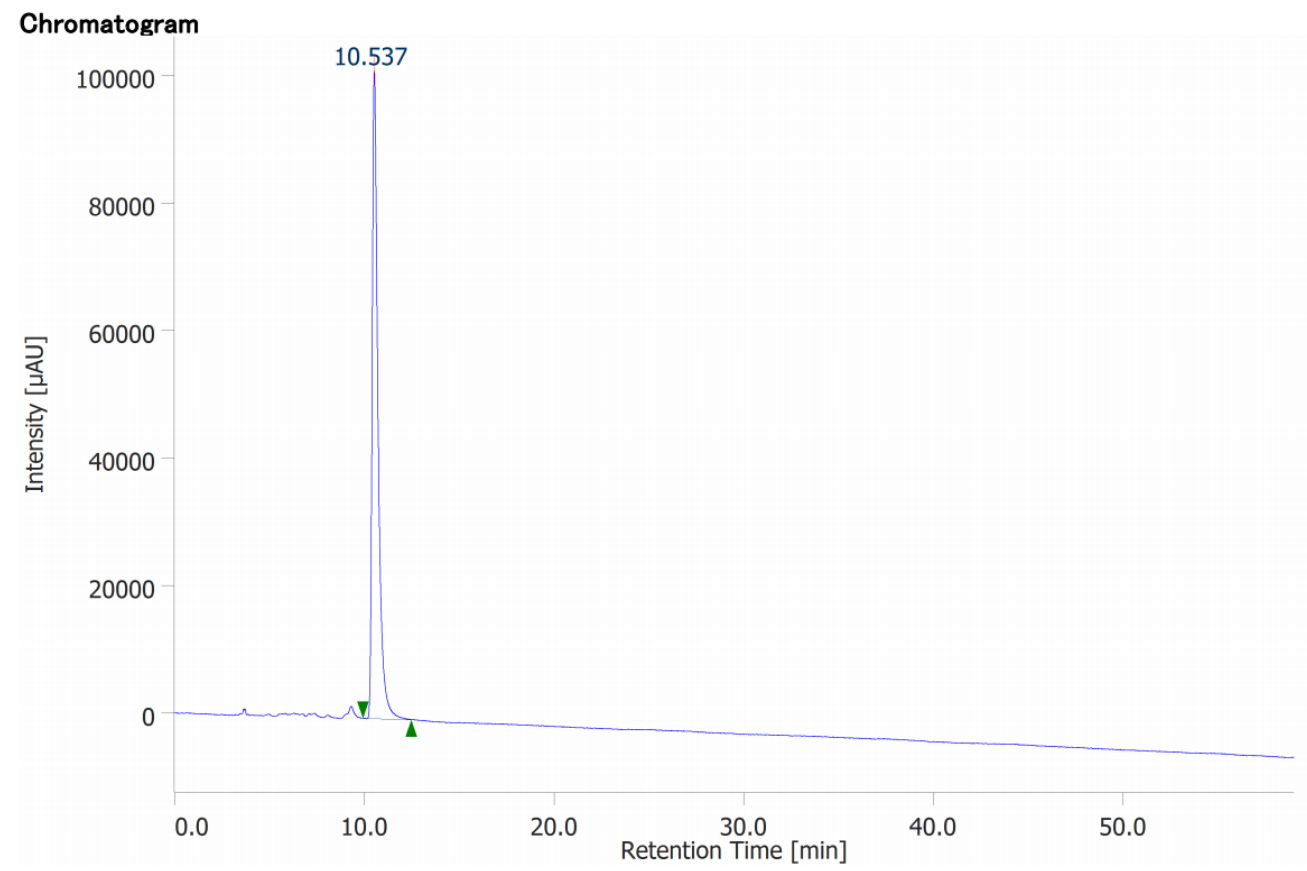




\section{(S)-1c}

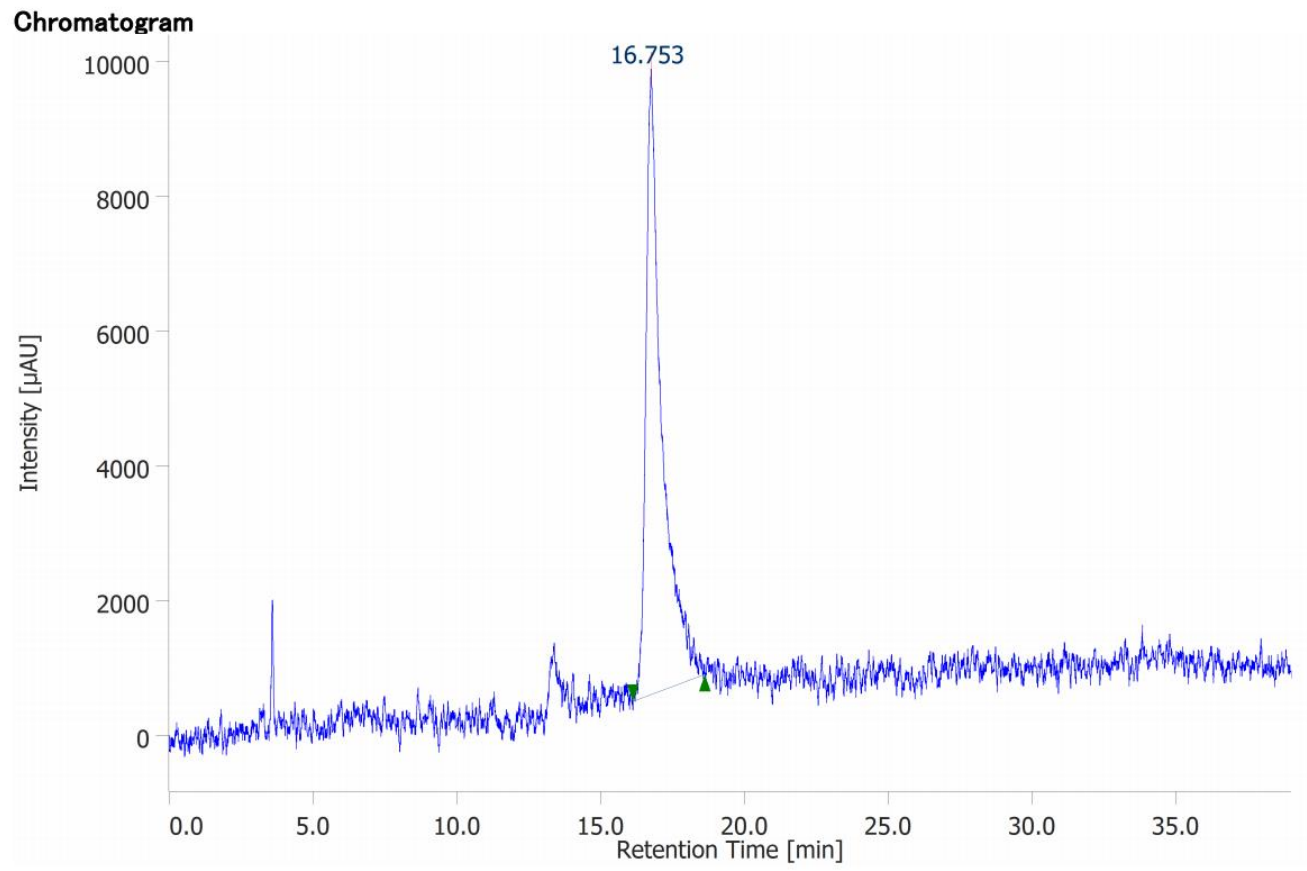

\section{(R)-1c}

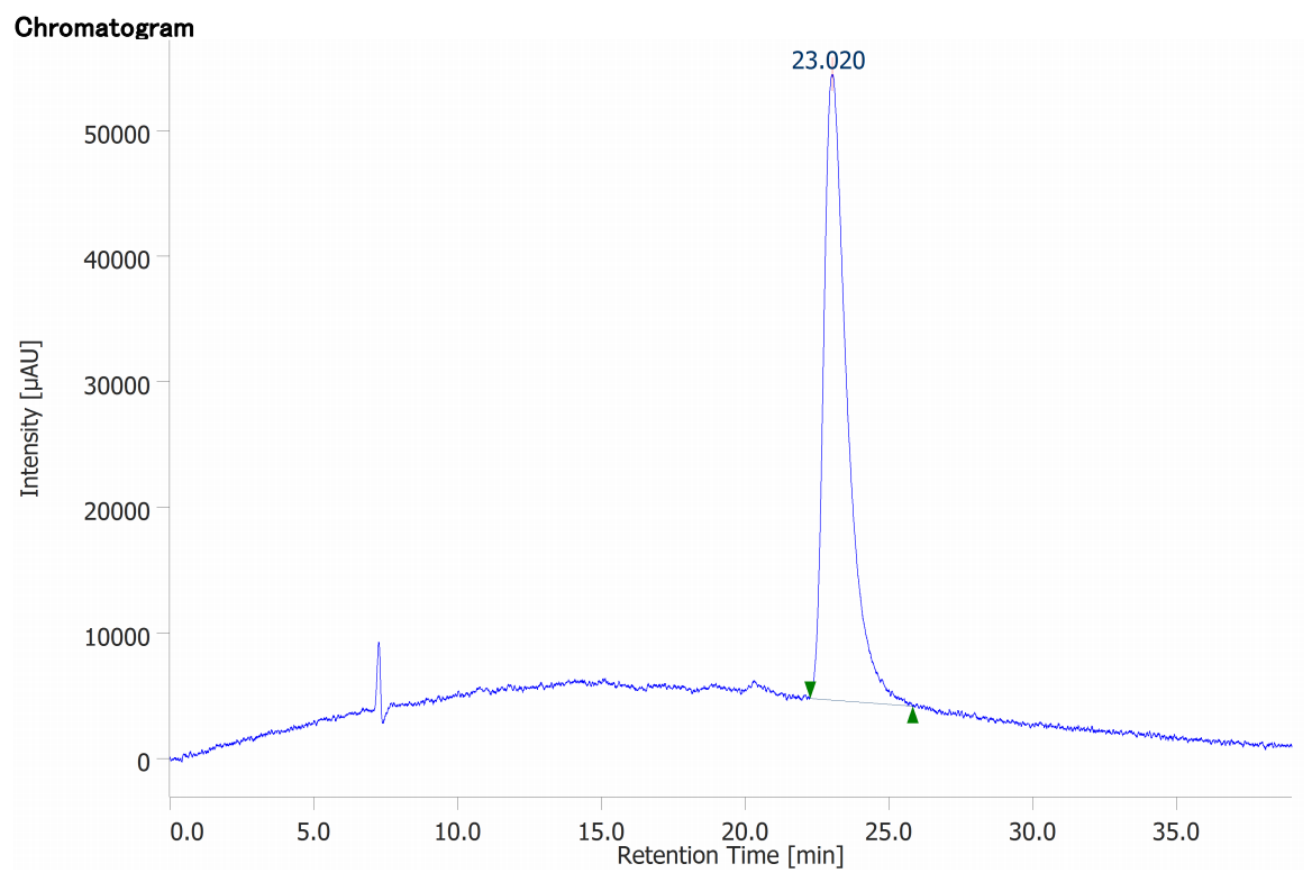




\section{(S)-2a}

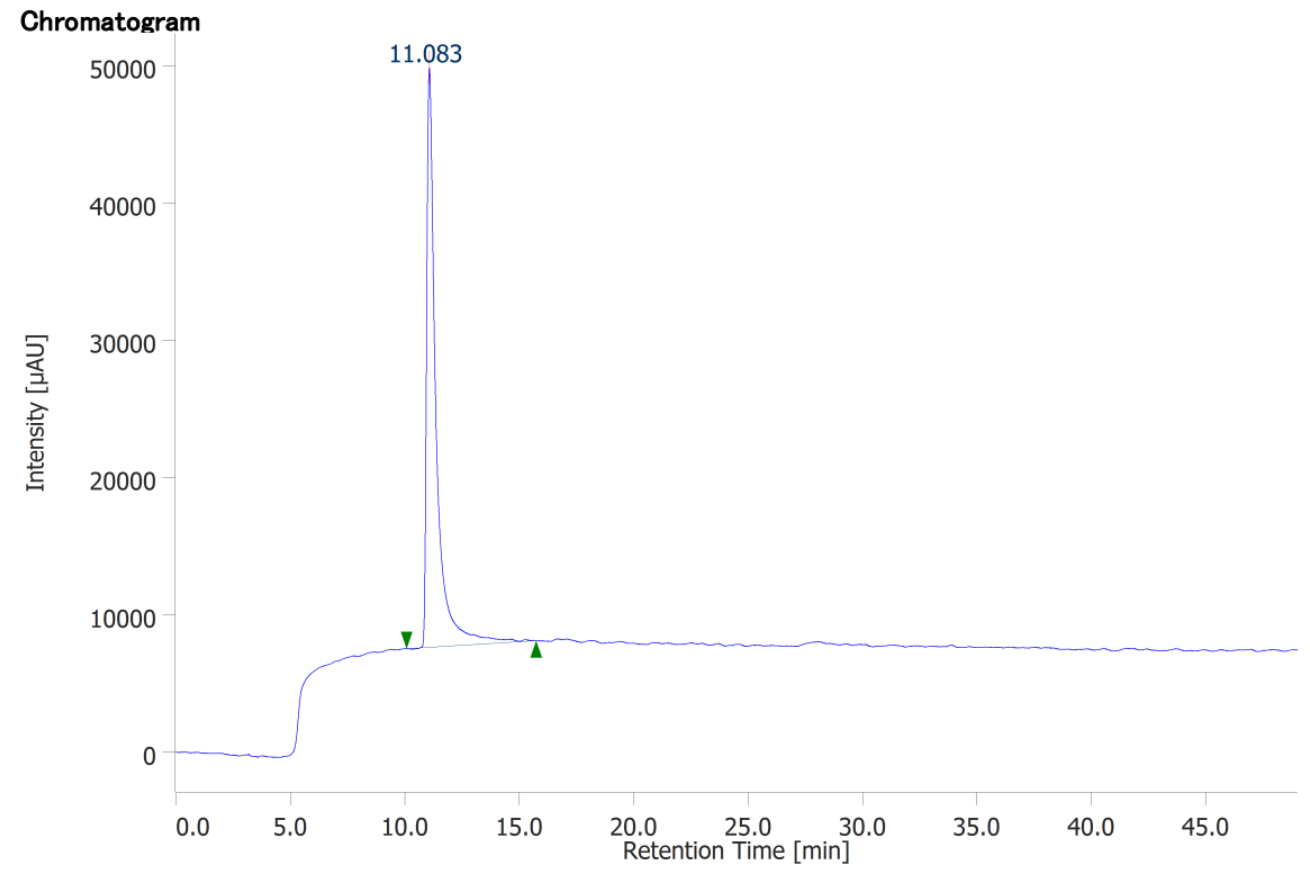

\section{(R)-2a}

Chromatogram

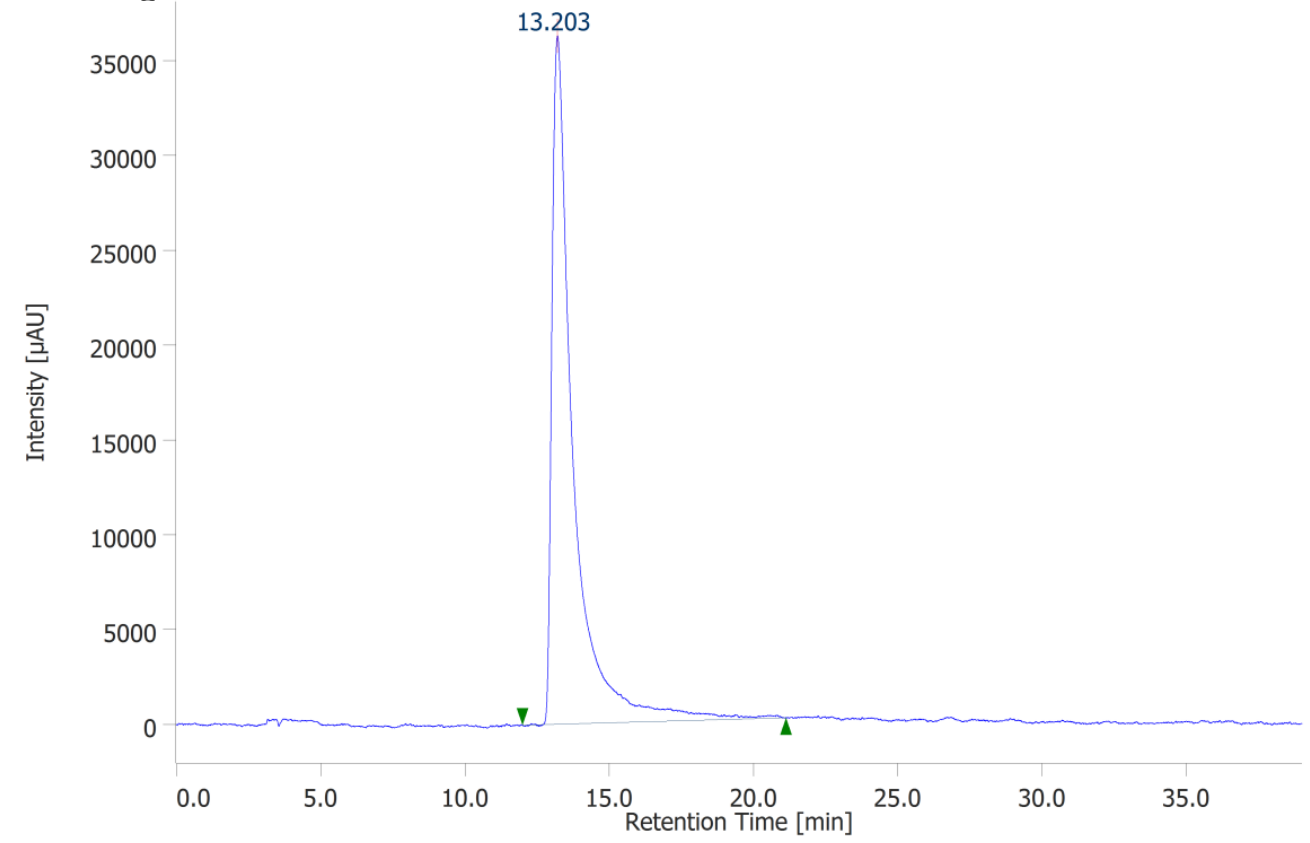


(S)-2b

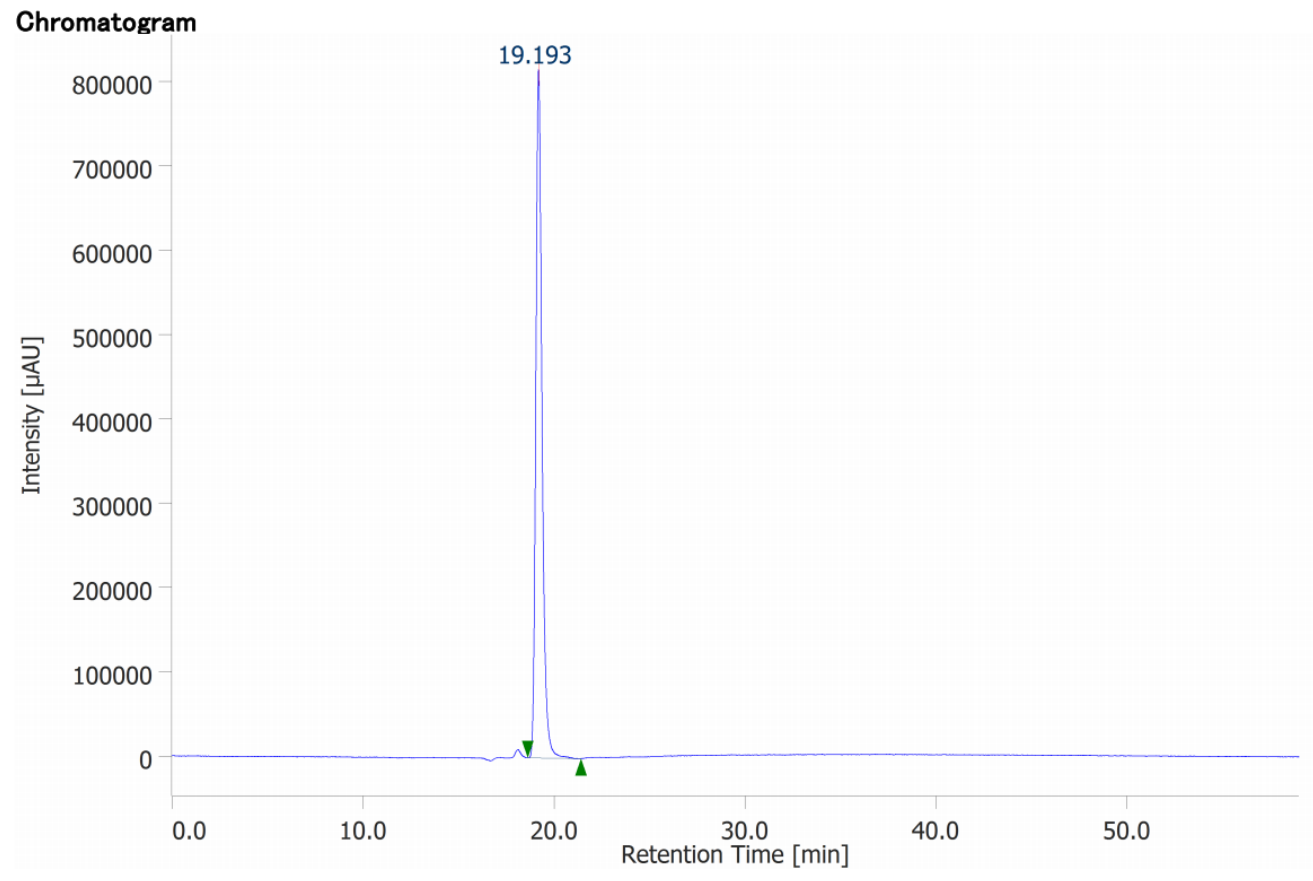

\section{(R)-2b}

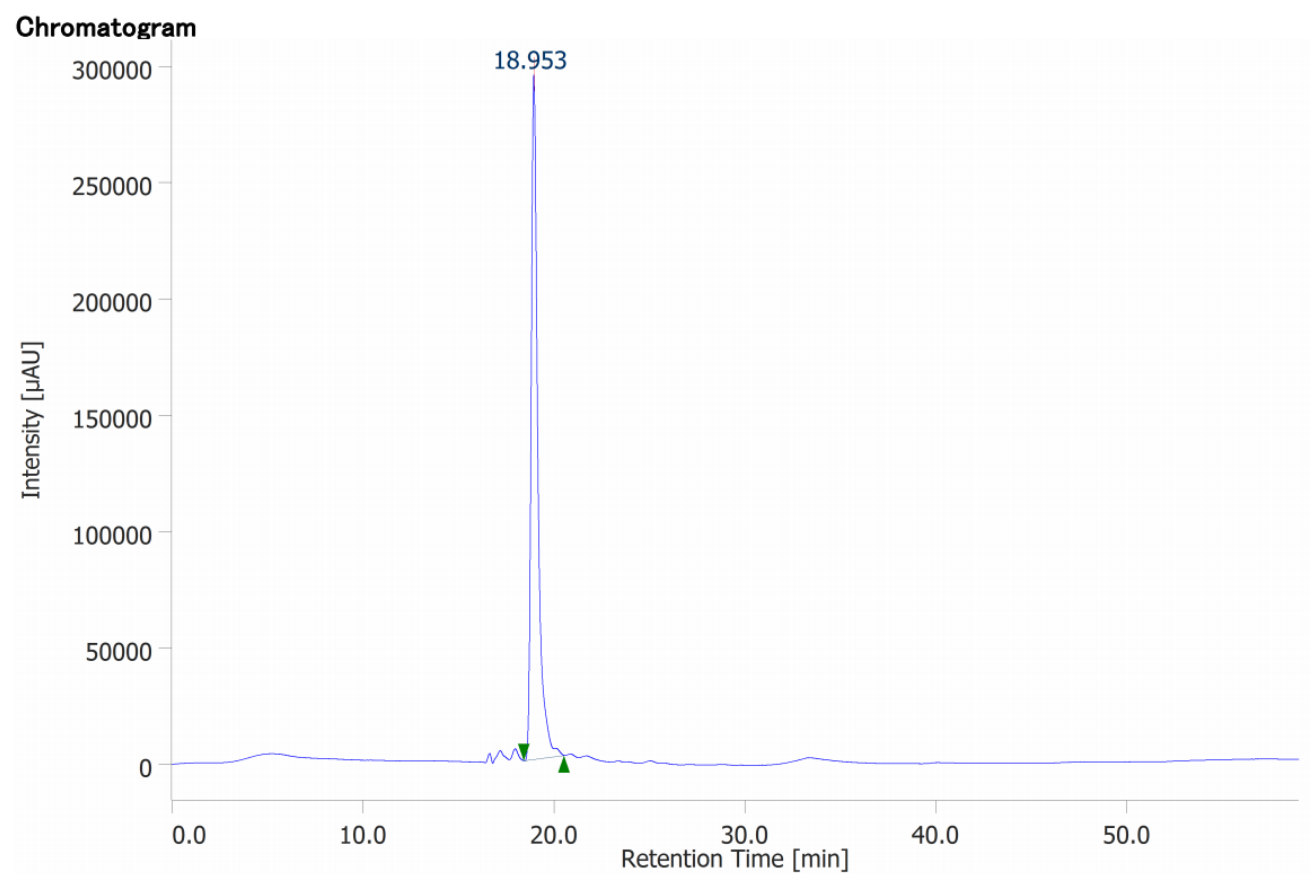


(S)-2c

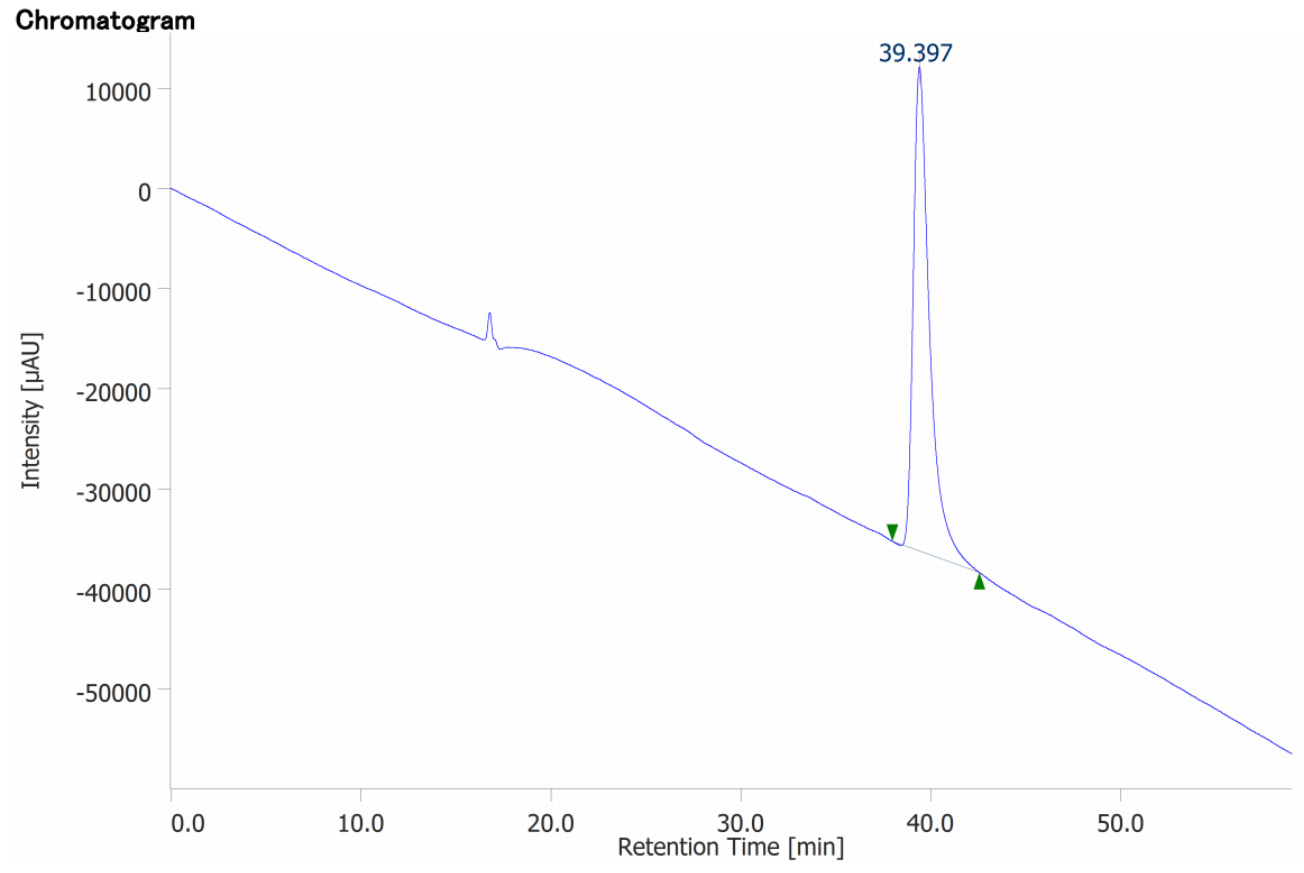

(R)-2c

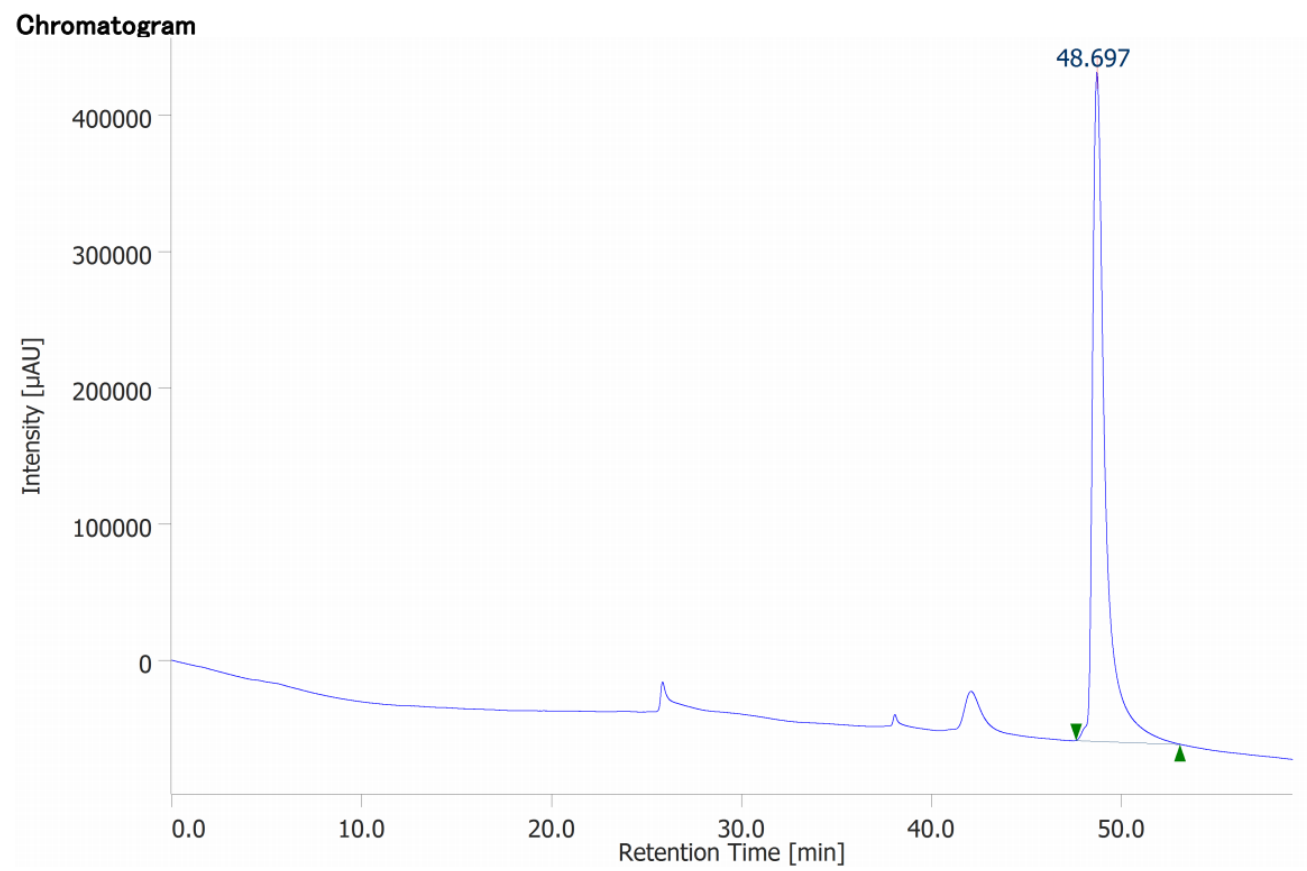


(S)-3a

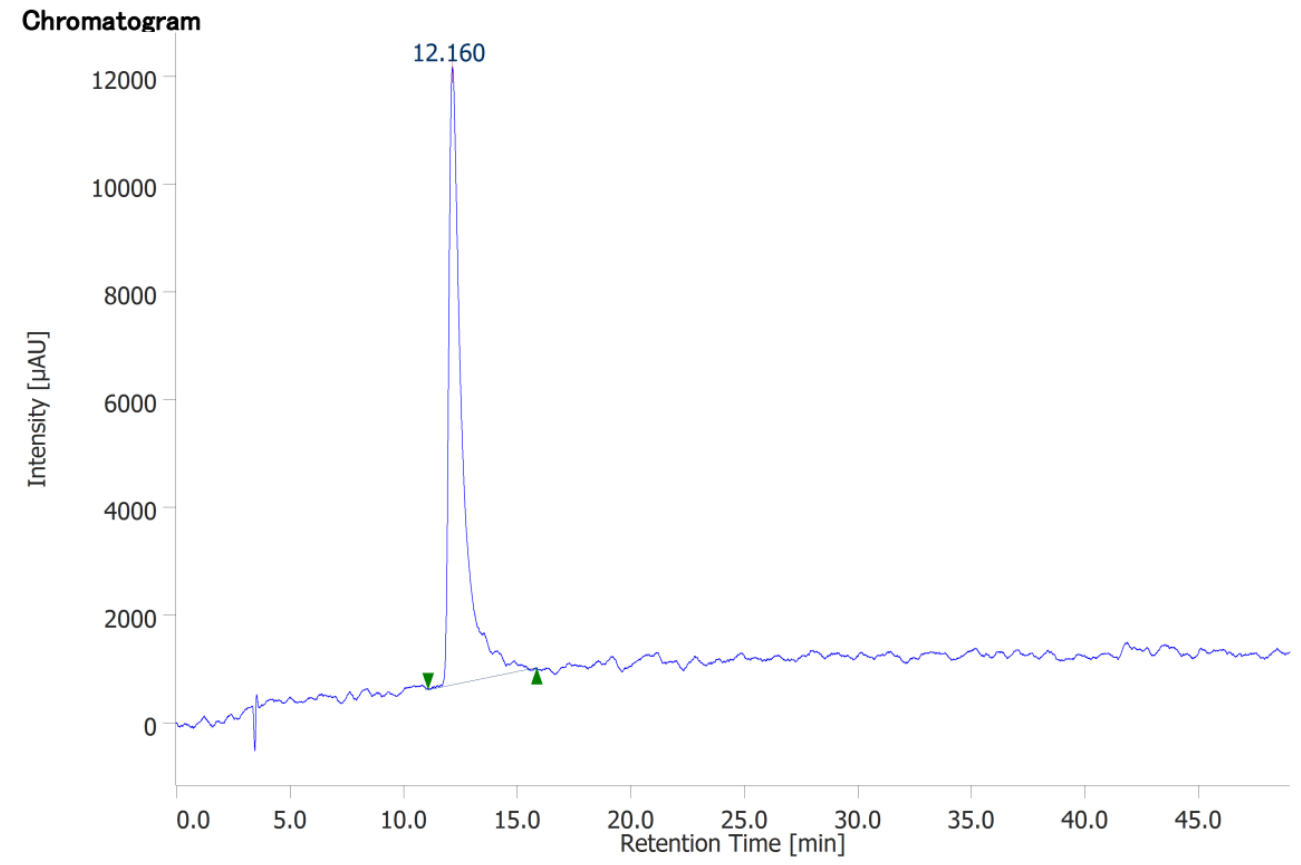

\section{(R)-3a}

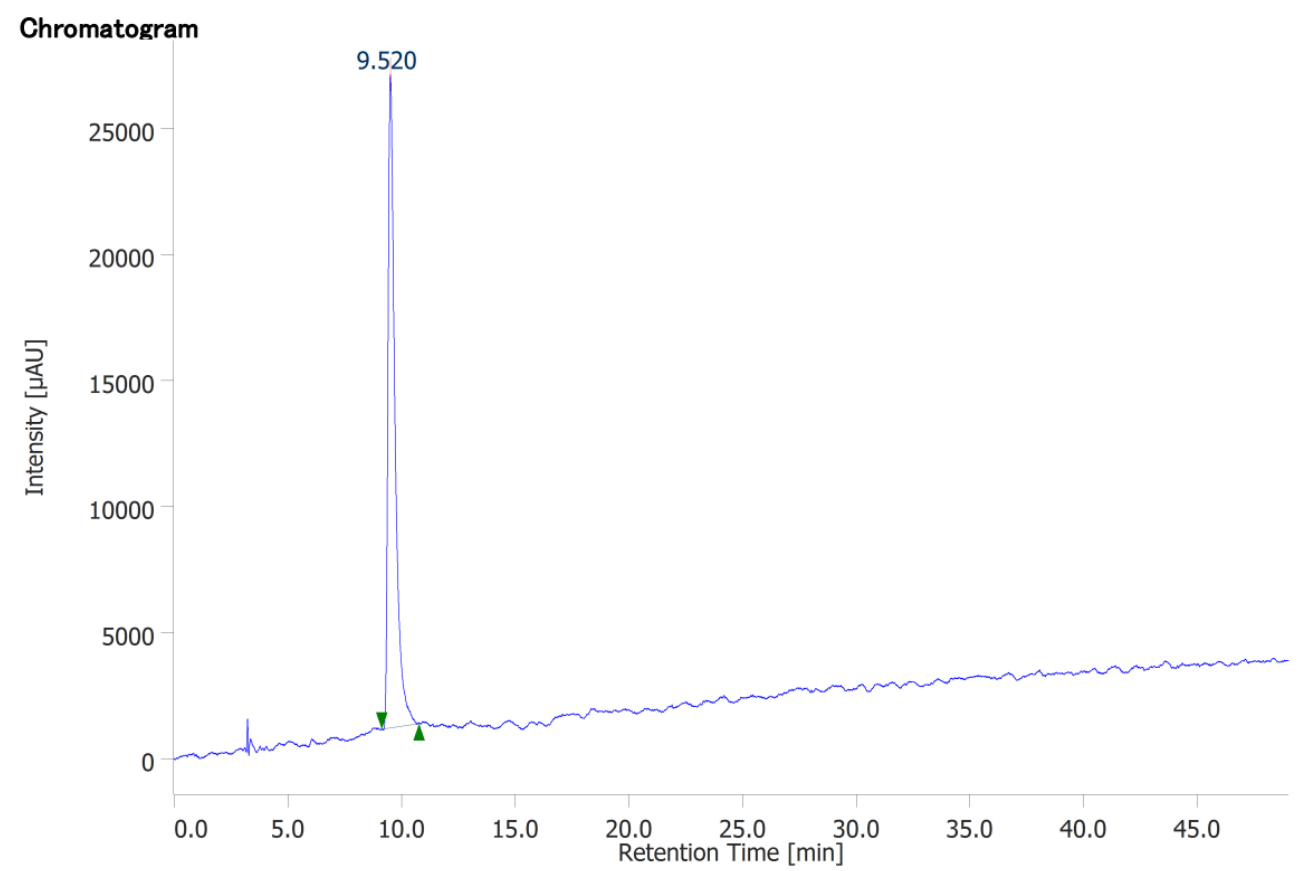


(S)-3b

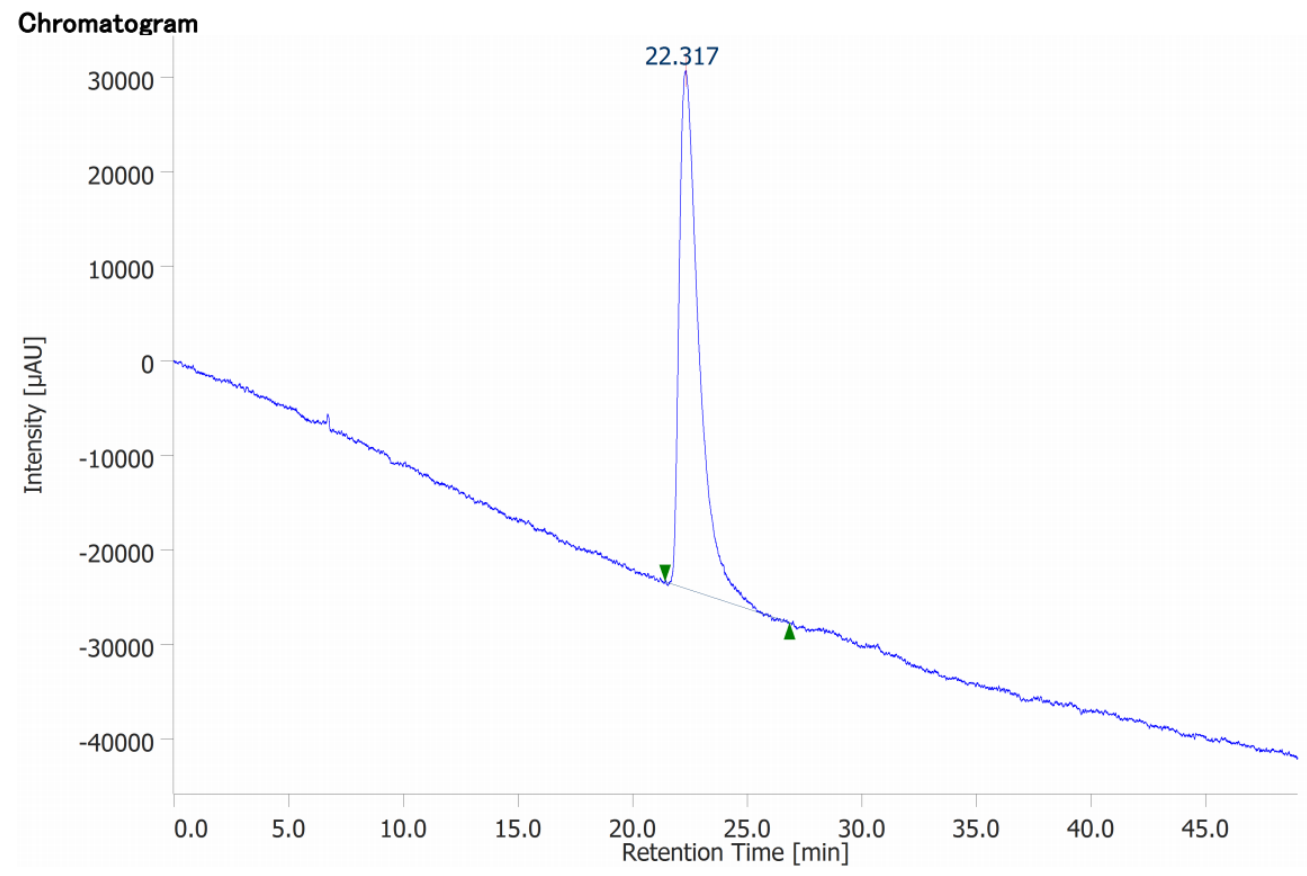

(R)-3b

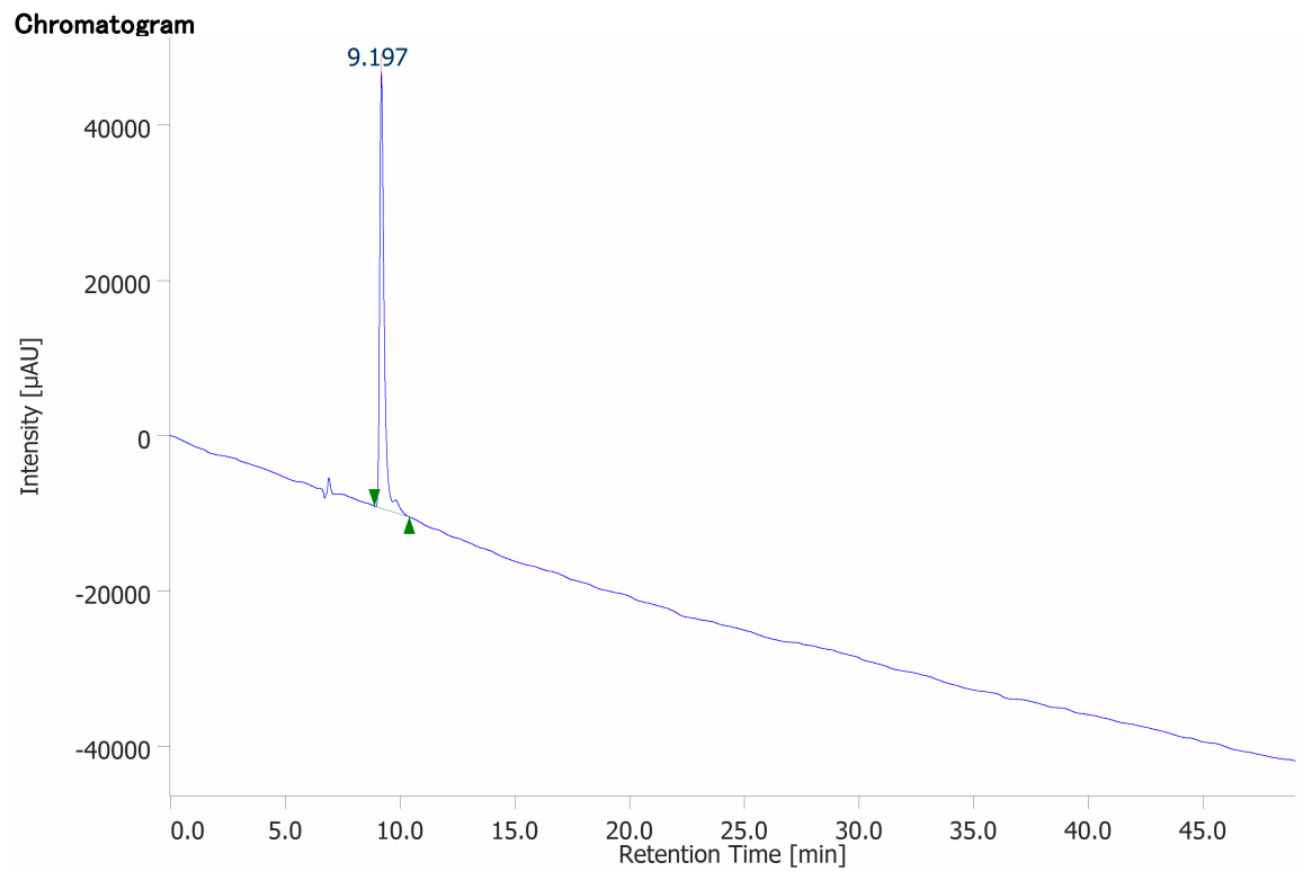




\section{(S)-3c}

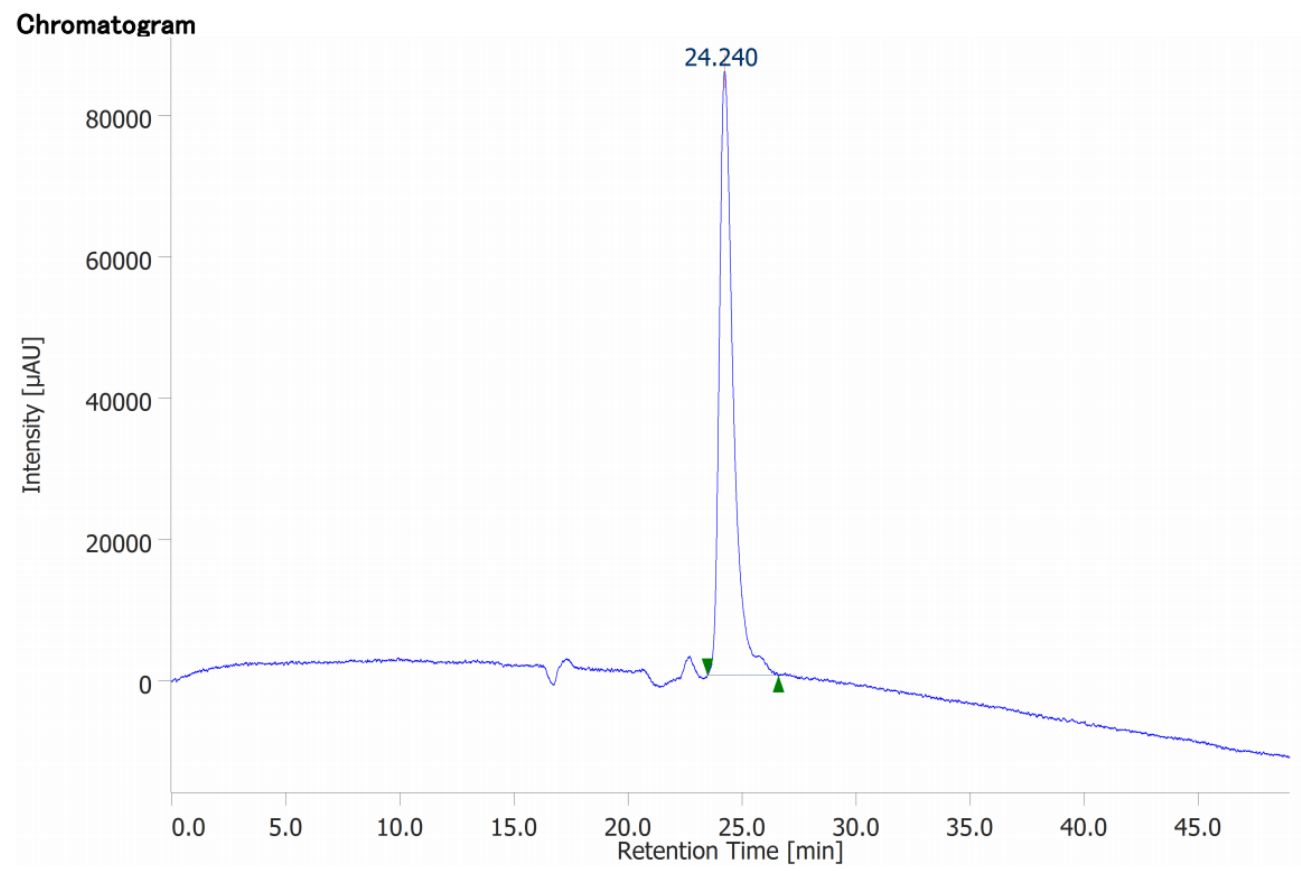

\section{(R)-3c}

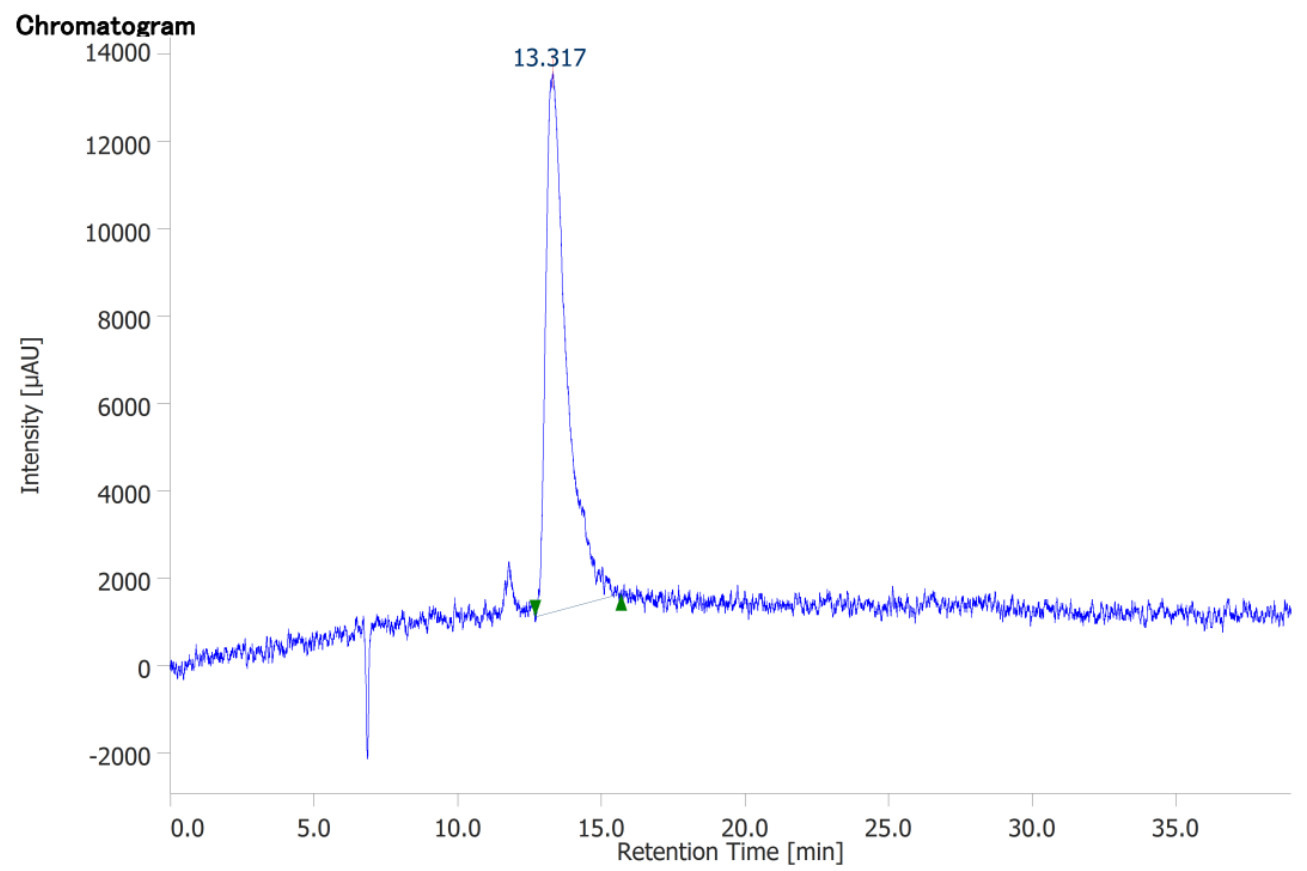




\section{(S)-4}

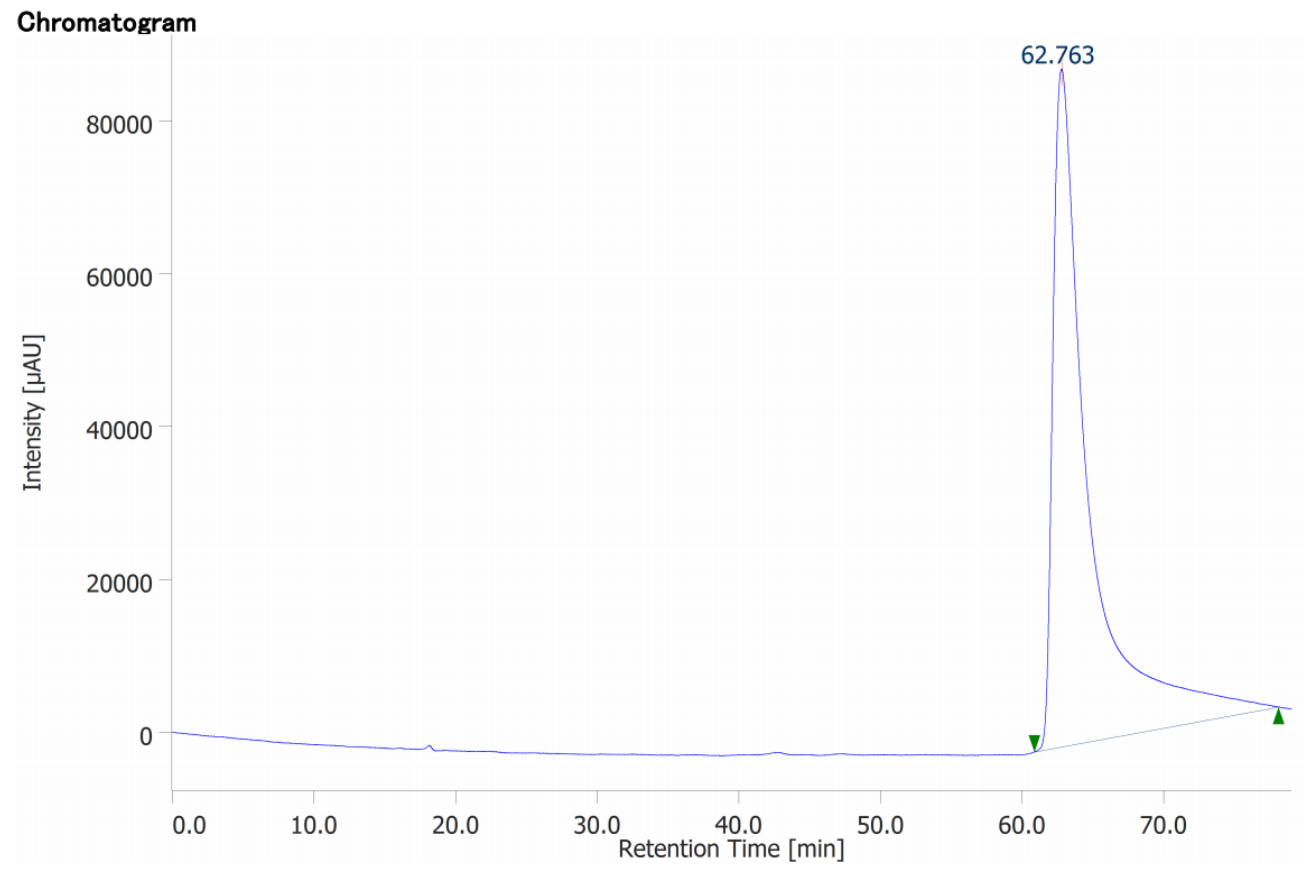

\section{(R)-4}

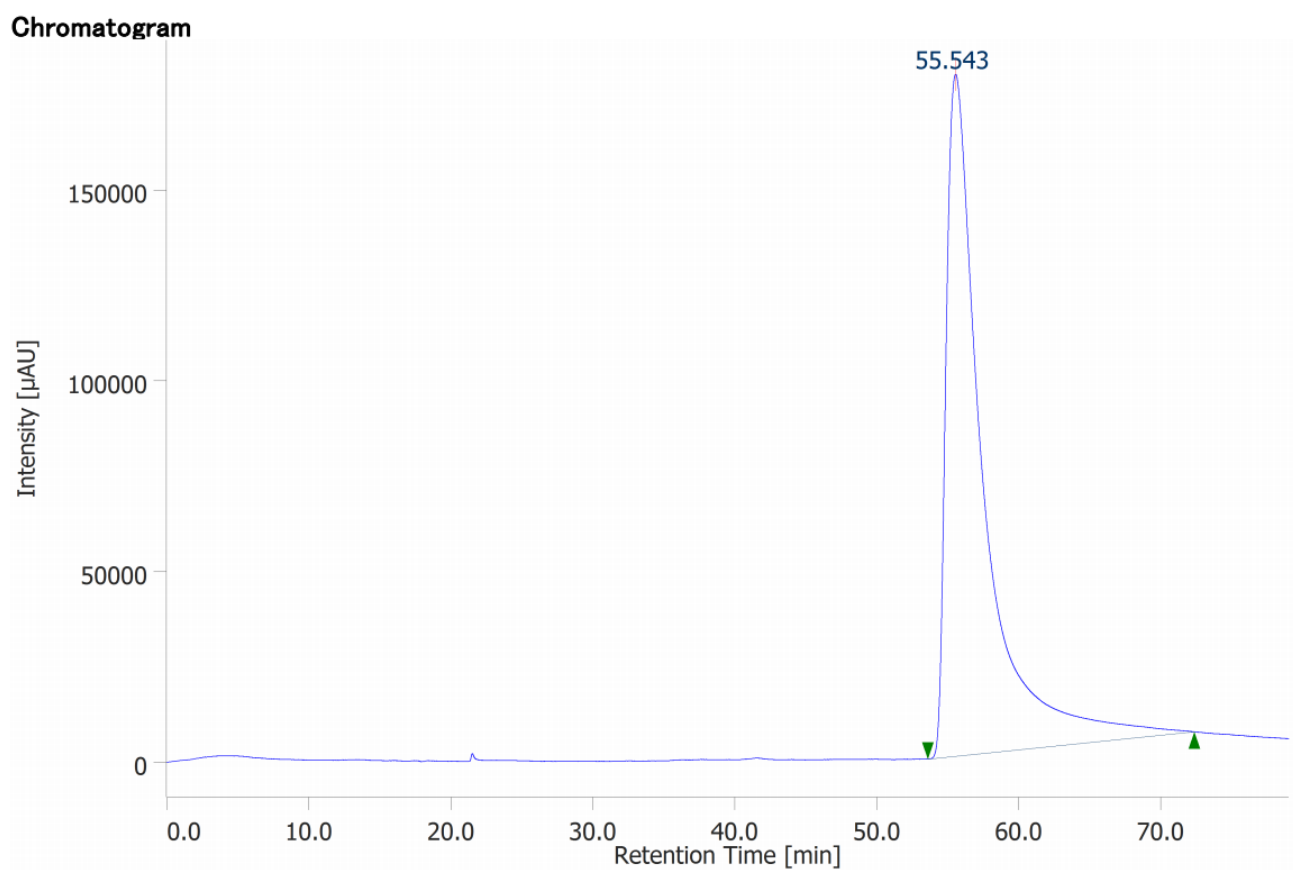


(S)-5

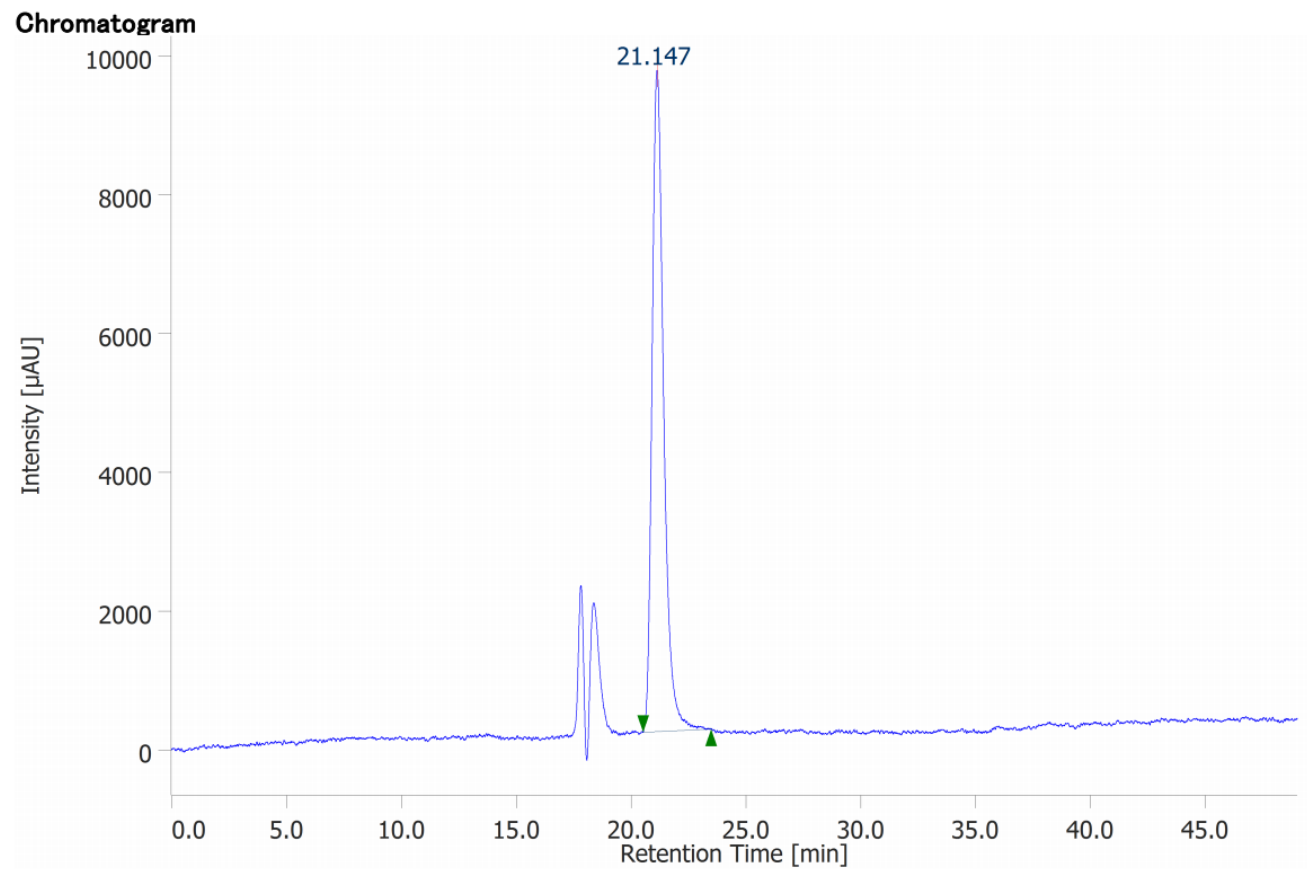

\section{(R)-5}

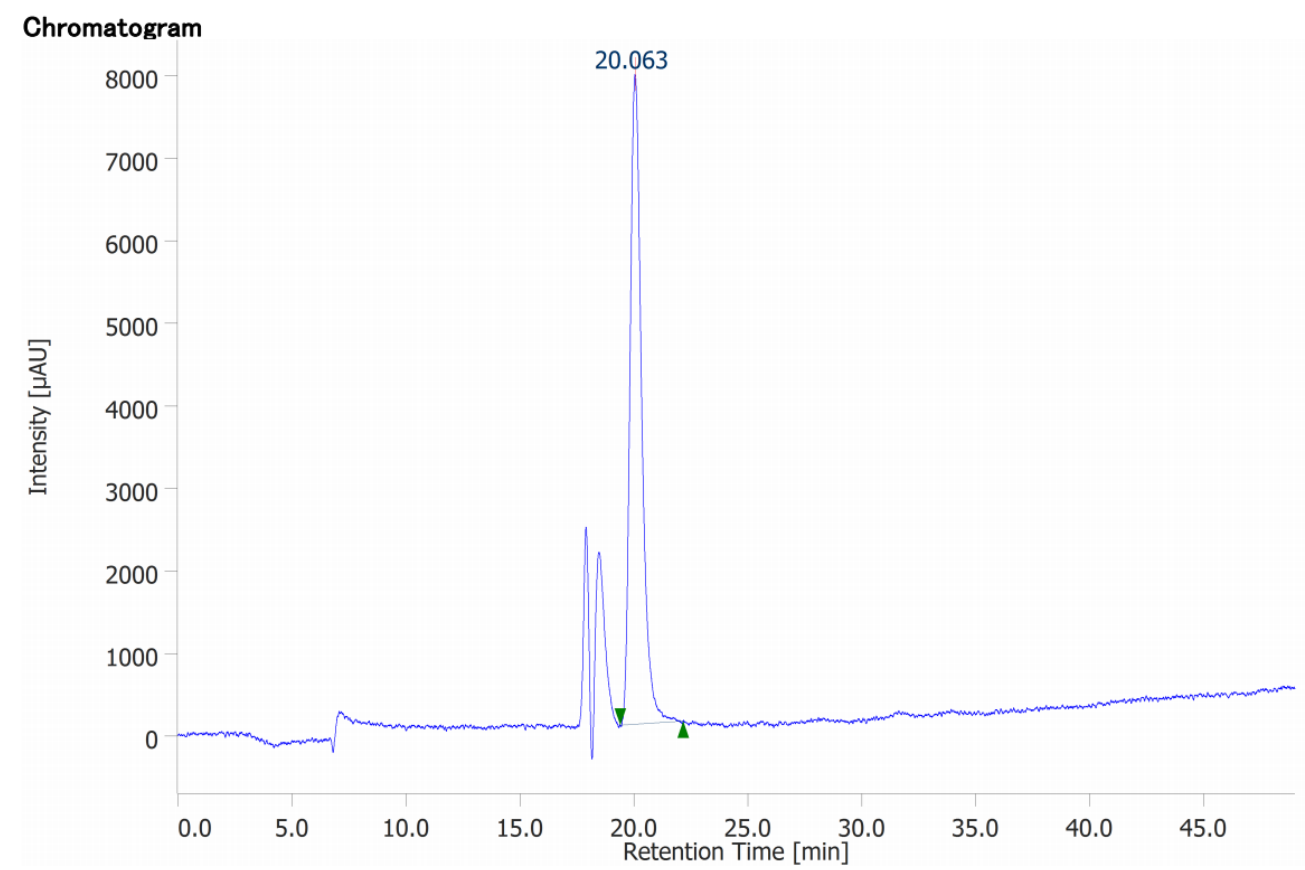




\section{Copy of NMR Spectra}

${ }^{1} \mathrm{H}$ NMR of BINAM (400 MHz, $\mathrm{CDCl}_{3}$ )
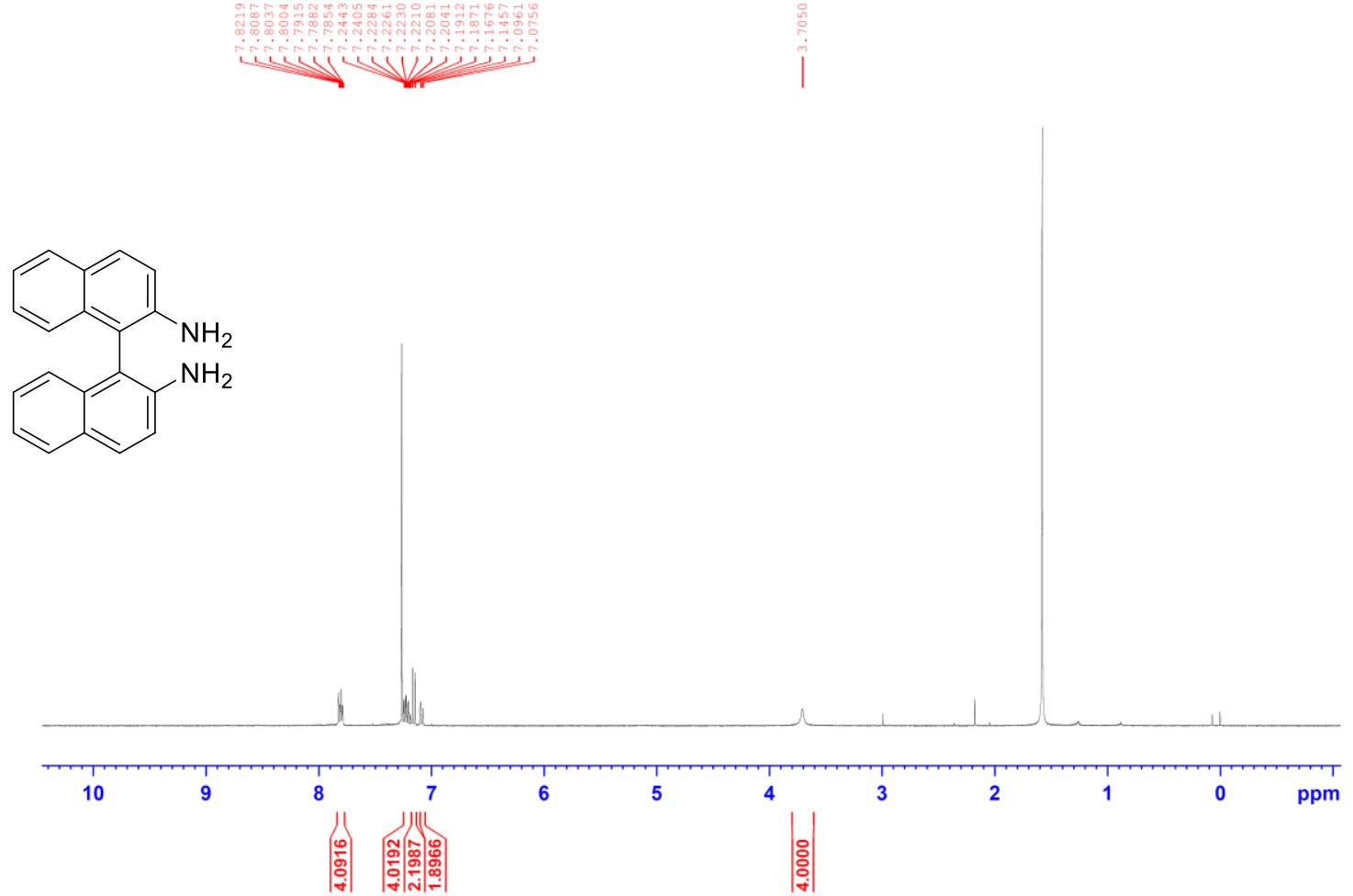

${ }^{13} \mathrm{C}$ NMR of BINAM (100 MHz, $\mathrm{CDCl}_{3}$ )

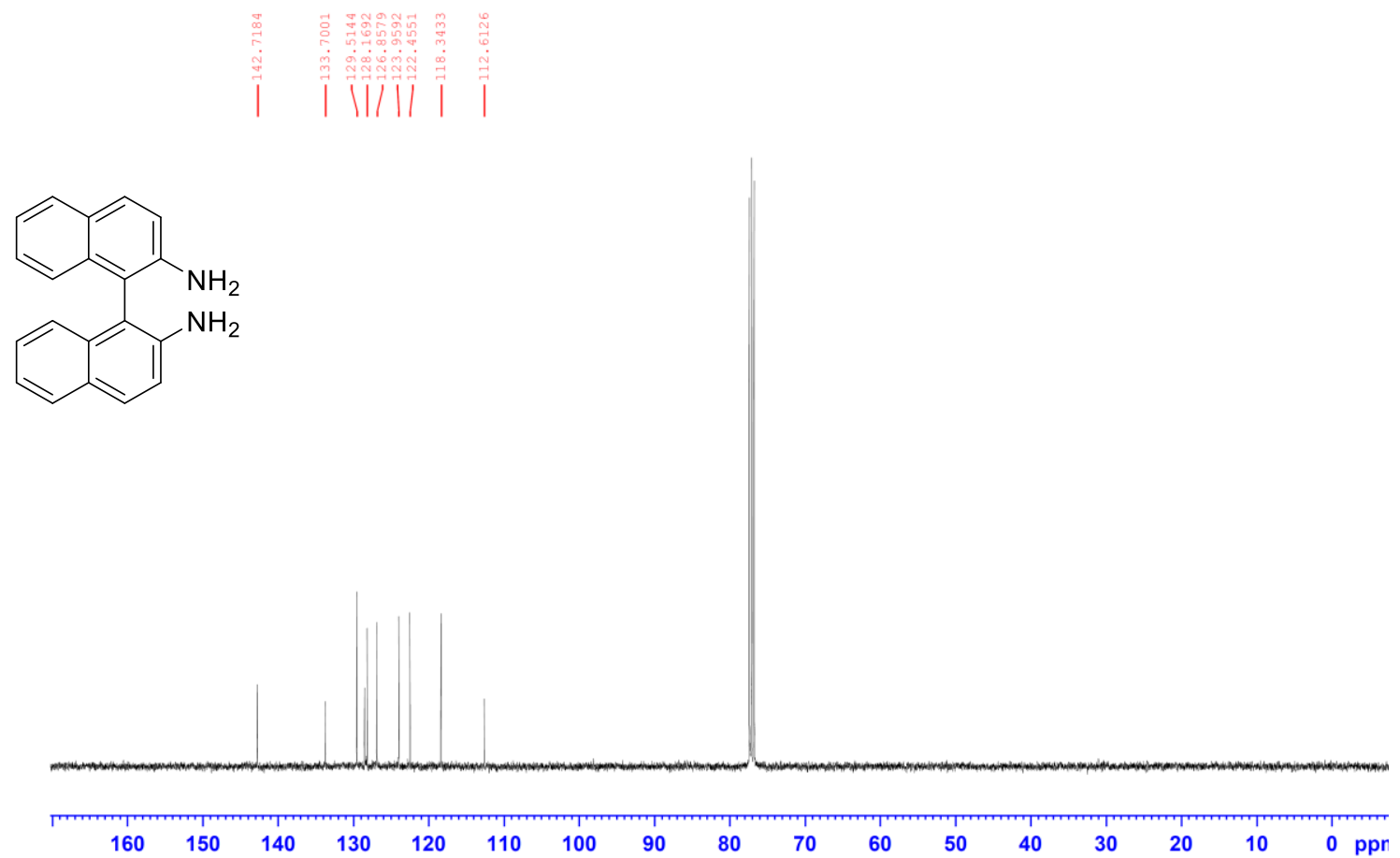


${ }^{1} \mathrm{H}$ NMR of $\mathrm{Ac}_{2}$-BINAM $\left(400 \mathrm{MHz}, \mathrm{CDCl}_{3}\right.$ )

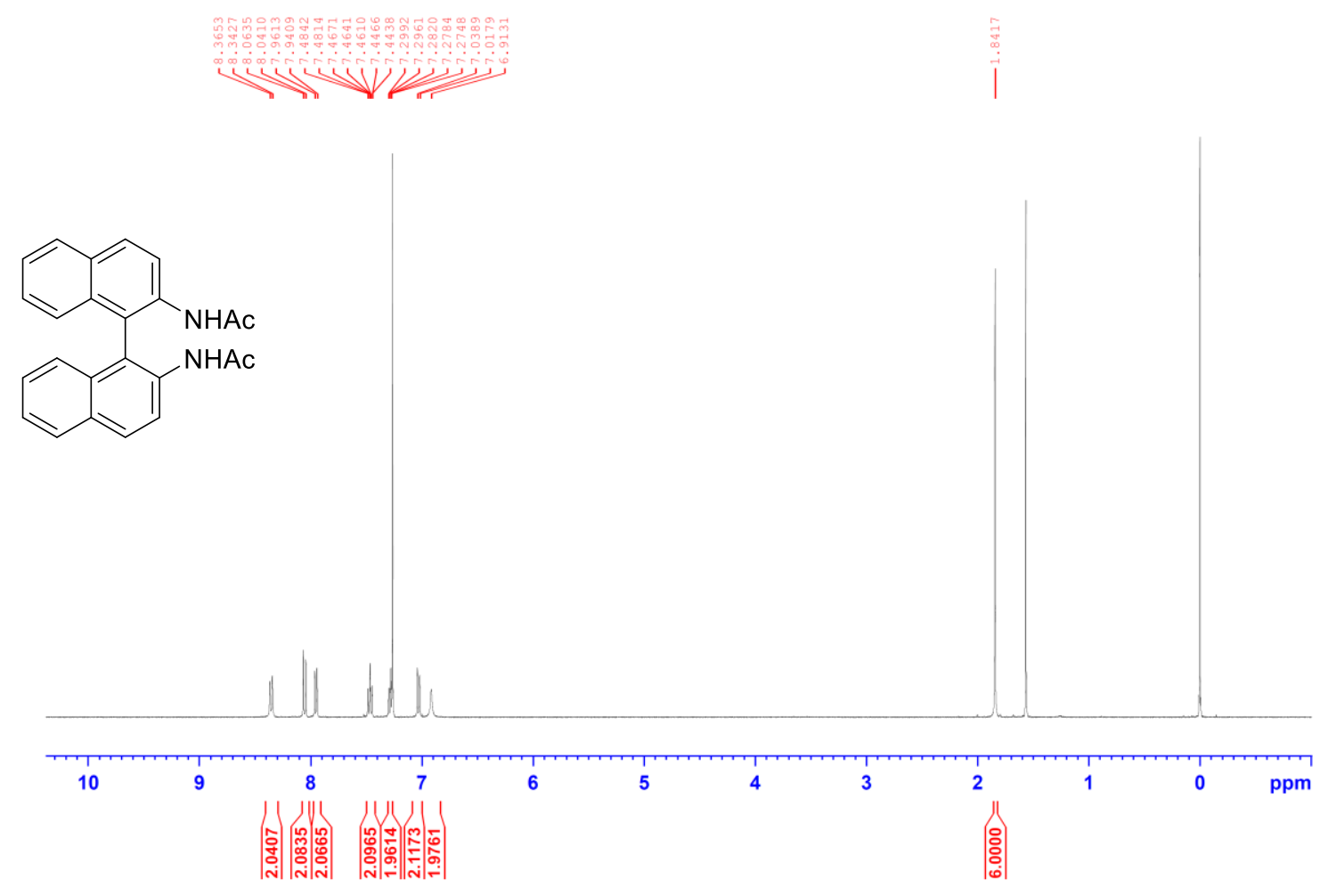

${ }^{13} \mathrm{C}$ NMR of $\mathrm{Ac}_{2}$-BINAM $\left(100 \mathrm{MHz}, \mathrm{CDCl}_{3}\right)$

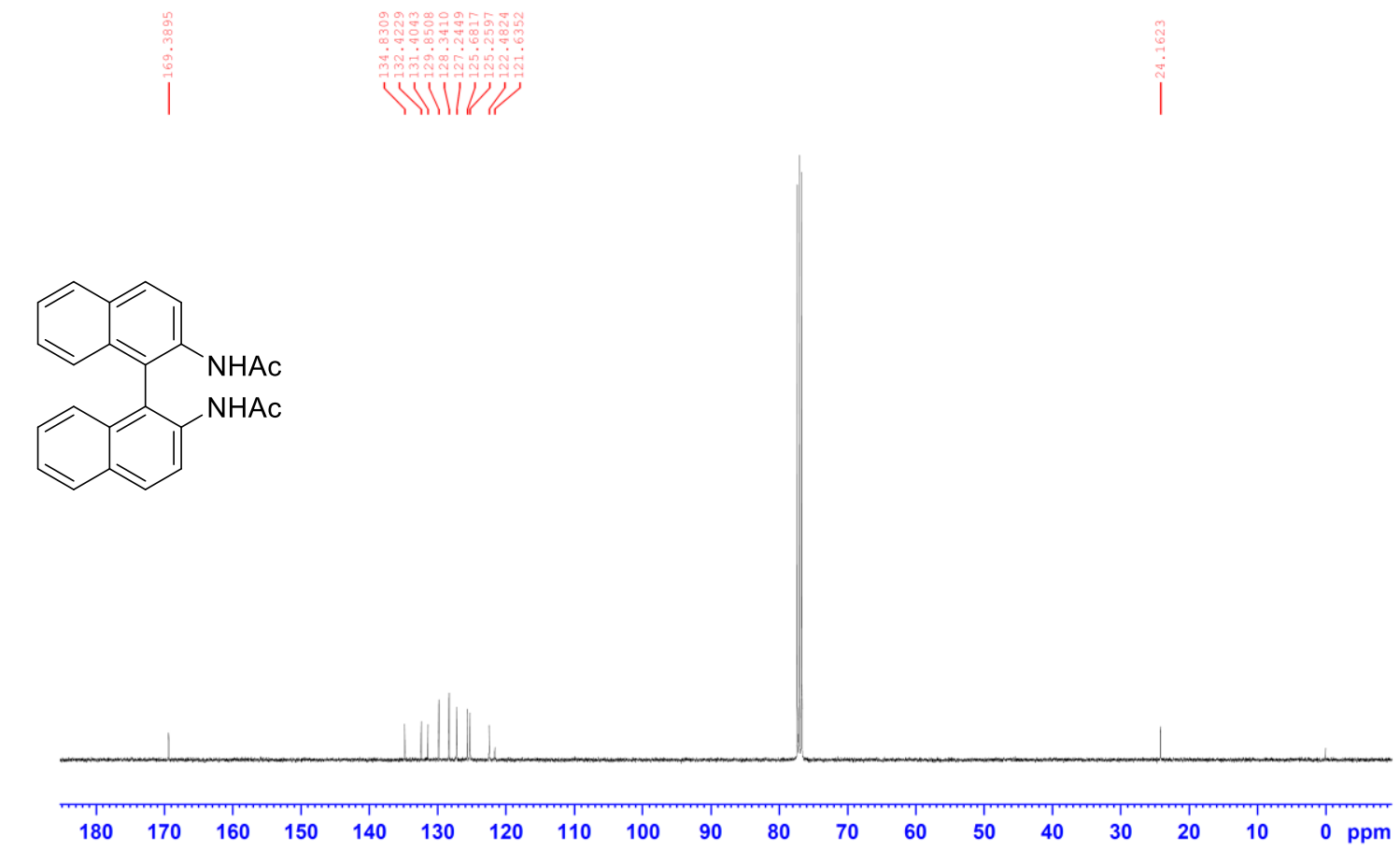


${ }^{1} \mathrm{H}$ NMR of $1 \mathbf{a}\left(400 \mathrm{MHz}, \mathrm{CDCl}_{3}\right)$

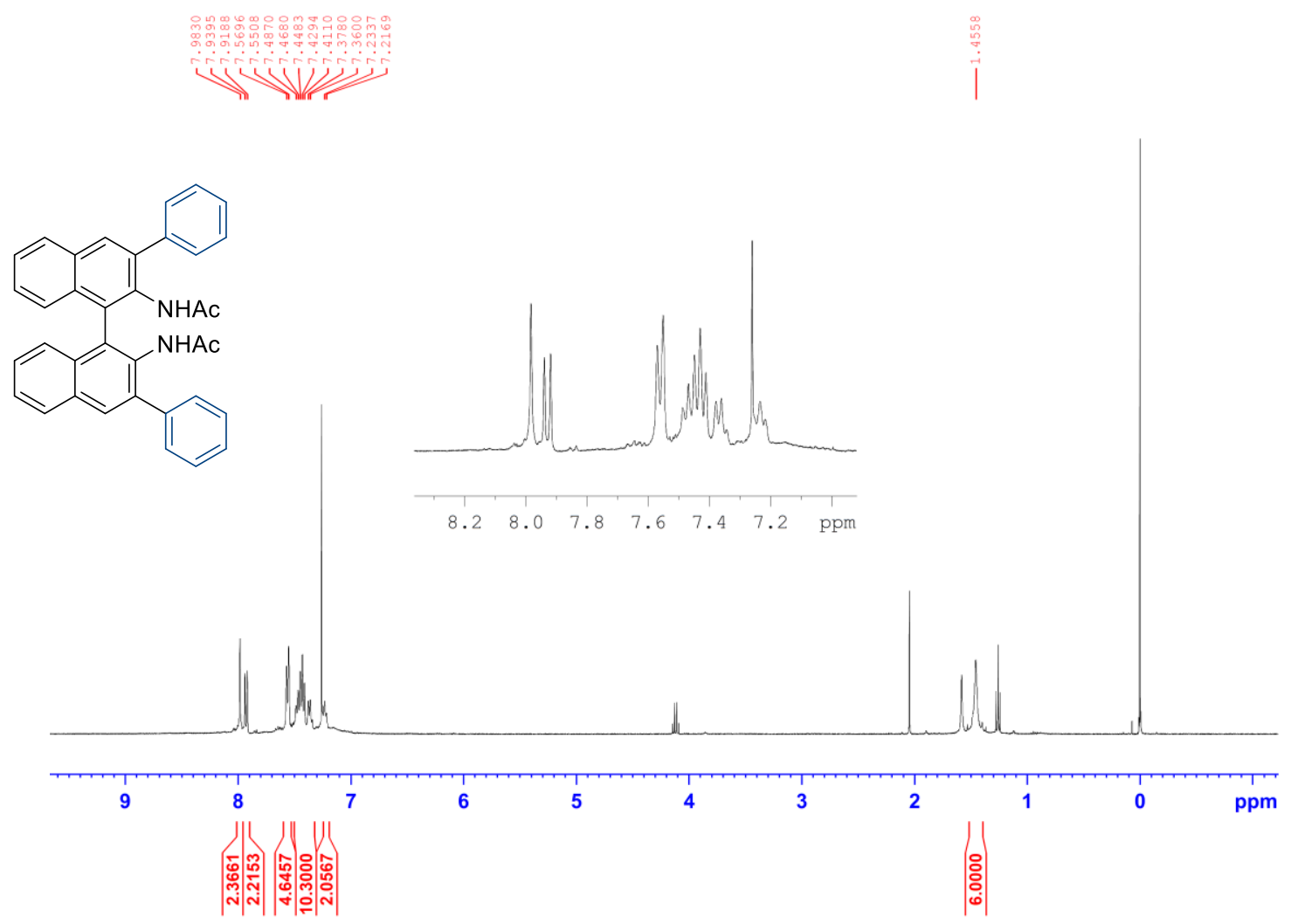

${ }^{13} \mathrm{C}$ NMR of $1 \mathbf{a}\left(100 \mathrm{MHz}, \mathrm{CDCl}_{3}\right)$

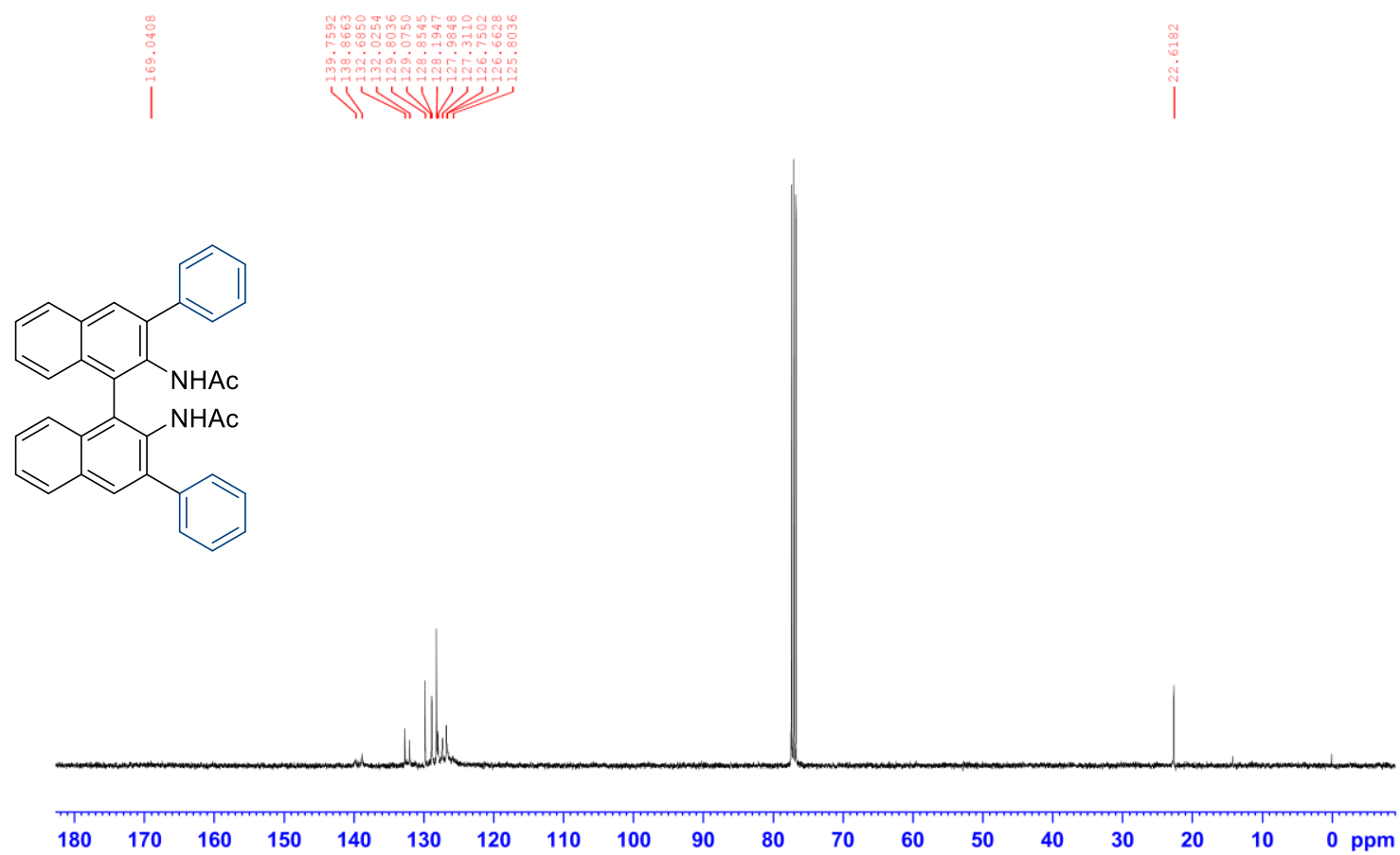


${ }^{1} \mathrm{H} \mathrm{NMR}$ of $\mathbf{1 b}\left(400 \mathrm{MHz}, \mathrm{CDCl}_{3}\right)$

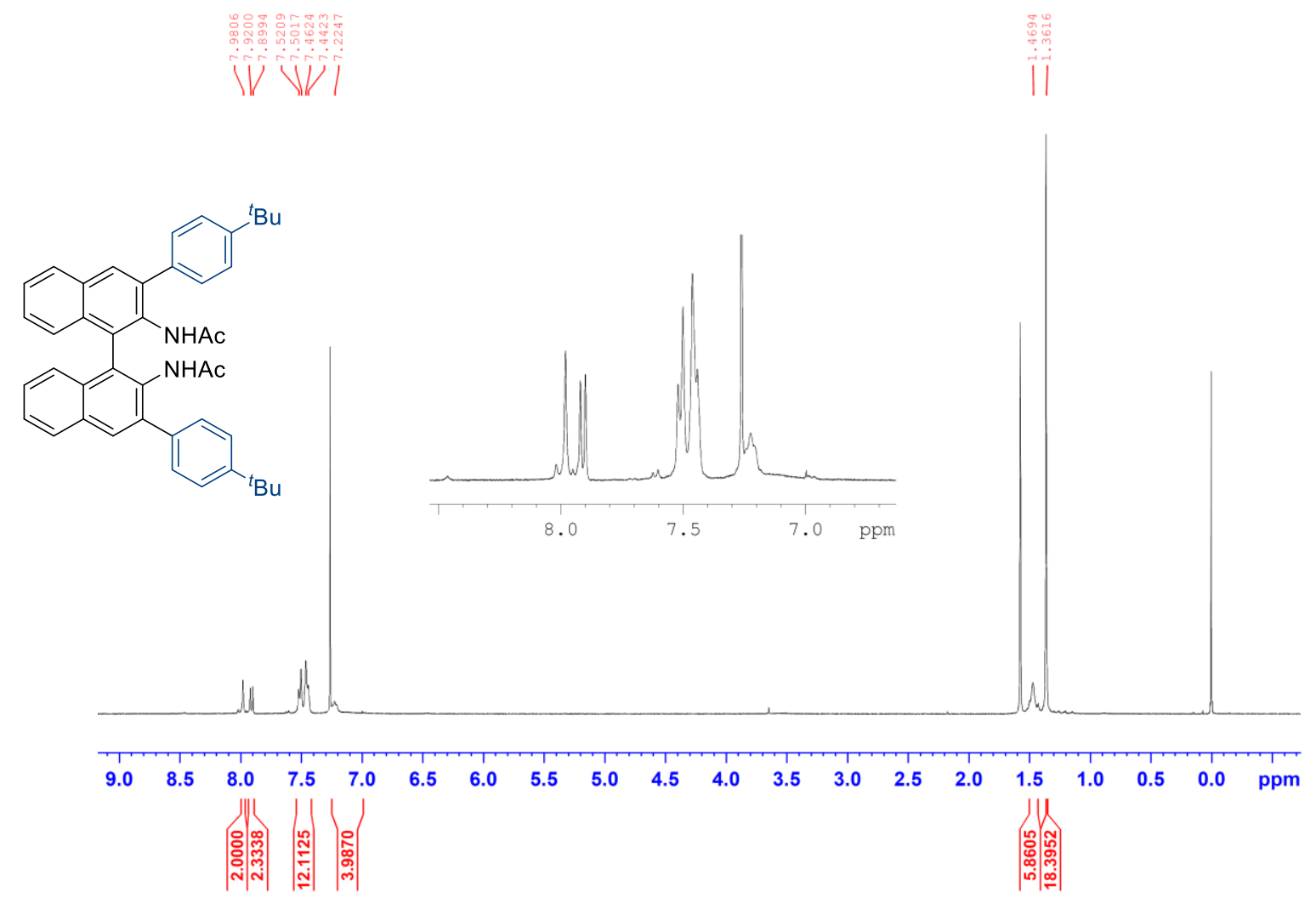

${ }^{13} \mathrm{C}$ NMR of $1 \mathbf{b}\left(100 \mathrm{MHz}, \mathrm{CDCl}_{3}\right)$

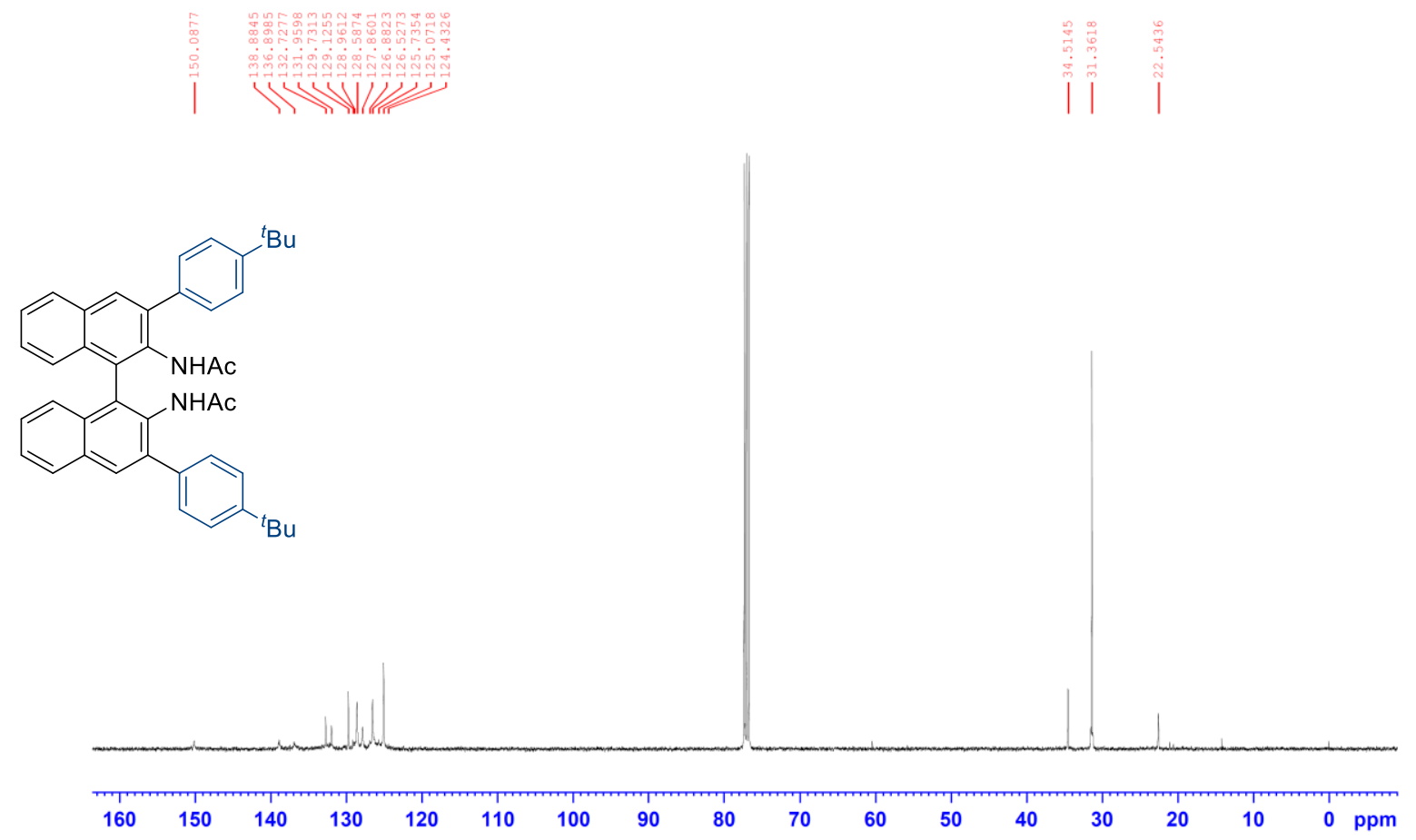


${ }^{1} \mathrm{H}$ NMR of $1 \mathbf{c}\left(400 \mathrm{MHz}, \mathrm{CDCl}_{3}\right)$

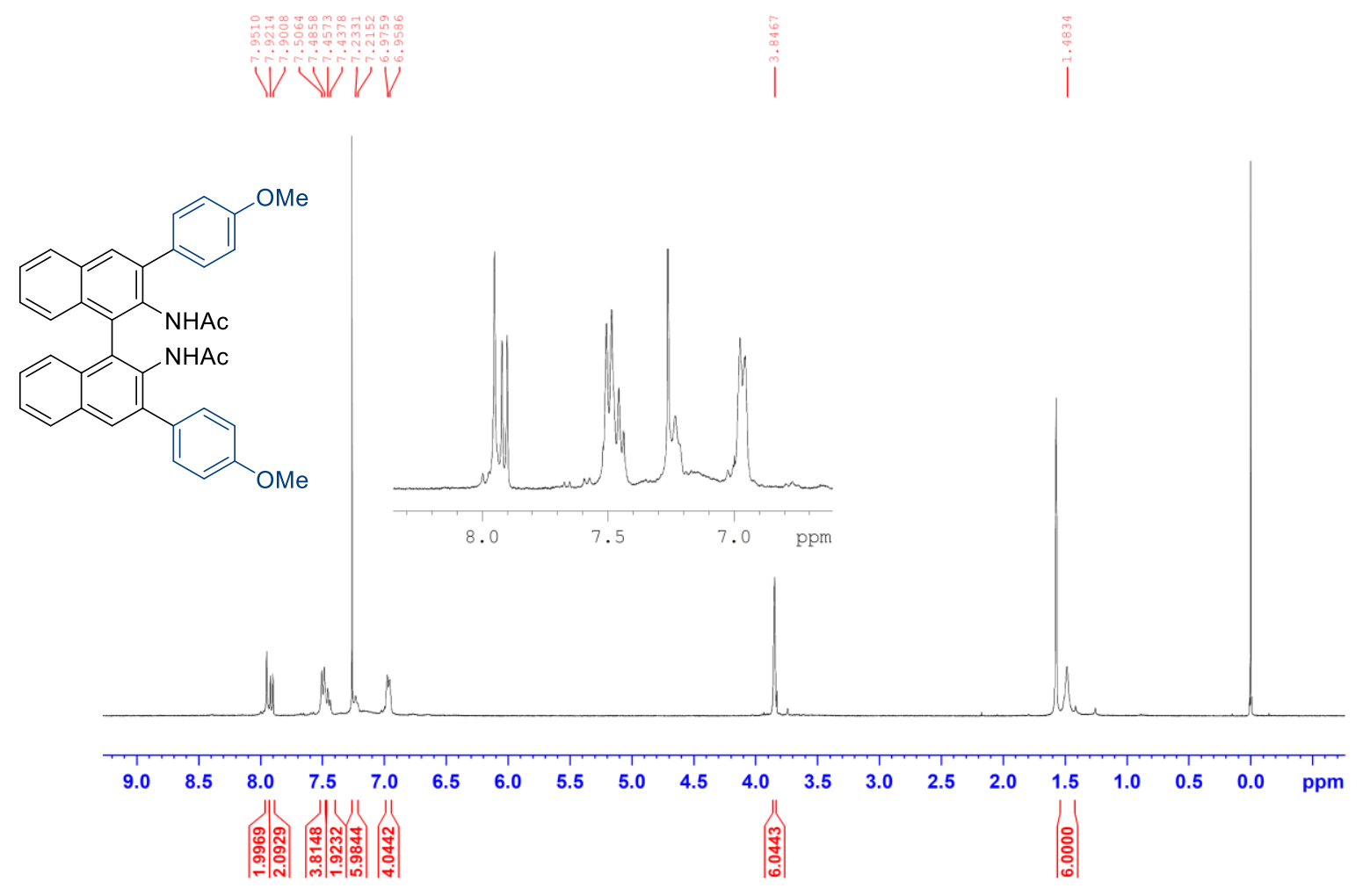

${ }^{13} \mathrm{C}$ NMR of $1 \mathbf{c}\left(100 \mathrm{MHz}, \mathrm{CDCl}_{3}\right)$

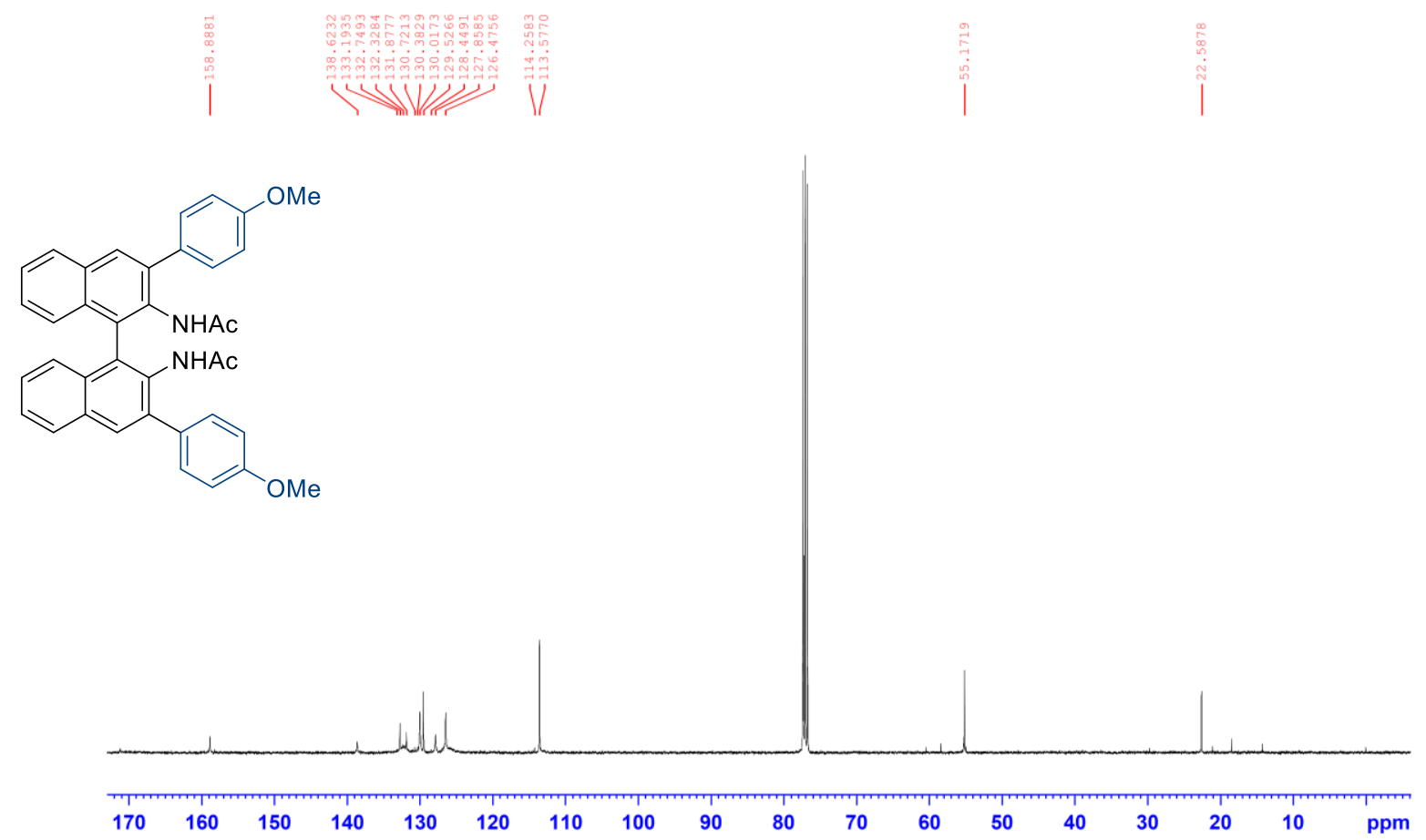


${ }^{1} \mathrm{H}$ NMR of $2 \mathbf{a}\left(400 \mathrm{MHz}, \mathrm{CDCl}_{3}\right)$

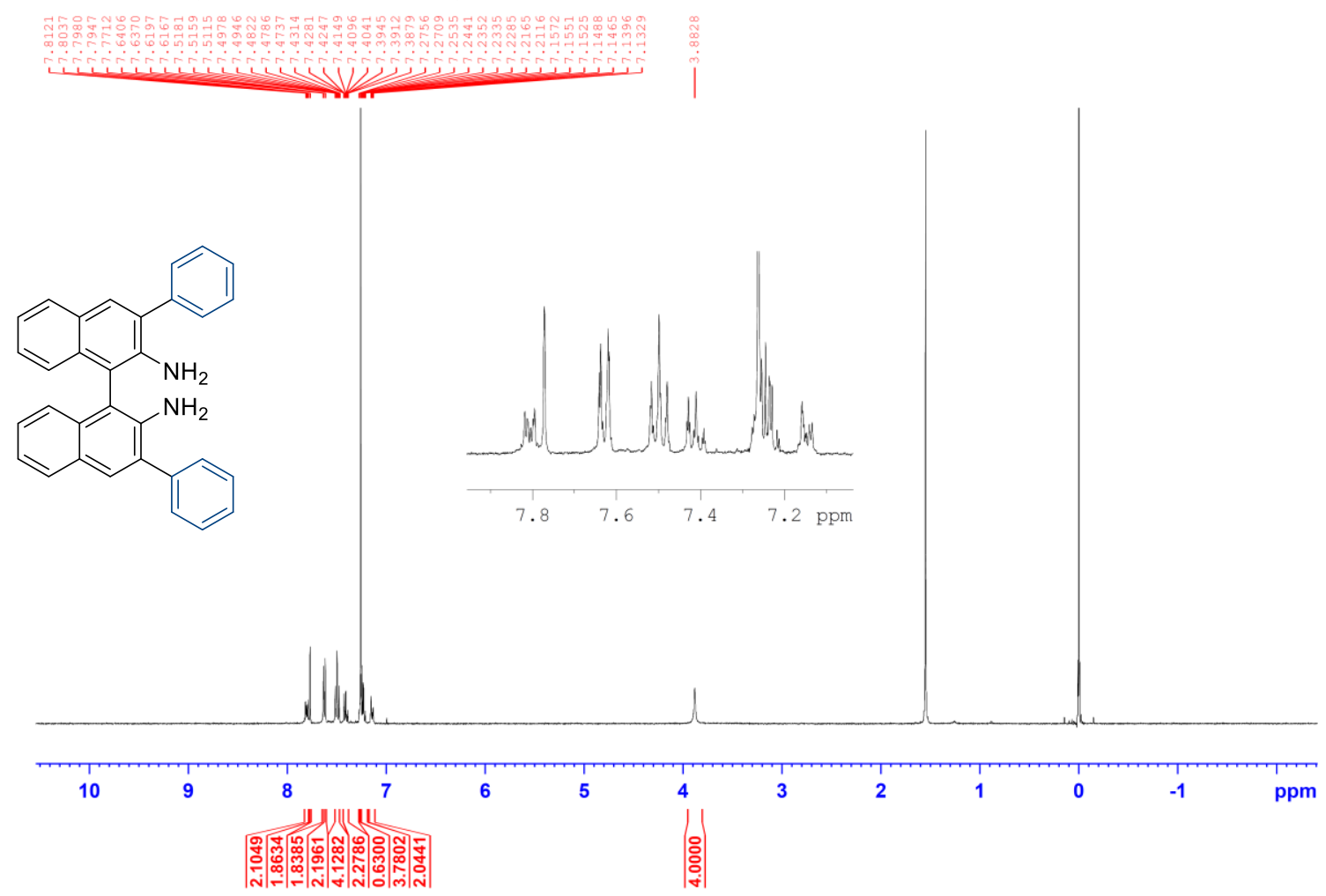

${ }^{13} \mathrm{C}$ NMR of 2a $\left(100 \mathrm{MHz}, \mathrm{CDCl}_{3}\right)$

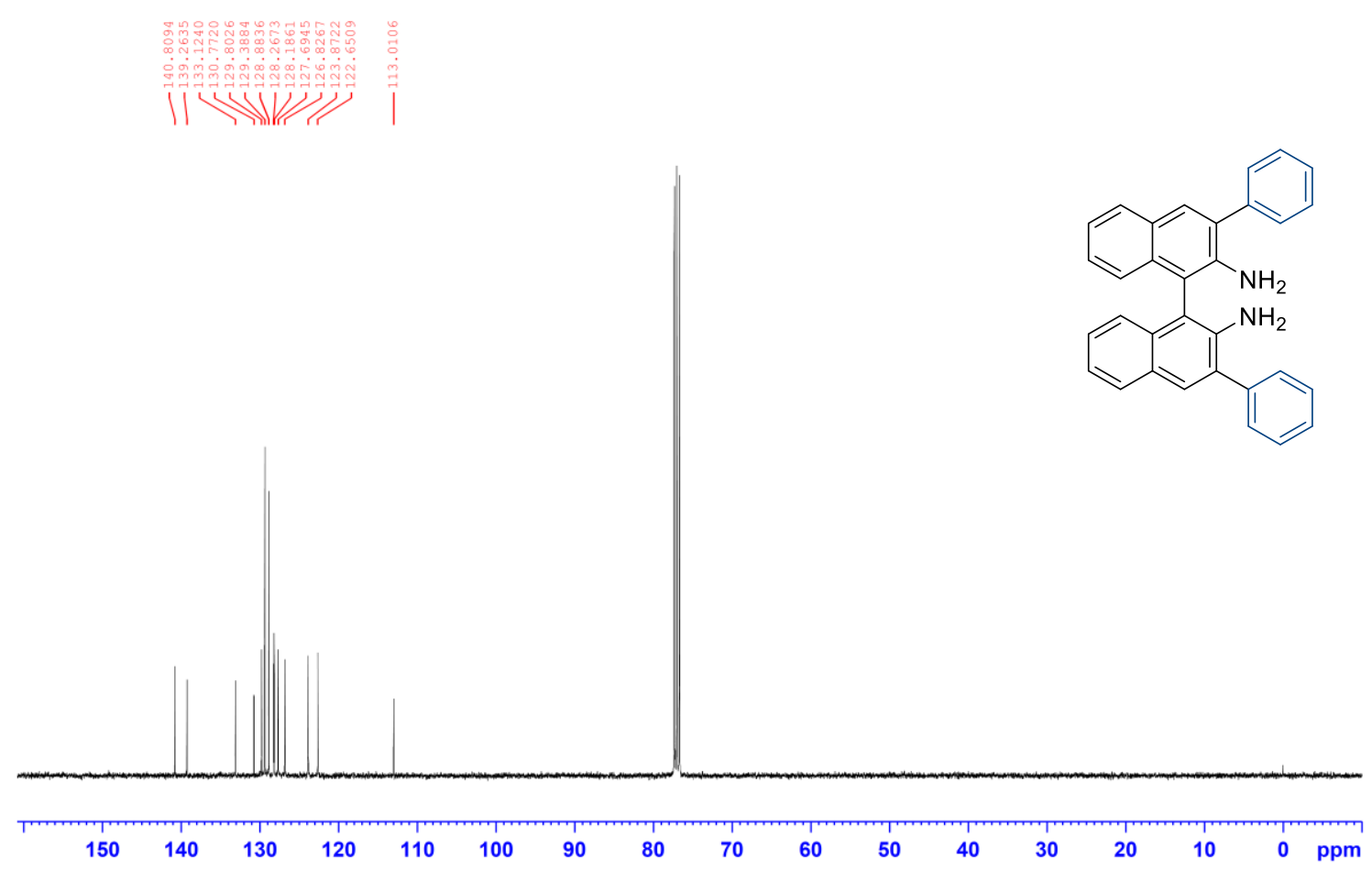


${ }^{1} \mathrm{H}$ NMR of $2 \mathbf{b}\left(400 \mathrm{MHz}, \mathrm{CDCl}_{3}\right)$

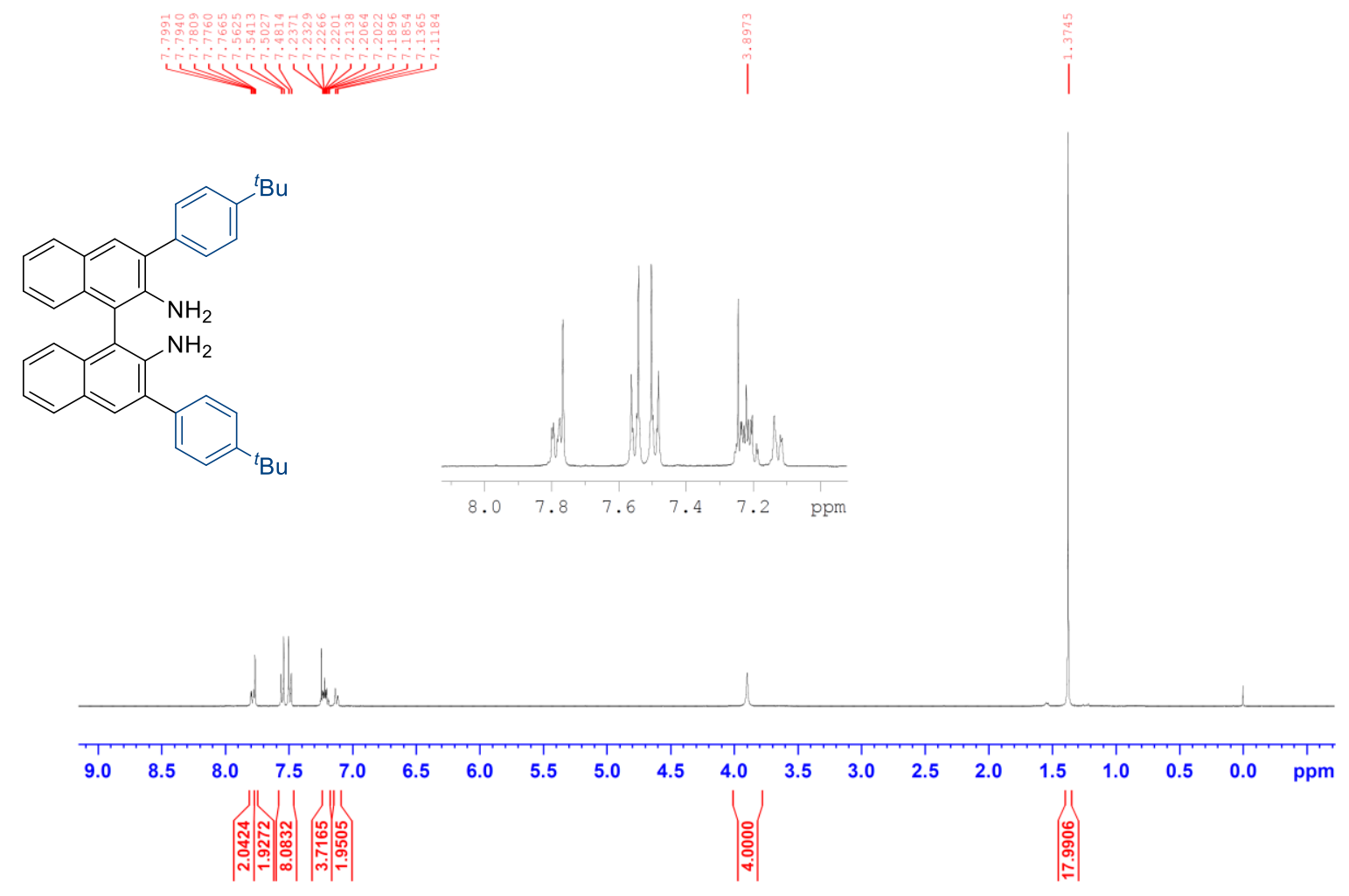

${ }^{13} \mathrm{C}$ NMR of $\mathbf{2 b}\left(100 \mathrm{MHz}, \mathrm{CDCl}_{3}\right)$

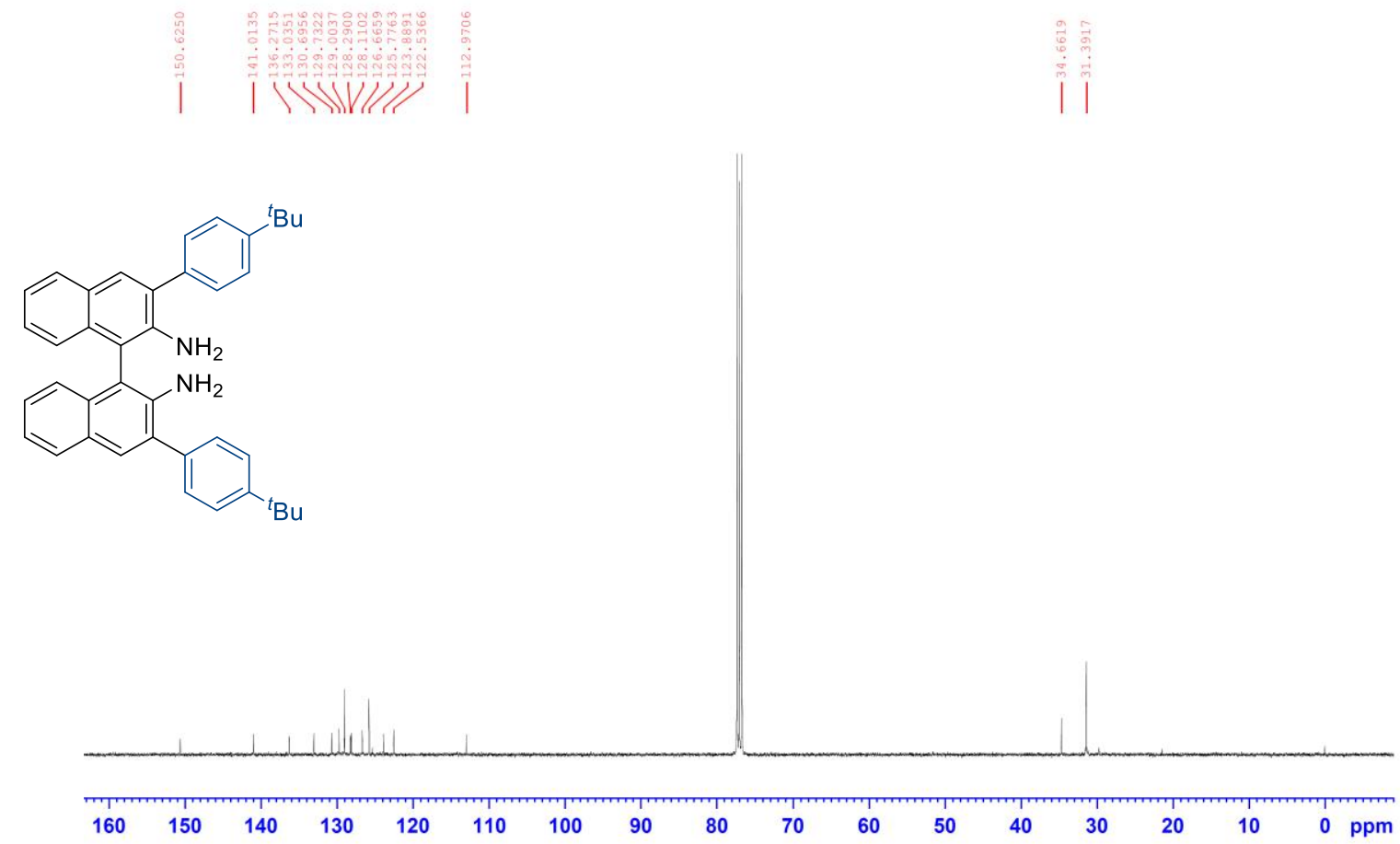


${ }^{1} \mathrm{H}$ NMR of $2 \mathbf{c}\left(400 \mathrm{MHz}, \mathrm{CDCl}_{3}\right)$
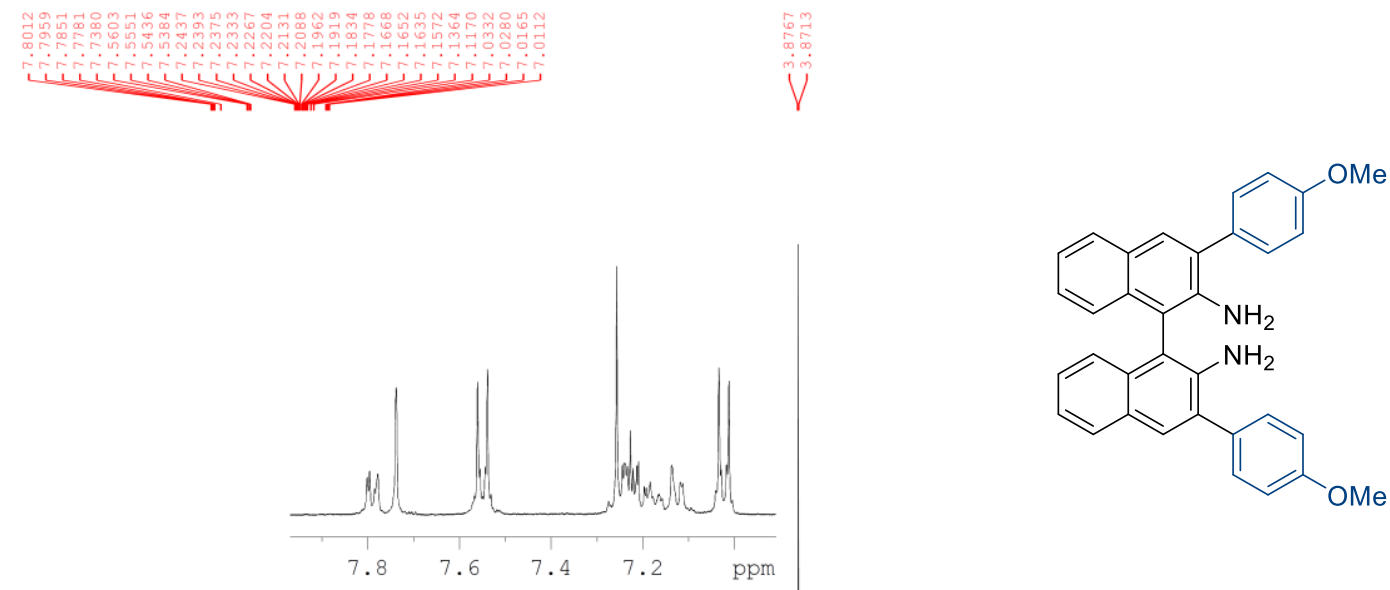

ppm
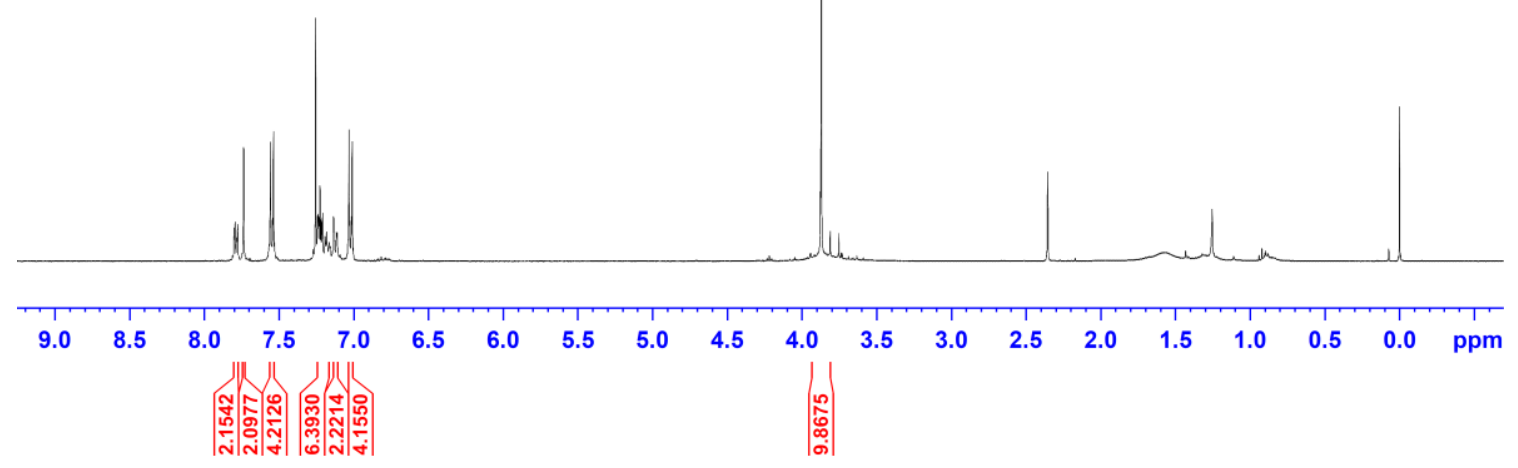

${ }^{13} \mathrm{C} \mathrm{NMR}$ of $2 \mathrm{c}\left(100 \mathrm{MHz}, \mathrm{CDCl}_{3}\right)$

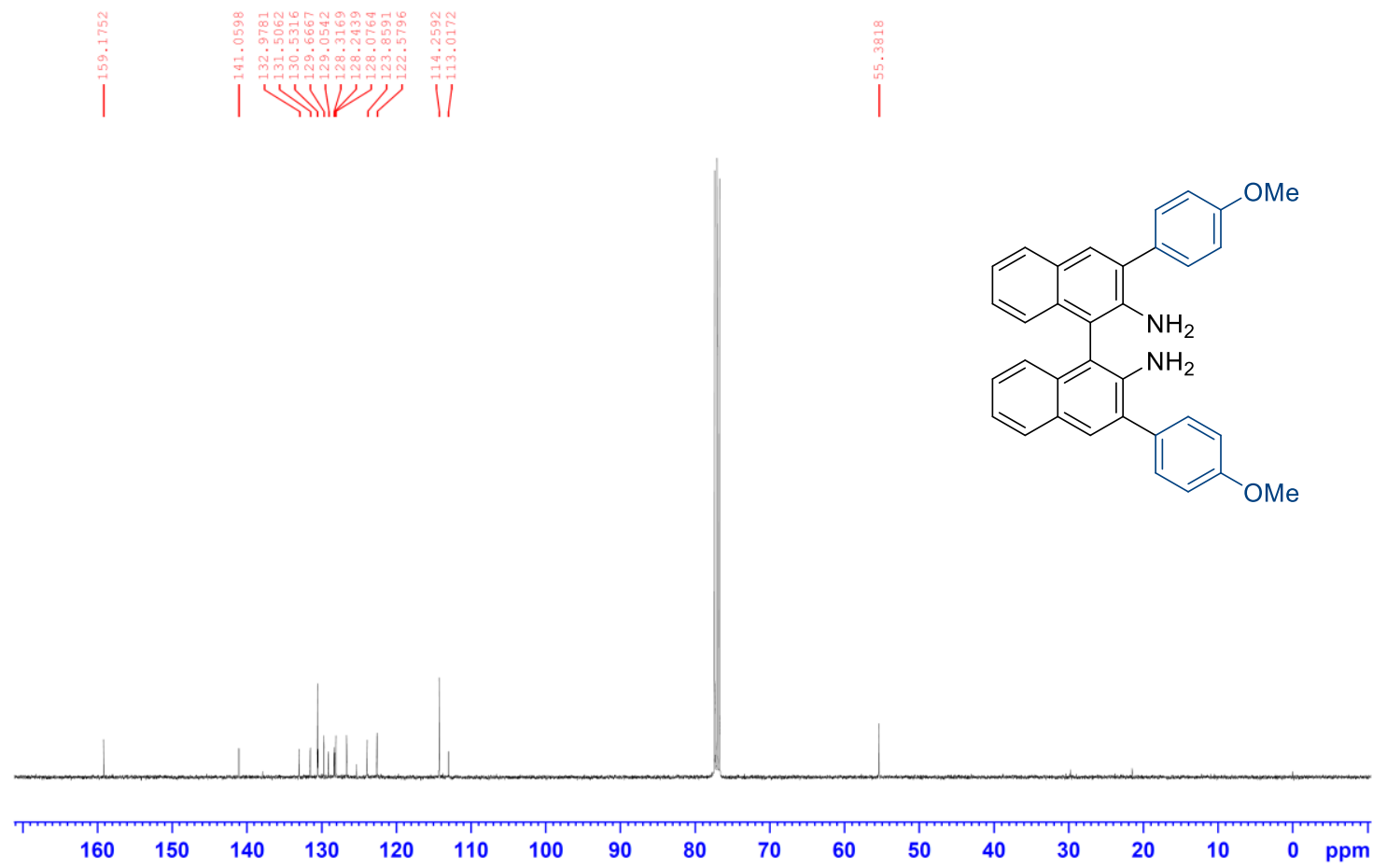


${ }^{1} \mathrm{H}$ NMR of 3a $\left(400 \mathrm{MHz}, \mathrm{CDCl}_{3}\right)$

$\underbrace{\underbrace{1}_{m}}_{m}$<smiles>c1ccc2c(-c3c4ccccc4cc4c3[nH]c3ccccc34)c3ccccc3cc2c1</smiles>
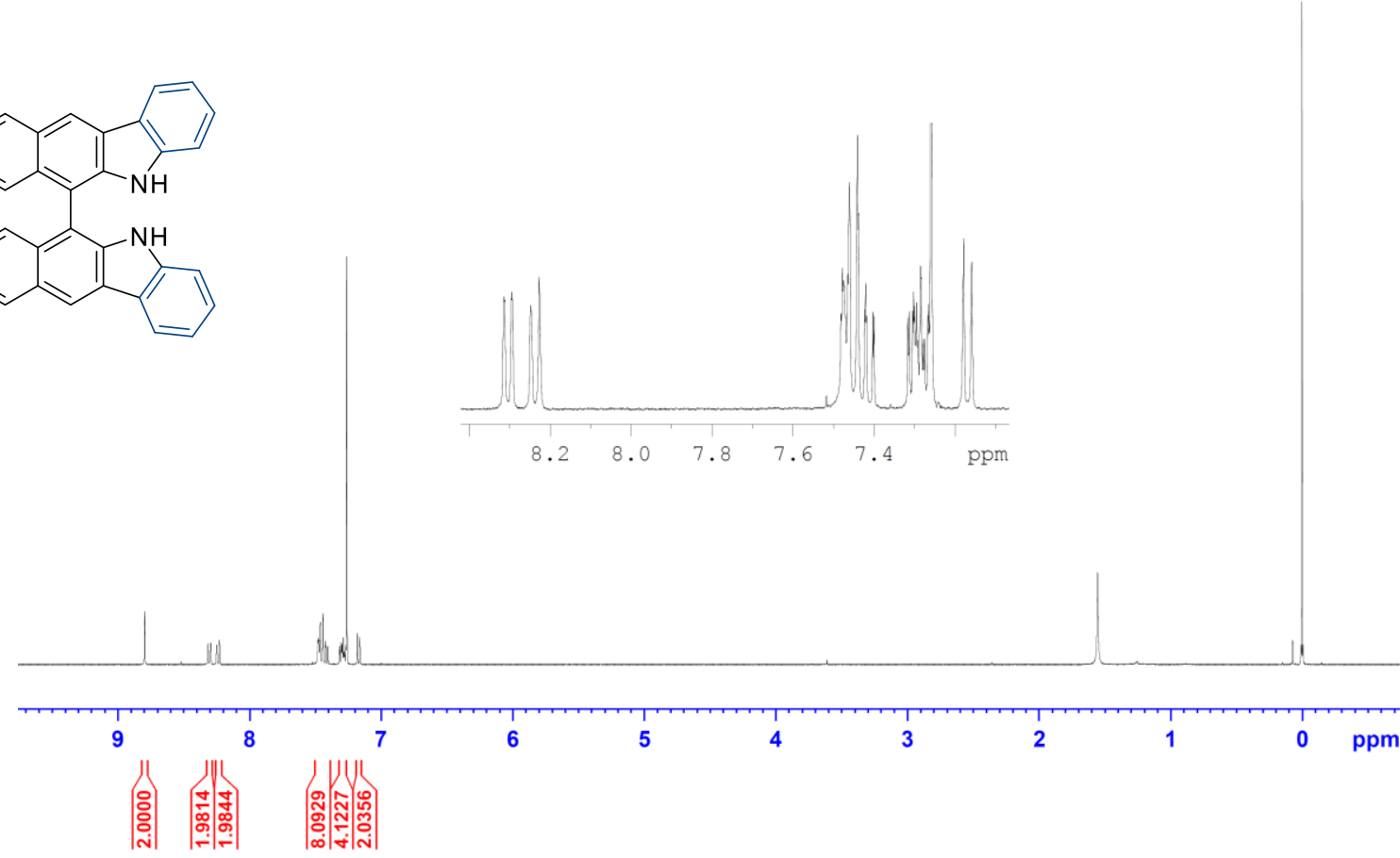

${ }^{13} \mathrm{C} \mathrm{NMR}$ of 3a $\left(100 \mathrm{MHz}, \mathrm{CDCl}_{3}\right)$
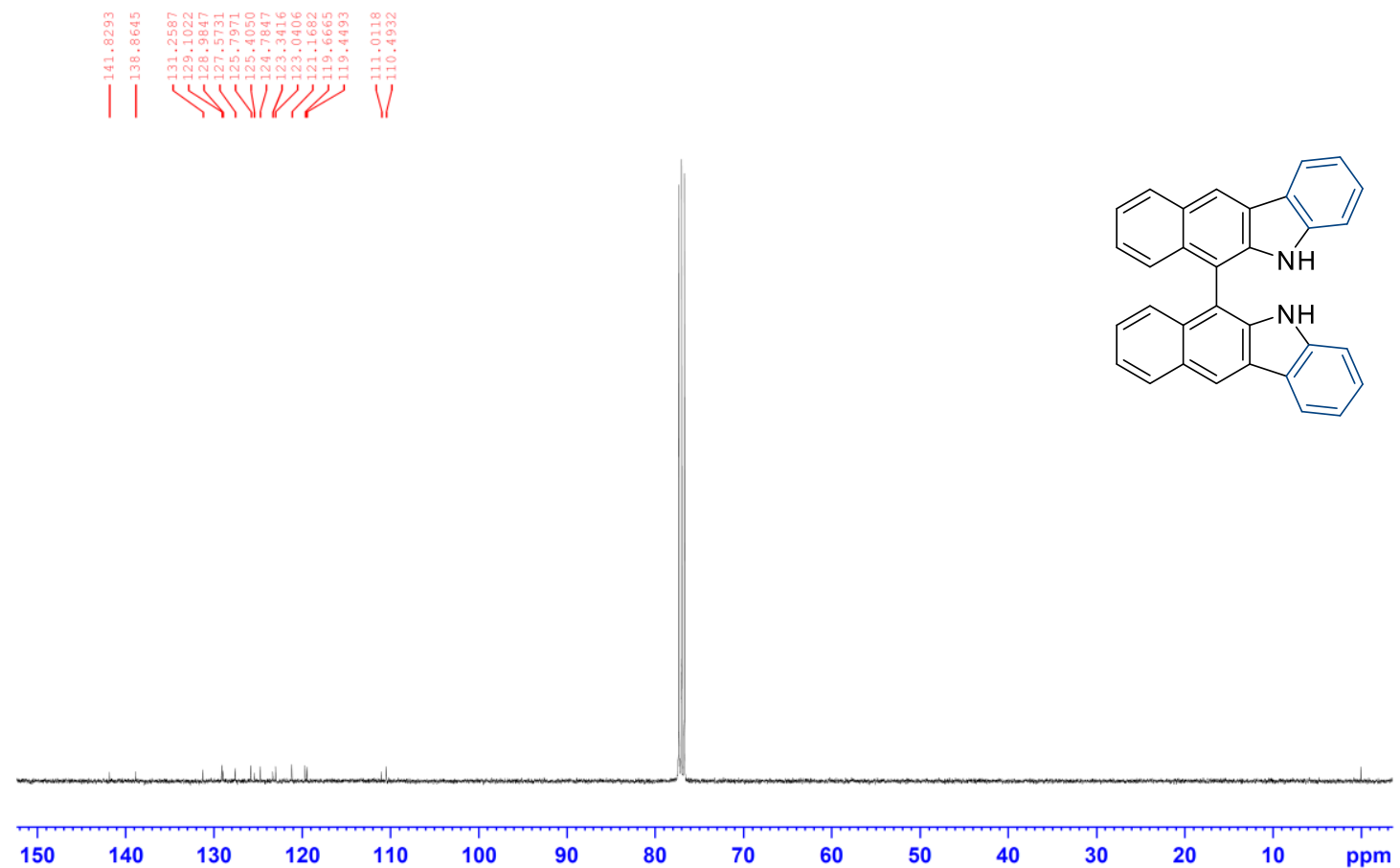
${ }^{1} \mathrm{H}$ NMR of $\mathbf{3 b}\left(400 \mathrm{MHz}, \mathrm{CDCl}_{3}\right)$

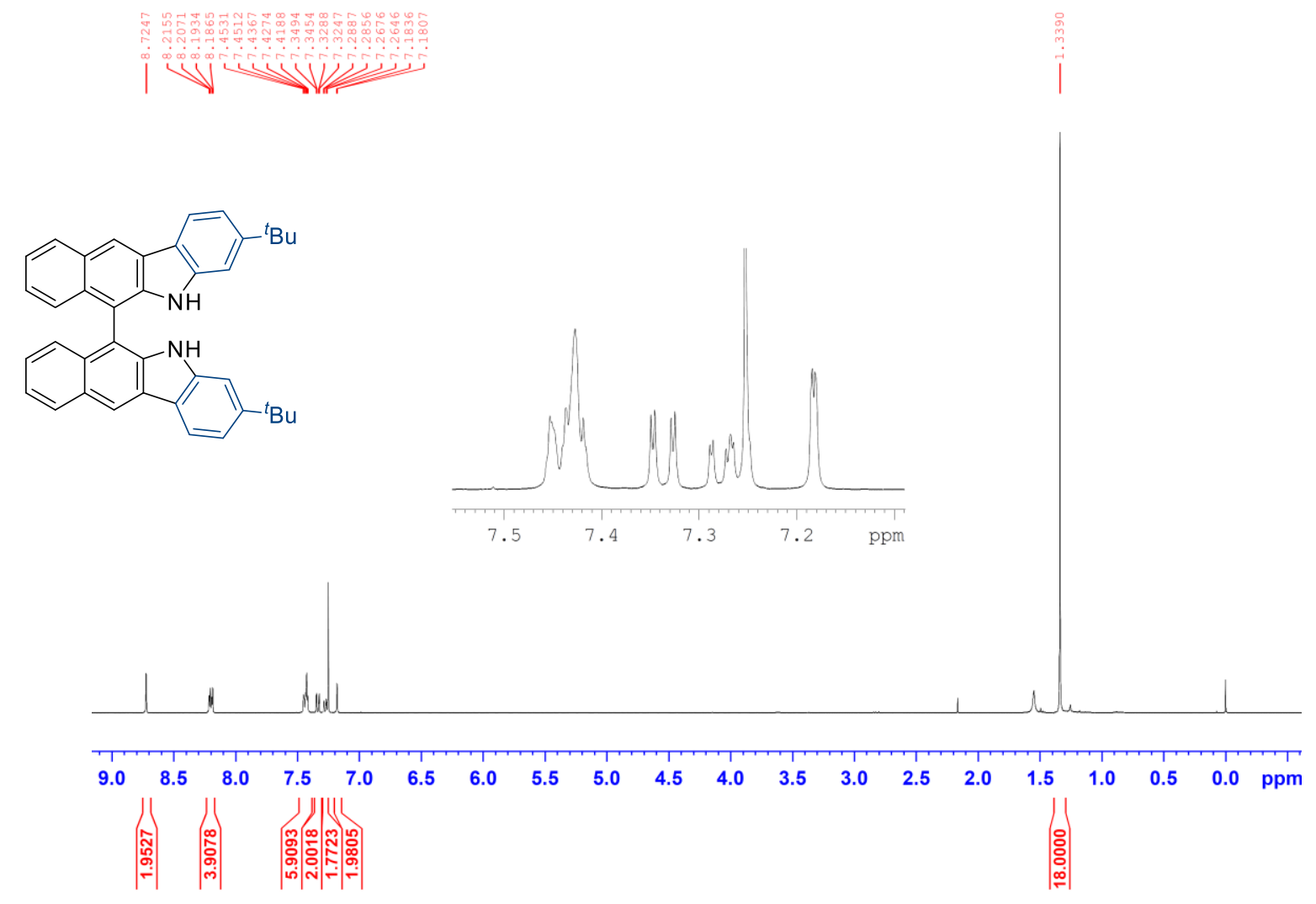

${ }^{13} \mathrm{C} \mathrm{NMR}$ of $\mathbf{3 b}\left(100 \mathrm{MHz}, \mathrm{CDCl}_{3}\right)$
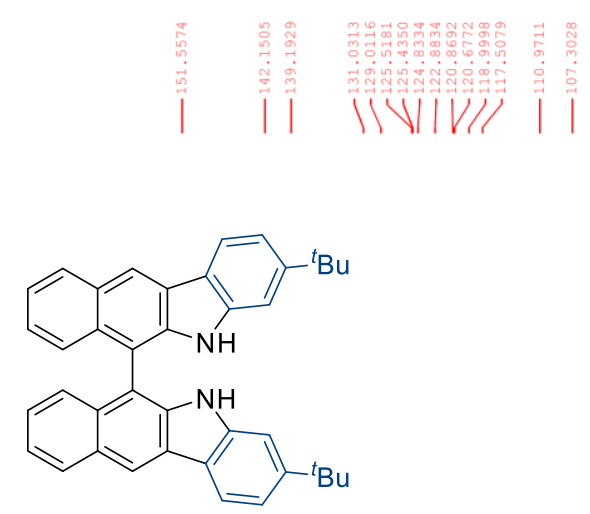
${ }^{1} \mathrm{H}$ NMR of $\mathbf{3 c}\left(400 \mathrm{MHz}, \mathrm{CDCl}_{3}\right)$

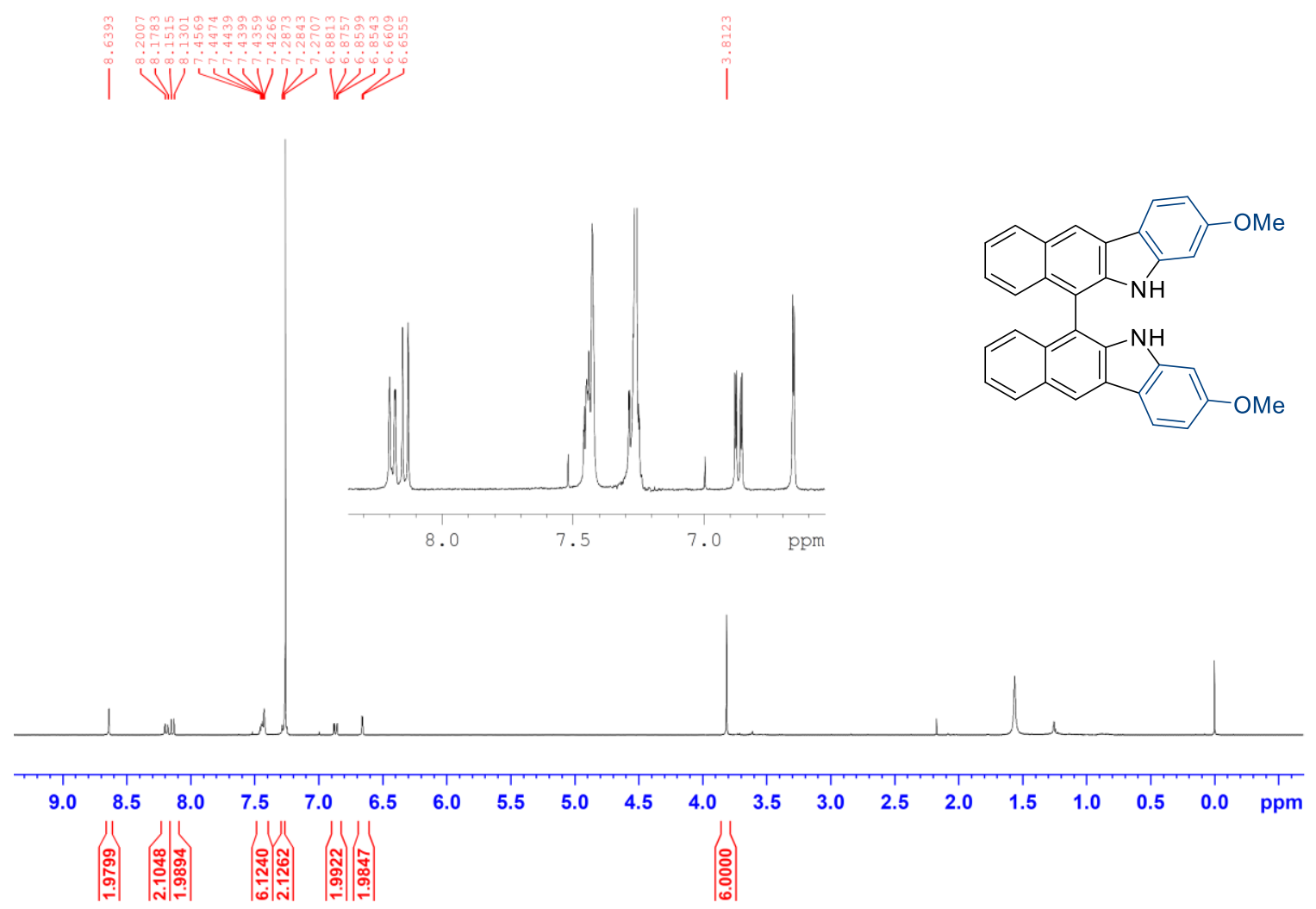

${ }^{13} \mathrm{C}$ NMR of $3 \mathbf{c}\left(100 \mathrm{MHz}, \mathrm{CDCl}_{3}\right)$

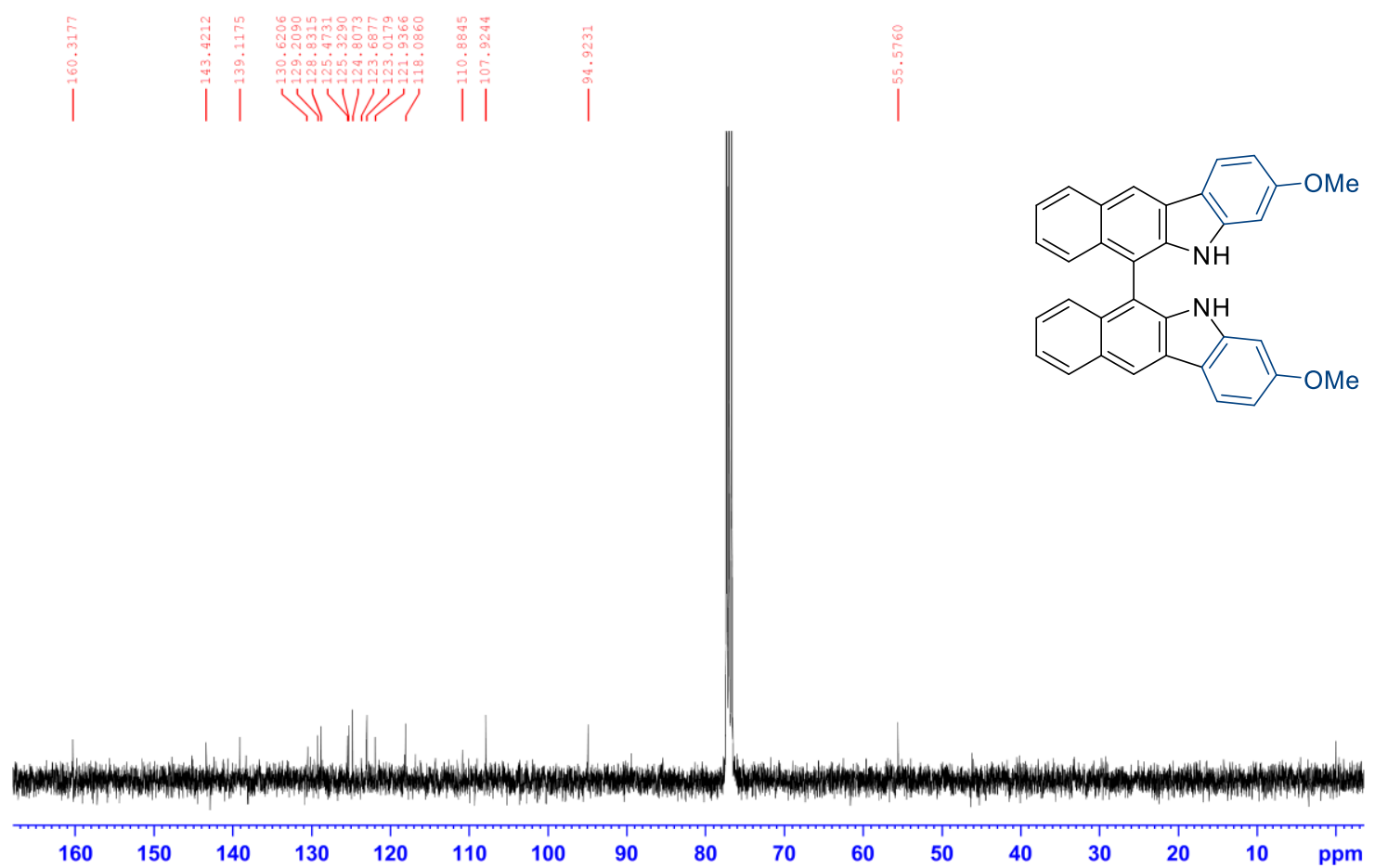


${ }^{1} \mathrm{H}$ NMR of $4\left(400 \mathrm{MHz}, \mathrm{CDCl}_{3}\right)$
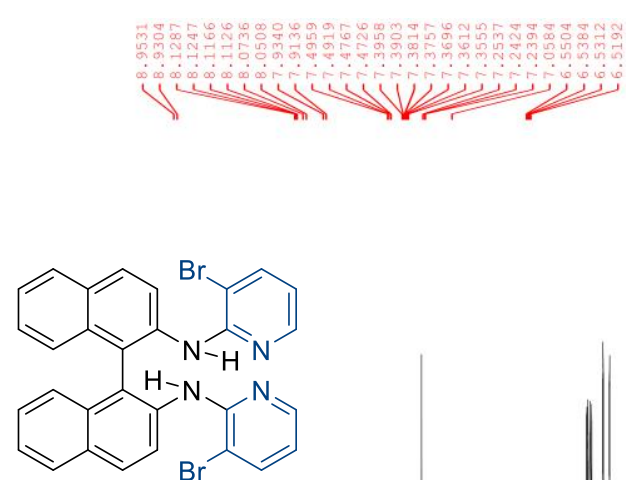
${ }^{1} \mathrm{H}$ NMR of $5\left(400 \mathrm{MHz}, \mathrm{CDCl}_{3}\right)$

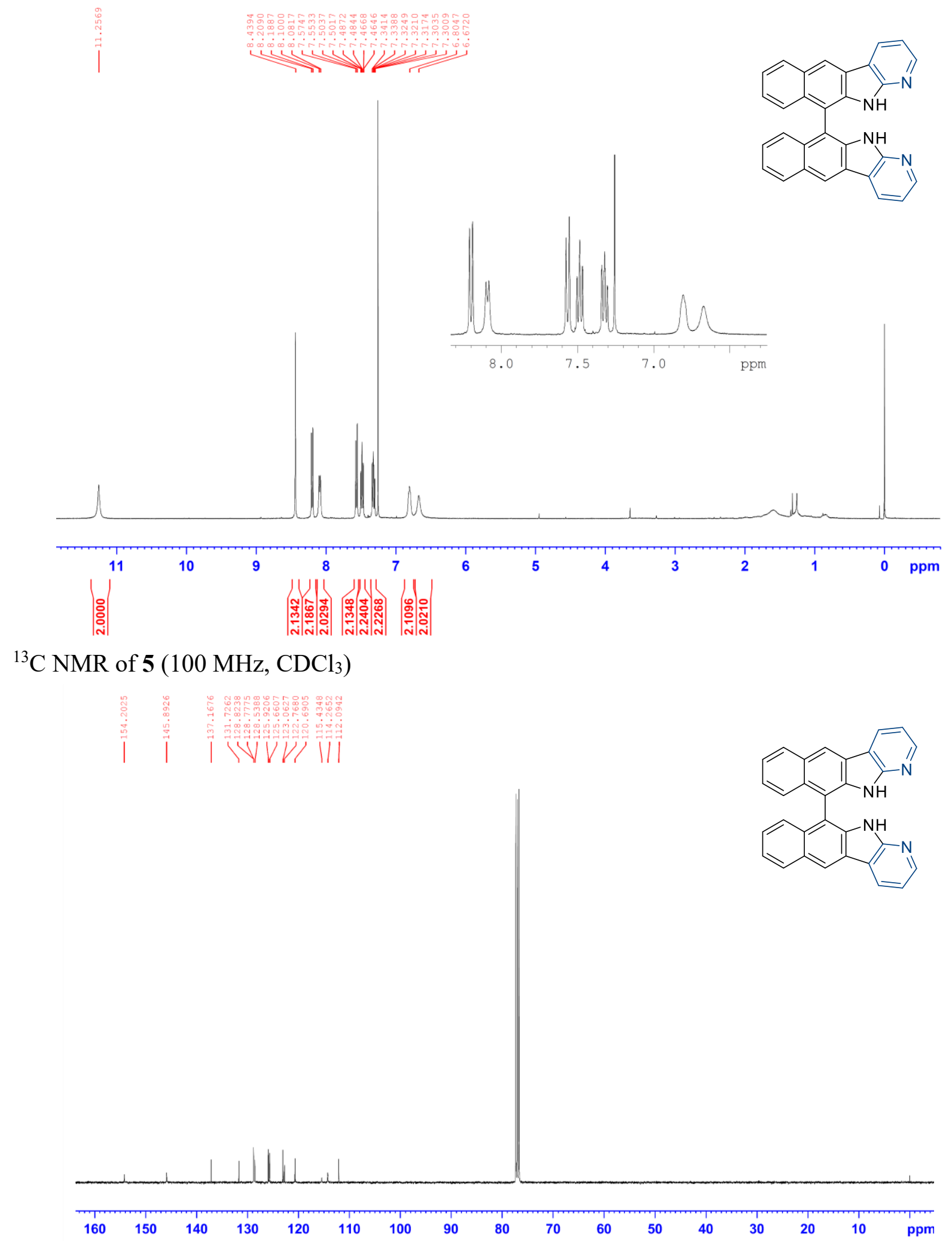




\section{References}

${ }^{1}$ Chang, X.; Zhang, Q.; Guo, C. Org. Lett. 2019, 21, 4915-4918.

${ }^{2}$ Cuřínová, P.; Dračínský, M.; Jakubec, M.; Tlustý, M.; Janků, K.; Izák, P.; Holakovský, R. Chirality 2018, 30, 798-806.

3 Scarborough, C. C.; McDonald, R. I.; Hartmann, C.; Sazama, G. T.; Bergant, A.; Stahl, S. S. J. Org. Chem. 2009, 74, 2613-2615.

${ }^{4}$ Yoshimura, M.; Muraoka, T.; Nakatsuka, H.; Huang, H.; Kitamura, M. J. Org. Chem. 2010, 75, 43154318.

${ }^{5}$ Kano, T.; Tanaka, Y.; Osawa, K.; Yurino, T.; Maruoka, K. Chem. Commun. 2009, 15, 1956-1958.

${ }^{6}$ Nakatsuka, H.; Yamamura, T.; Shuto, Y.; Tanaka, S.; Yoshimura, M.; Kitamura, M. J. Am. Chem. Soc. 2015, 137, 8138-8149.

7 Sheldrick, G. M. Acta Crystallogr. Sect. A 2008, 64, 112-122.

${ }^{8}$ Farrugia, L. J. J. Appl. Cryst. 2012, 45, 849-854. 